\title{
Beam Effects From an Increase of LINAC Current From 40 ma to 49 Milliamperes
}

\author{
Ray Tomlin \\ FNAL
}

On March 25, 2002 the FNAL Linac had been running at a decreased 40 ma of beam current for some time. Both the $400 \mathrm{MeV}$ Linac and the $8 \mathrm{GeV}$ Booster had been tuned to optimum running during that time. Optimum running for the Booster was at $4.1 \mathrm{e} 12$ per pulse. Losses at injection and at transition were limiting intensity at the time.

By March 26, 2002 the Linac beam current had been increased to 49 ma. The optimum Booster intensity immediately jumped to $4.5 \mathrm{e} 12$ per pulse and increased in the next few days to $4.8 \mathrm{e} 12$ and $5 \mathrm{e} 12$ per pulse. Booster was not retuned until early April when a lowloss 5.0e12 was obtained for stacking operations. Linac current had sagged to 47 ma by then. Measurements were made on the $25^{\text {th }}$ at 40 ma and the $26^{\text {th }}$ and $27^{\text {th }}$ at 49 ma. This is a report and discussion of those measurements.

\section{Beam From Booster}

A higher current Linac seemed best.

Main Injector flying wires were flown to catch beam when it arrived from Booster. Transverse emittances remained unchanged despite the $10 \%$ increase in intensity from 4.1e12 (40 ma Linac) to 4.4e12 from Booster (49 ma Linac). The MI bunch length monitor showed 6.7 nanosecond bunches for both a 40 ma Linac (Booster at 4.1e12) and a 49 ma Linac (Booster at 4.4e12).

$8 \mathrm{GeV}$ multiwires showed no increase in (beam width) sigma despite running $4.8 \mathrm{e} 12$ at 49 ma rather than the $4.1 \mathrm{e} 12$ at $40 \mathrm{ma}$.

\section{Beam in Booster}

A higher current linac seemed best.

Beam width measurements during Booster acceleration were done with the Ion Profile Monitors. Vertical beam width was increased roughly $2.6 \%$ for the higher linac current. A 5\% increase in width was seen in the last 3 milliseconds of acceleration at $8 \mathrm{Gev}$. Horizontal beam width was approximately $3 \%$ larger at injection and shrank to less than $1 \%$ larger after transition. Beam intensities were $4.1 \mathrm{e} 12$ in Booster for 40 ma Linac and $4.4 \mathrm{e} 12$ fro the 49 ma Linac.

Beam energy lost in Booster decreased significantly when Linac current increased. BELOST was double during the first 5 milliseconds of acceleration for 40 ma Linac beam. 
A lower current Linac seemed to lower losses seen on Booster BLMs.

Booster radiation monitors above ground showed nothing notable except a sharp increase at Booster period Short 8 . These are the chipmunks that constitute the e-berm. Beam loss monitors in the tunnel scaled up with intensity. Losses were integrated over the acceleration cycle. Losses doubled at Period 13, a known aperture restriction. BLM data differentiated with respect to time showed most of the increase to be before 9 milliseconds. Beam intensities for these measurements were $4.1 \mathrm{e} 12$ at $8 \mathrm{GeV}$ for $40 \mathrm{ma}$ Linac current, and $4.4 \mathrm{e} 12$ at $8 \mathrm{GeV}$ for $49 \mathrm{ma}$ Linac current. None of these loss measurements are scaled or normalized to the two beam intensities encountered during these tests.

\section{$400 \mathrm{MeV}$ injected beam}

Low or high intensity beams are not favored here. Rather, one needs to consider how the Booster will handle beam having a larger energy range.

A look at $200 \mathrm{MHz}$ bunches arriving at a Long 18 resistive wall pickup during $1^{\text {st }}, 2^{\text {nd }}$, and $3^{\text {rd }}$ revolutions shows an increase in bunch population. For the LINAC current increase of $22.5 \%$ ( 40 to $49 \mathrm{ma}$ ), there was a $35 \%$ increase in the observed $200 \mathrm{MHz}$ bunches, a $2 \%$ increase in DC beam during the $1^{\text {st }}$ turn, a $50 \%$ increase in DC beam during the $2^{\text {nd }}$ turn, and no increase in DC beam during the $3^{\text {rd }}$ turn. If the Booster acts like a mass spectrometer during the first 6 microseconds, then this shows that a lower current LINAC delivers a more monochromatic beam. But we know from the previous section (Beam in the Booster) that Booster could capture the increased energy spread associated with an increase in LINAC current from 40 to 49 milliamperes. Linac bunches are unevenly populated so an increase in observed bunch intensity that is larger than the beam current increase is possible.

\section{Beam in the $400 \mathrm{MeV}$ line}

Trace 3D models used the same multiwire profile files and the BPM data for the line did not change significantly. Consequently the Trace 3D models were about the same for 40 and 49 ma beam.

There are two stripline beam pickups in the $400 \mathrm{MeV}$ line. By measuring the phase between them, we can see the beam energy changing during the LINAC spill. This phase detector showed no difference between 40 and 49 ma beam currents save one; the 40 ma spill was actually a bit longer than the 49 ma spill.

Horizontal position at Q4, HPQ4, located downstream from $\mathrm{MH} 1$ remained unchanged in total slew $(1.15 \mathrm{~mm})$, intra-spill $125 \mathrm{KHz}$, intra-spill $5 \mathrm{MHz}$ oscillation. Vertical position at Q8, VPQ8, located after vertical benders MV1-MV2 showed an increase in the $5 \mathrm{MHz}$ vacuum instability as the spill ended. This improved on the second day. Since the $49 \mathrm{ma}$ spill was actually shorter, this implies that an increase in beam current in the I- source has 
a similar effect as lengthening the spill; that is growing vacuum oscillations in the $750 \mathrm{KeV}$ line.

$400 \mathrm{MeV}$ BPMs showed no change other than about a millimeter at HPQ4 and HPQ7. Beam on W5H showed a $10 \%$ increase in area. The tail to the left which was present during 40 ma running disappeared during 49 ma running. Beam on W5V showed a $31 \%$ increase and a significant lower tail went away with increased beam current.

$400 \mathrm{MeV}$ line losses stayed about the same except at Q4 which decreased from $0.5 \mathrm{R} / \mathrm{S}$ to $0.15 \mathrm{R} / \mathrm{S}$ when beam current increased form 40 to 49 milliamperes. This counterintuitive decrease may be due to the disappearance of the 40 ma beam tails.

Beam on $400 \mathrm{MeV}$ multiwires generally showed a small decrease in horizontal sigma for 49 ma beam. MW3 was out of service. Vertical sigmas generally increased a small amount for 49 ma current. That increase might be attributed to the predominately vertical fast vacuum oscillations. These fast oscillations do paint Booster injection, and render single and multiwire scanners ineffective for monitoring beam quality.

Beam in the LINAC

Linac losses were smaller at 49 ma. 40 ma conditions showed higher losses at 51LM, $31 \mathrm{LM}$ and $400 \mathrm{MeV}$ DELM4.

LINAC BPMs $>2 \mathrm{~mm}$ horizontal change at $43 \mathrm{BPH}$ and 1 and $2 \mathrm{~mm}$ changes at $42 \mathrm{BPV}$ and 62BPV.

These changes in losses and positions are likely within the normal tuning range and do not matter. Since there are a couple hundred quads, their effect was not monitored.

Beam on BPMs in the low energy drift tube LINAC generally showed a marked increase of vertical vacuum oscillations during and especially near the end of spill. Horizontal position was slewing a lot as beam left tank 3 out. This slewing and the growth of vacuum oscillations with time attests to using a short, high current beam pulse rather than a longer, low current beam pulse.

Klystron beam loading was measured by measuring the difference due to beam as seen on L:CXPOWR where $\mathrm{x}$ is 1 through 7 and $\mathrm{D}$ (for the debuncher). In general beam loading increased by a half to one percent. Beam loading is approximately $3 \%$ for 40 ma beam and $4 \%$ for 49 ma beam.

\section{Beam in the PREACC}

This is where changes were made to increase the beam. Vacuum pressure remained unchanged. Vacuum pressure determines vacuum oscillations seen on the beam to Booster injection. These are the significant changes: 


\begin{tabular}{llll} 
& & $40 \mathrm{ma}$ & \multicolumn{1}{c}{$49 \mathrm{ma}$} \\
IEXTV & extractor voltage & $16.62 \mathrm{KV}$ & $21.47 \mathrm{KV}$ \\
IEXTI & extractor current & $-2.615 \mathrm{ma}$ & $-3.271 \mathrm{ma}$ \\
IMAGI & Magnet current & $-5.8 \mathrm{Amps}$ & $-7.6 \mathrm{Amps}$ \\
IARCSV & arc voltage & $296.4 \mathrm{~V}$ & $301.5 \mathrm{~V}$ \\
Gas valve open & & $85 \mu \mathrm{sec}$ & $87 \mu \mathrm{sec}$ \\
I- ground vacuum & & $2.6 \mu \mathrm{torr}$ & $2.9 \mu \mathrm{torr}$ \\
I- Toroid \#1 & & $58.2 \mathrm{ma}$ & $78 \mathrm{ma}$
\end{tabular}

\section{Summary}

This data is fairly incomplete but a couple items listed favor 49 millampere operation. In addition, other known operating limits favor 49 milliampere operation over 40 milliampere operation. Not included here is a set of LINAC single wire scans. This was not completed for two reasons; they are not particularly useful given the intra-beam instabilities in LINAC, and I ran out of time.

When seen from the LINAC, a higher current beam can cause a small increase in beam loading. The low energy quads (pulsed sine wave) would favor a shorter beam pulse. The klystron charging circuits favor a shorter beam pulse. Linac beam instabilities favor a shorter beam pulse. The slewing of beam position and the growth of vacuum oscillations with time attests to using a short, high current beam pulse rather than a longer, low current beam pulse. However pulse lengths were within $5 \mu \mathrm{sec}$ for the two beam currents tried here. The higher current did seem to produce vacuum instabilities not seen at the lower current, but the effect was not as severe as seen when spill continues long enough for the instabilities to grow.

When seen from the Booster, a short, high current pulse is best. This is likely because LINAC beam quality is better with a shorter 49 milliampere pulse than with a 40 milliampere pulse.

Finally, a couple other known things were happening during the time of these tests. Many of the LINAC DTL quads were not timed in so beam went through on the slopes of sine waves rather than at peaks. This has since been adjusted. The Booster longitudinal dampers were in a state of flux and only stable to first order rather than well tuned. Both runs were done using the I- source. The H- source has a completely different and much worse effect on beam position slewing and vacuum oscillations. Experience suggests that if $\mathrm{H}$ - is used, a shorter spill is much better. See Appendix A. 


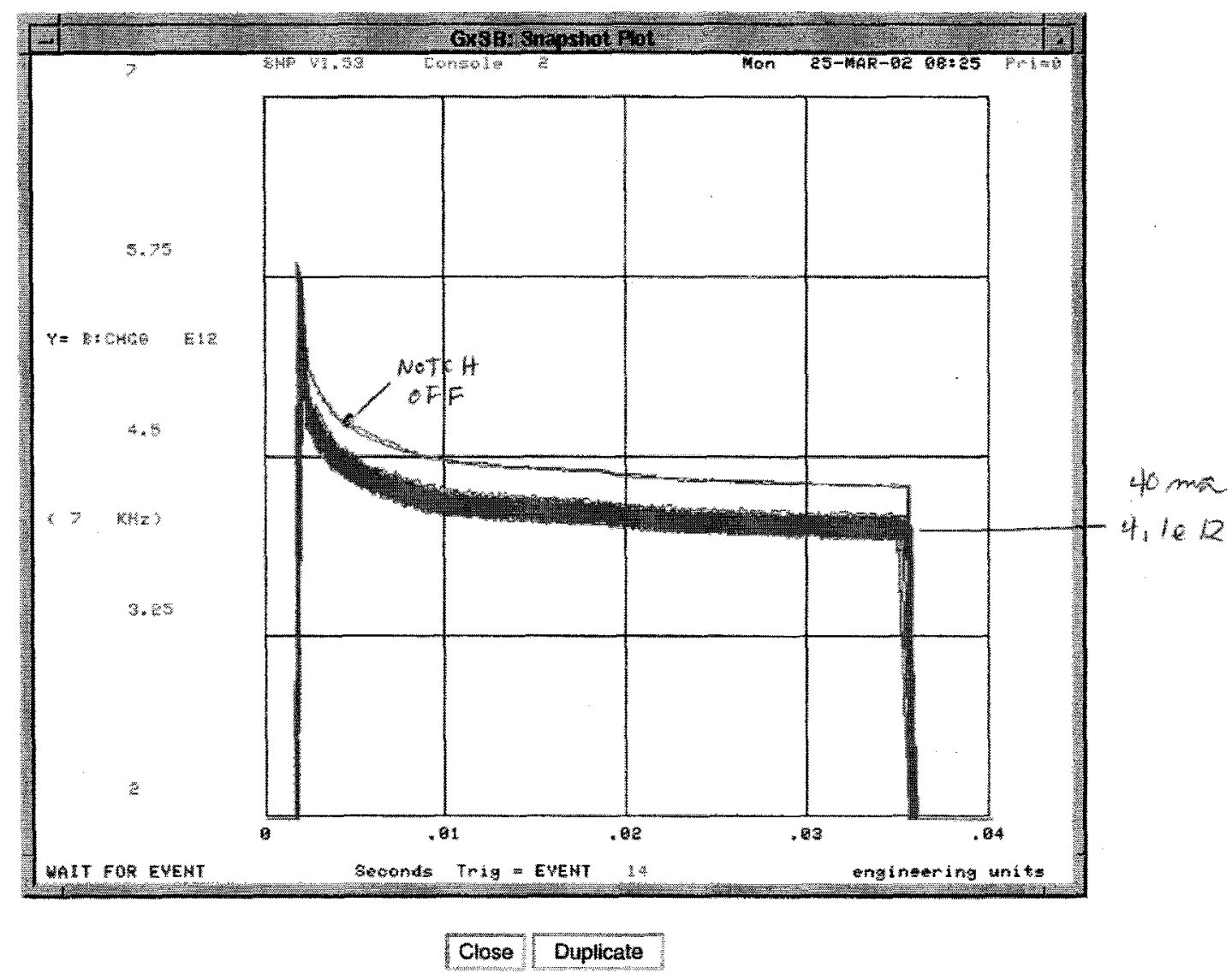




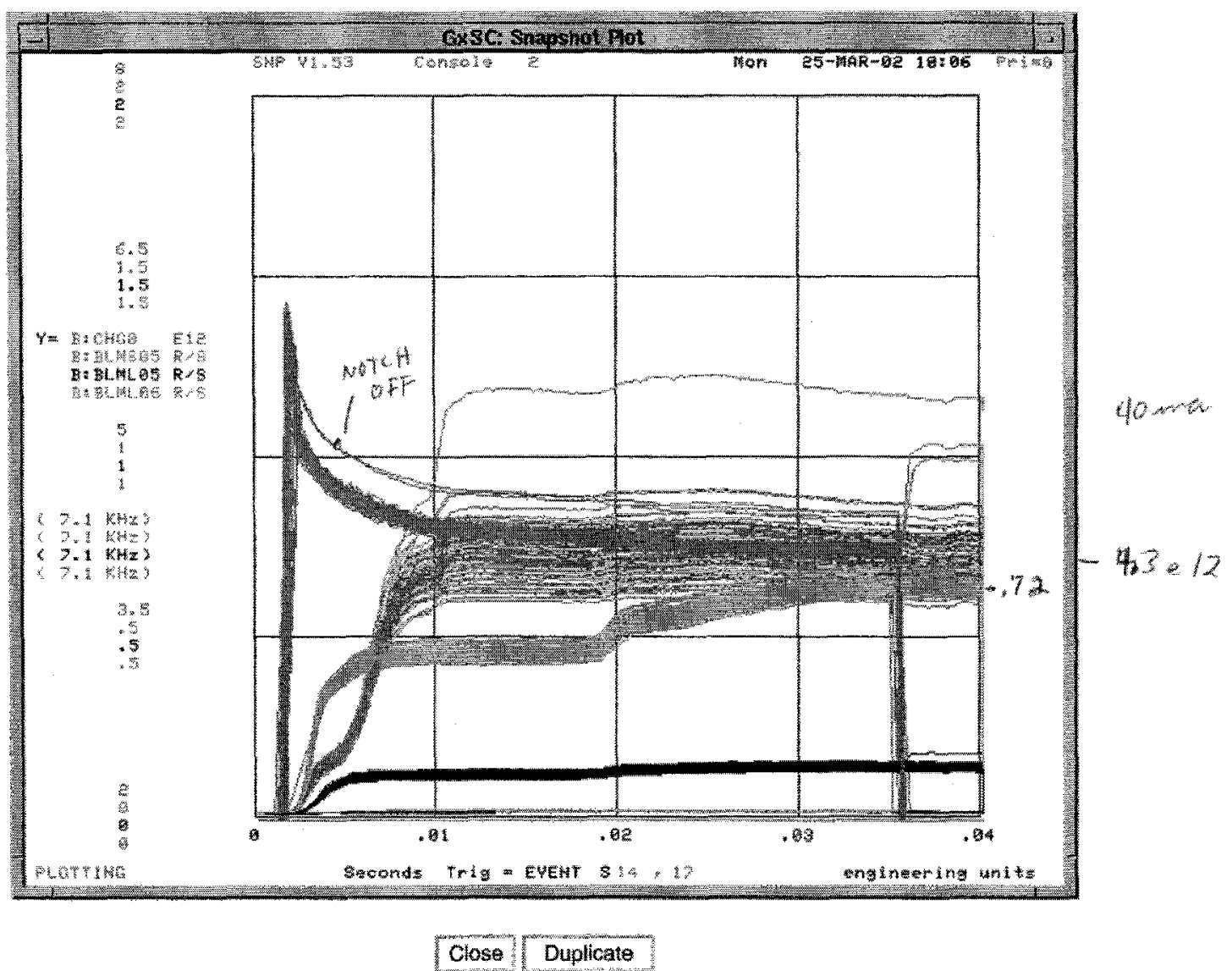




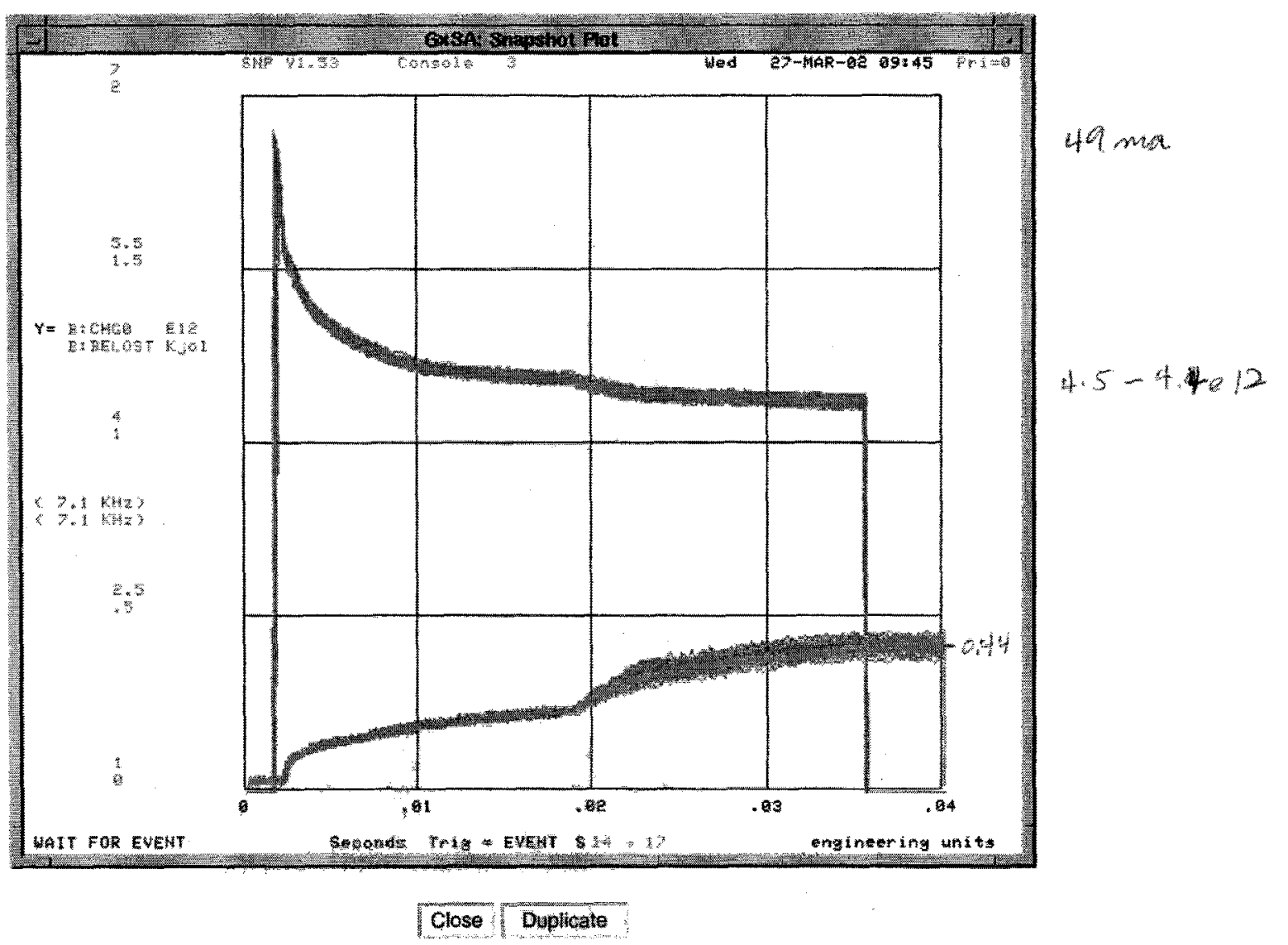




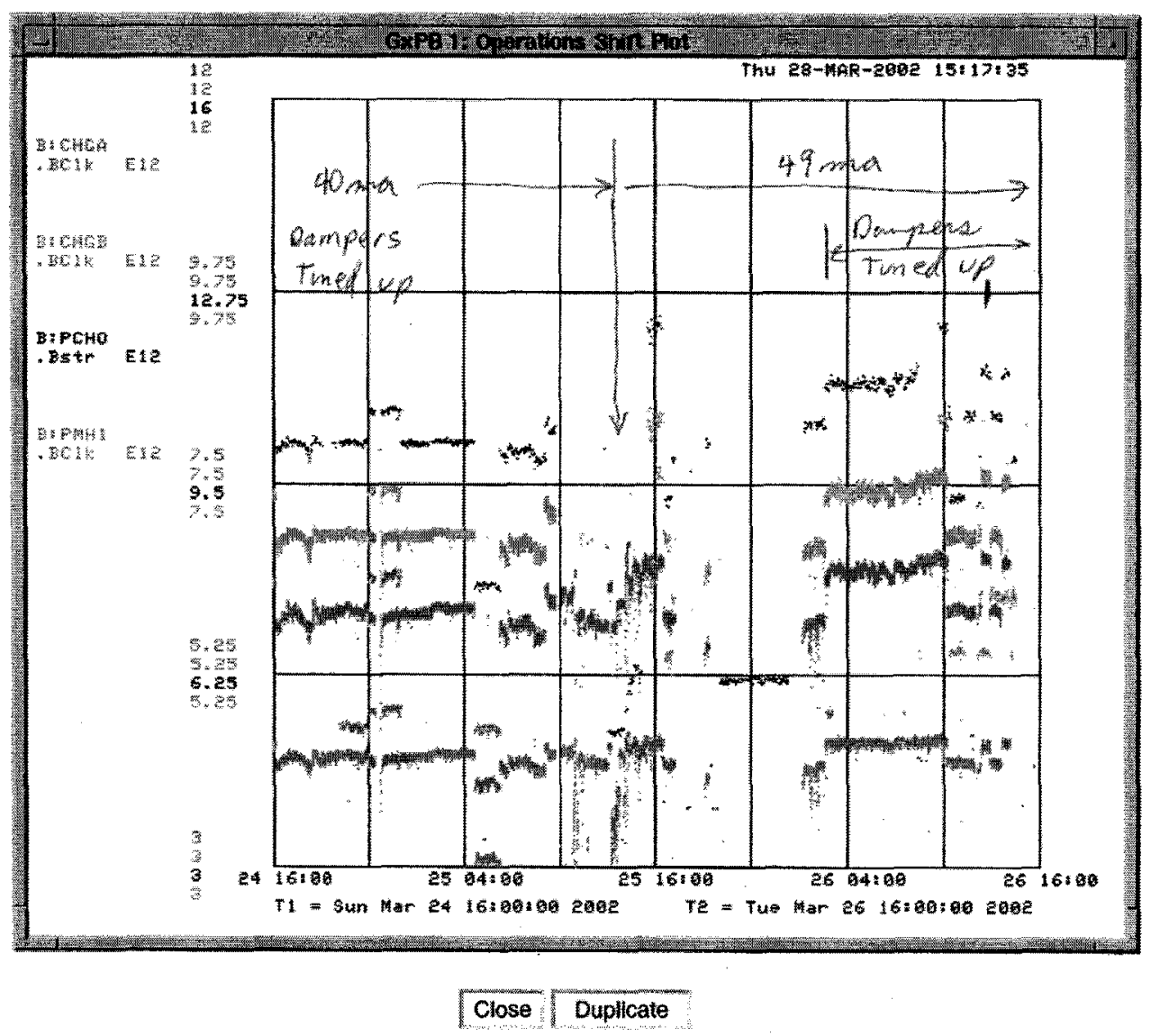




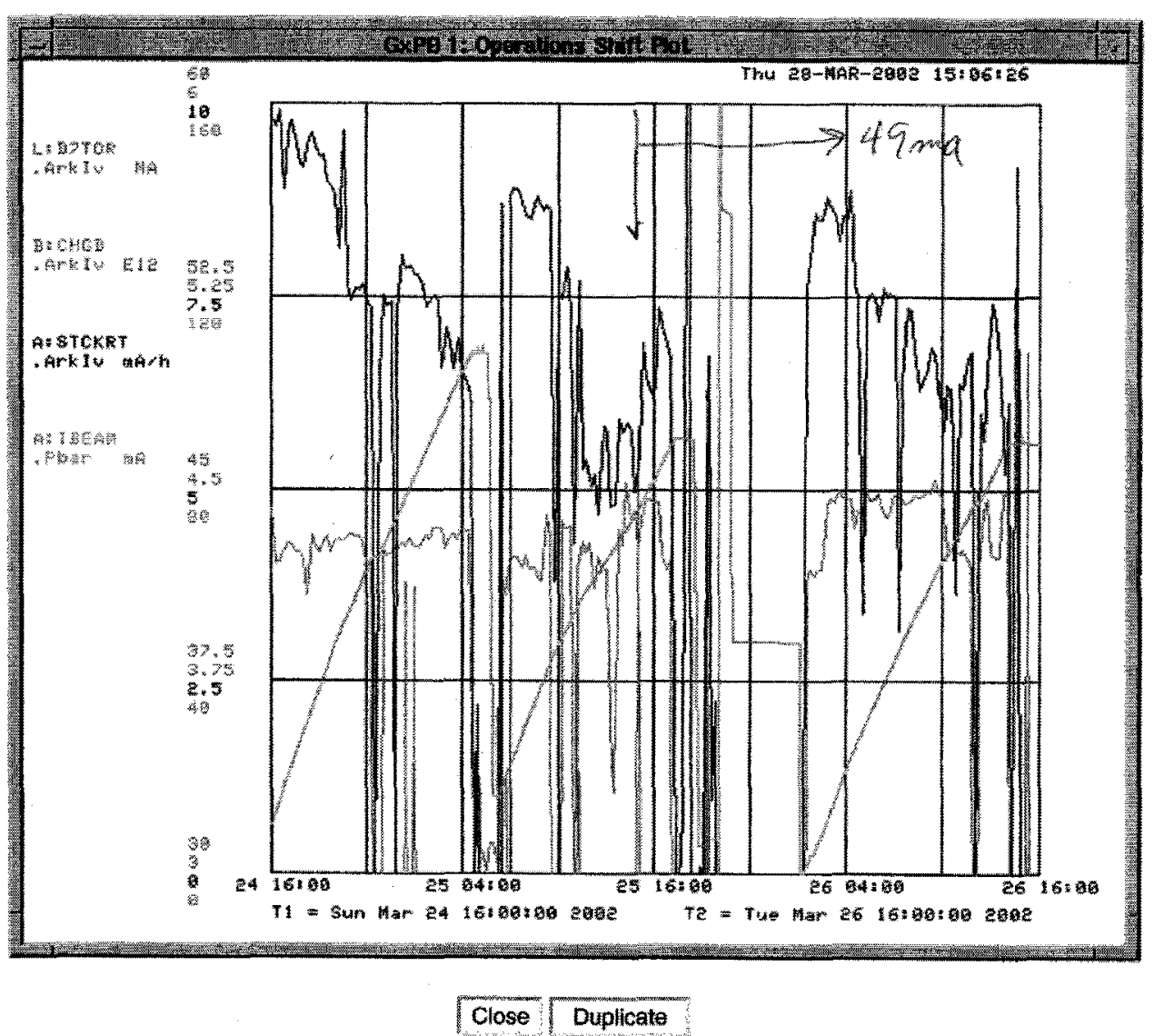




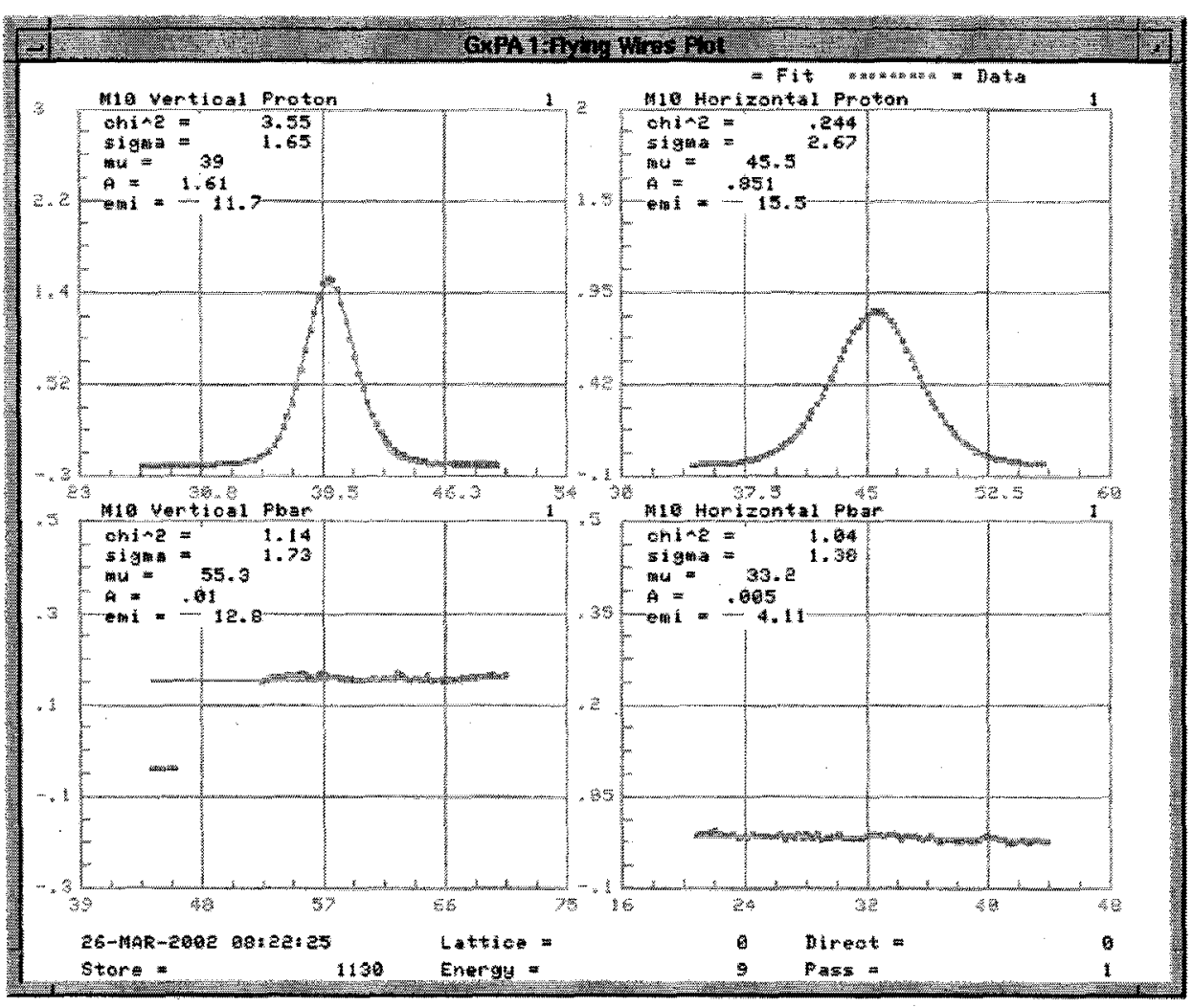

$49 \mathrm{ma}$

$4,4 \times 12$

Close Duplicate 


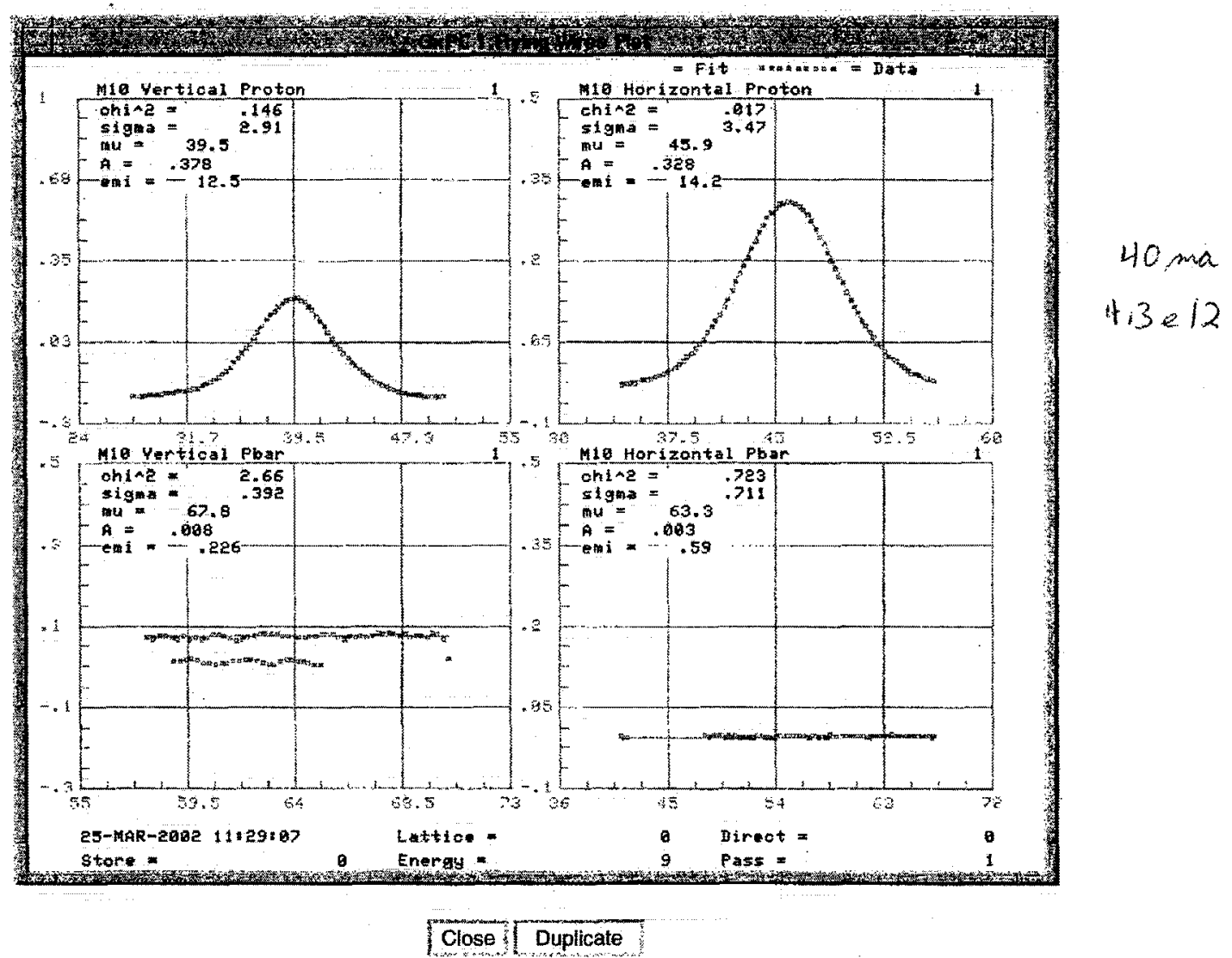




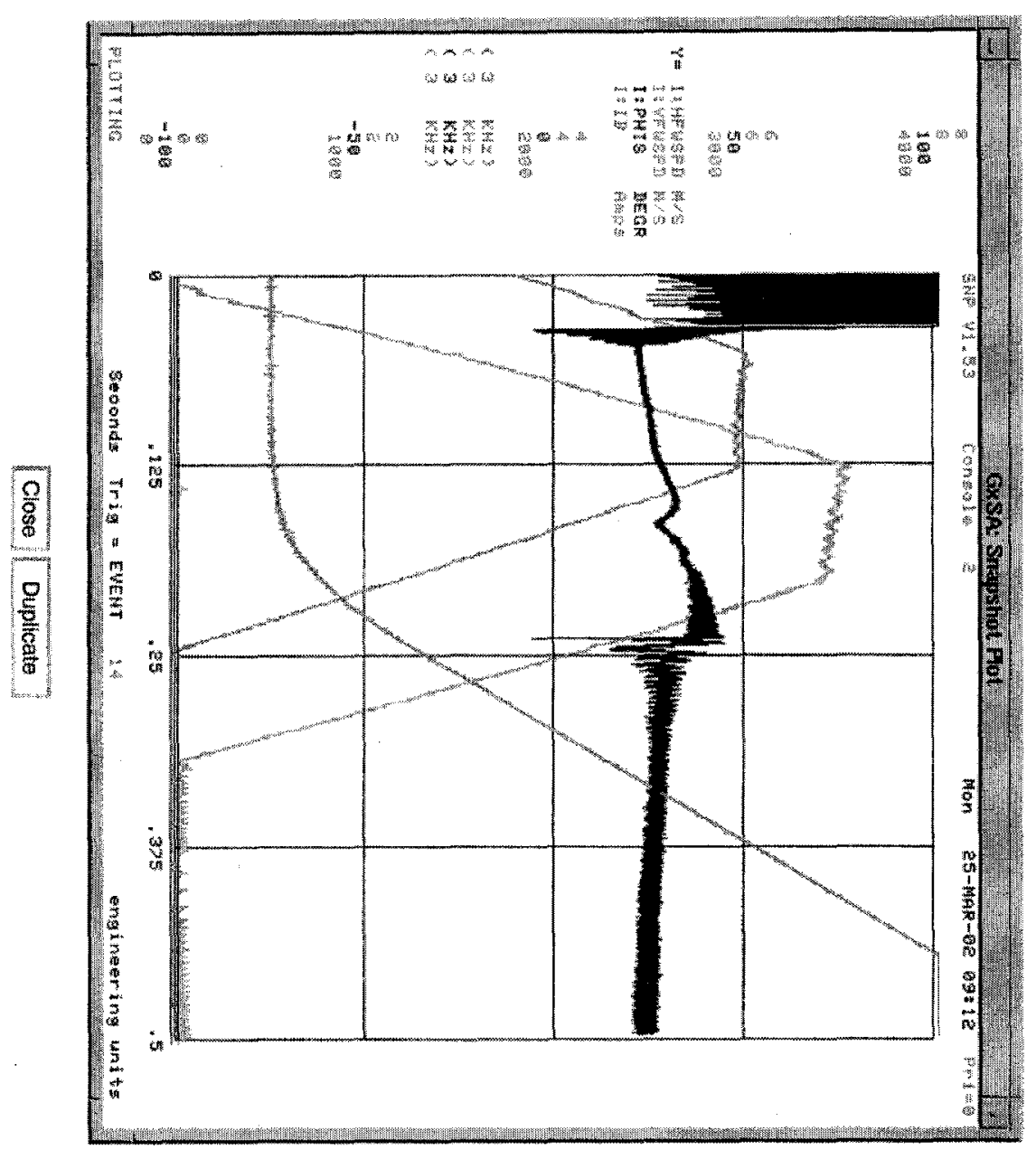

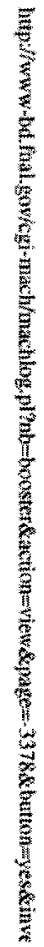


4.1e12 from $\mathbf{4 0}$ ma beam, $4.8 \mathrm{e} 12$ from $\mathbf{4 9}$ ma beam

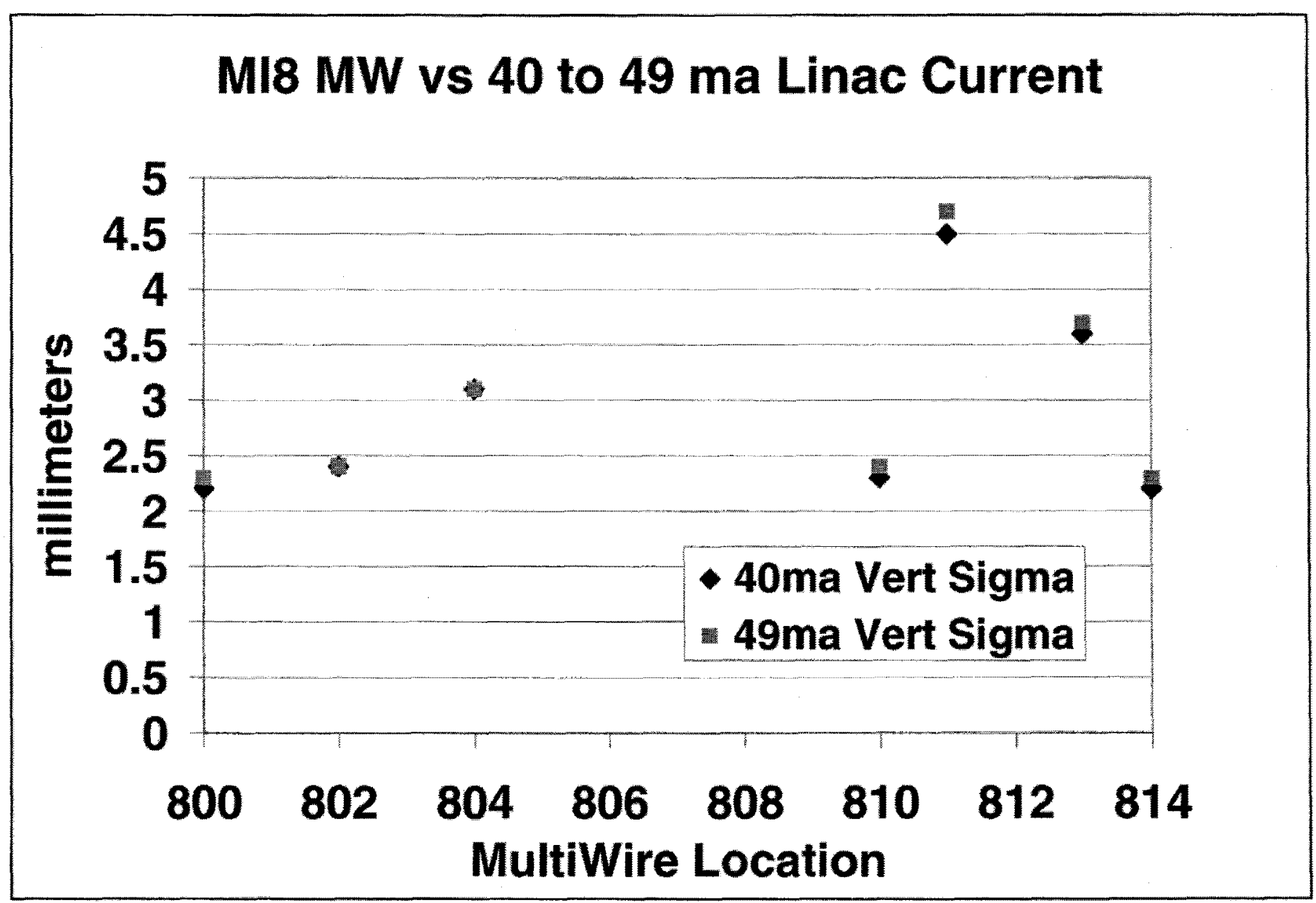


4.1e12 from 40 ma beam, $4.8 \mathrm{e} 12$ from 49 ma beam.

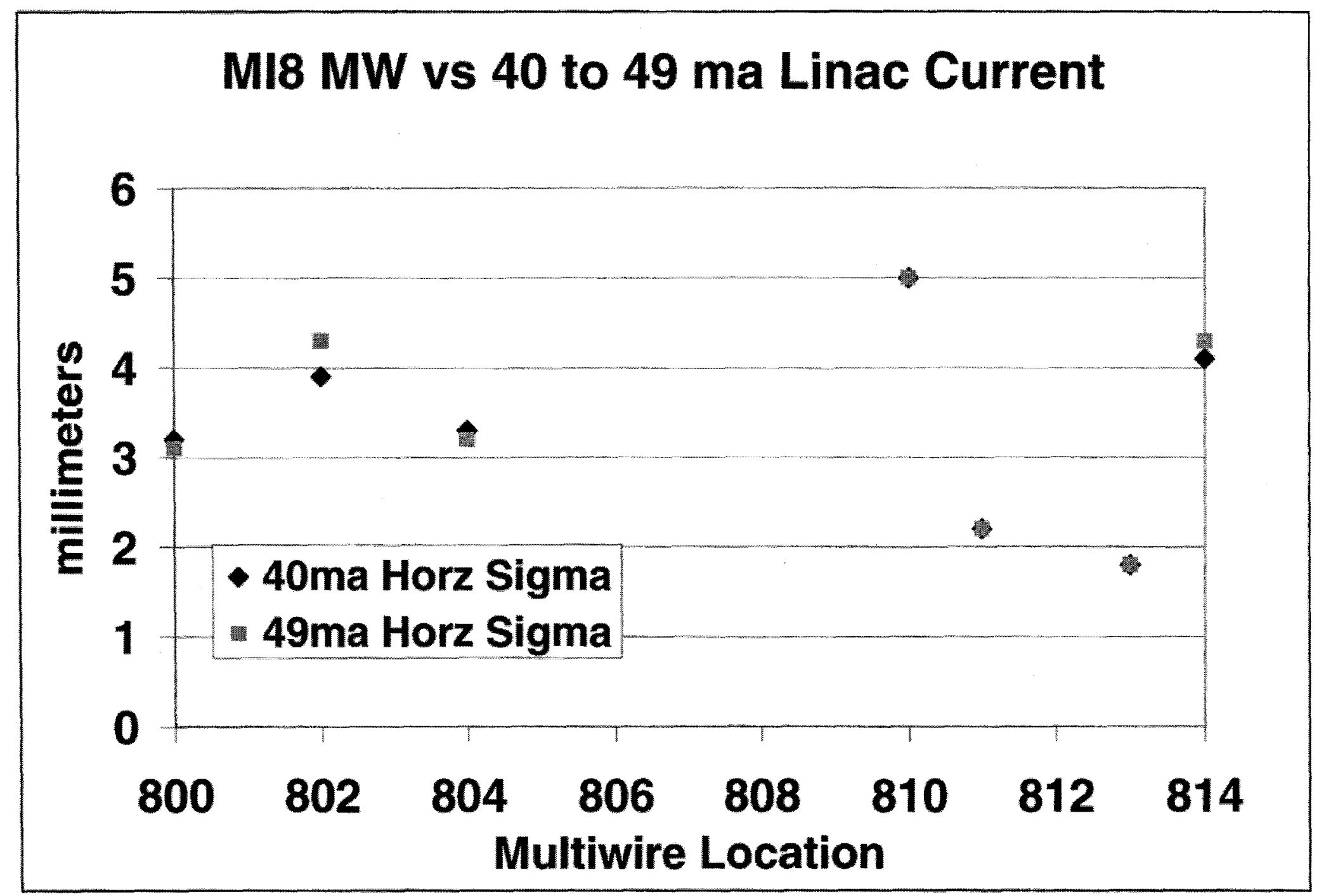




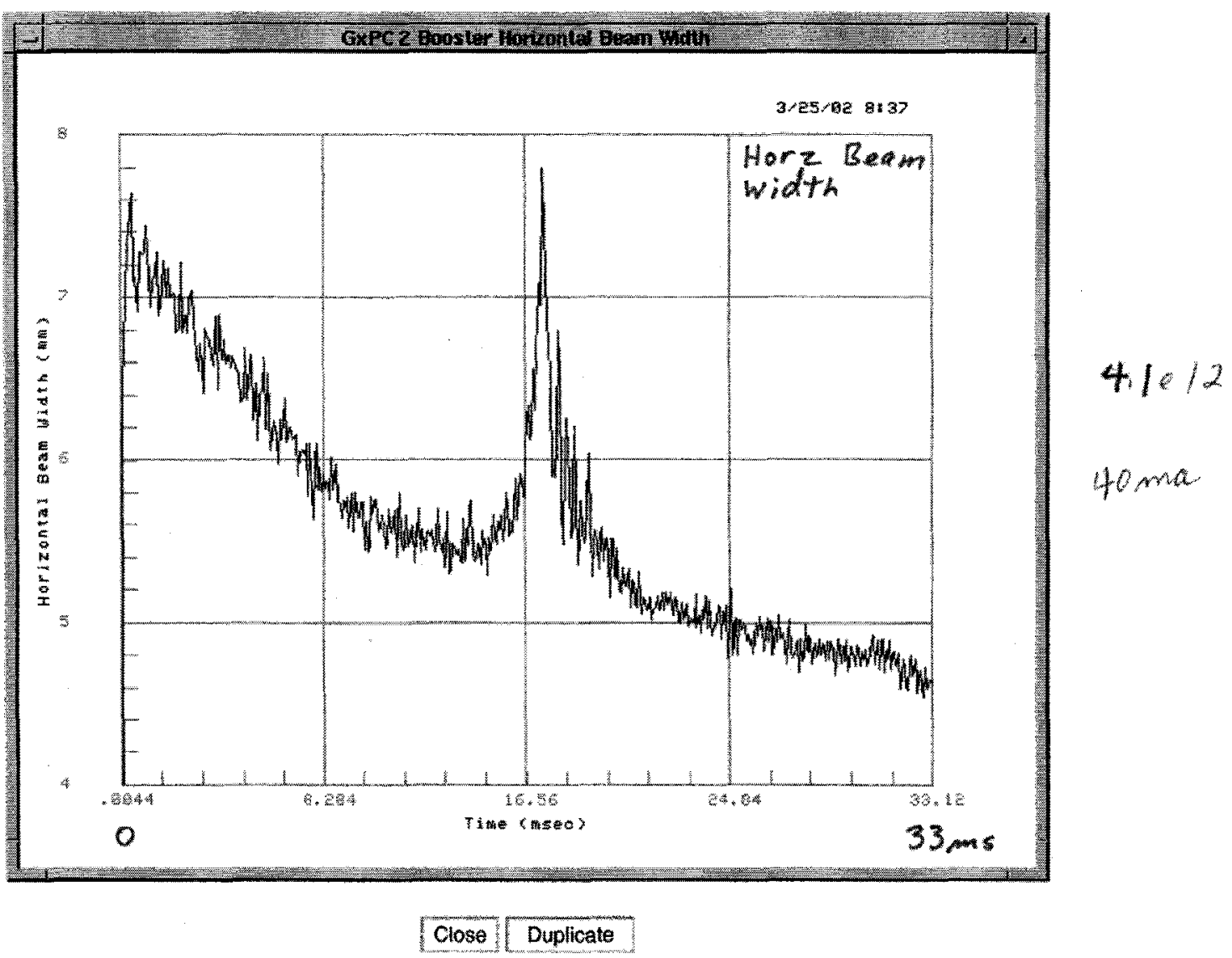




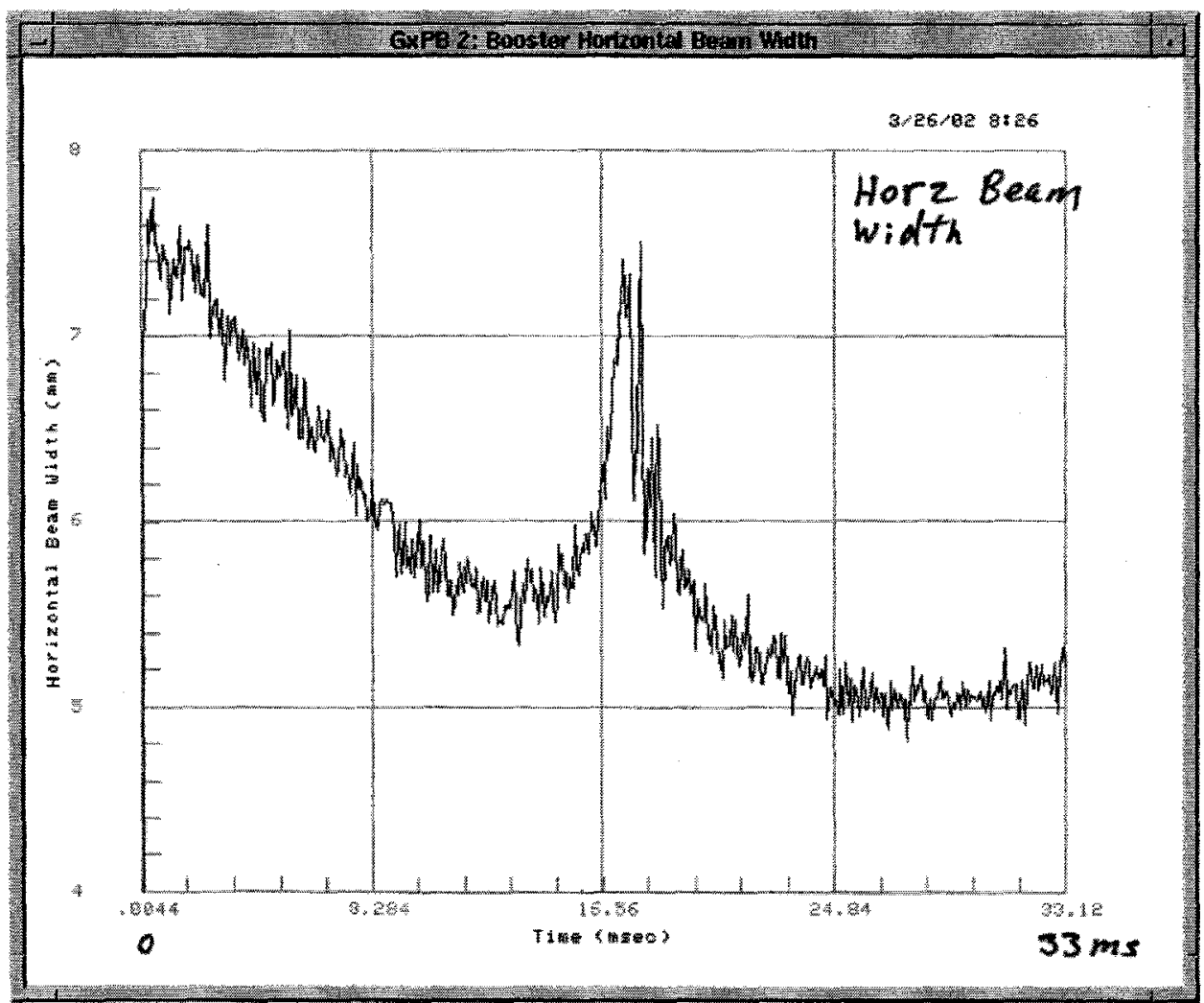

$49 \mathrm{ma}$

$4.4 \div 12$

Close $\longdiv { \text { Duplicate } }$ 


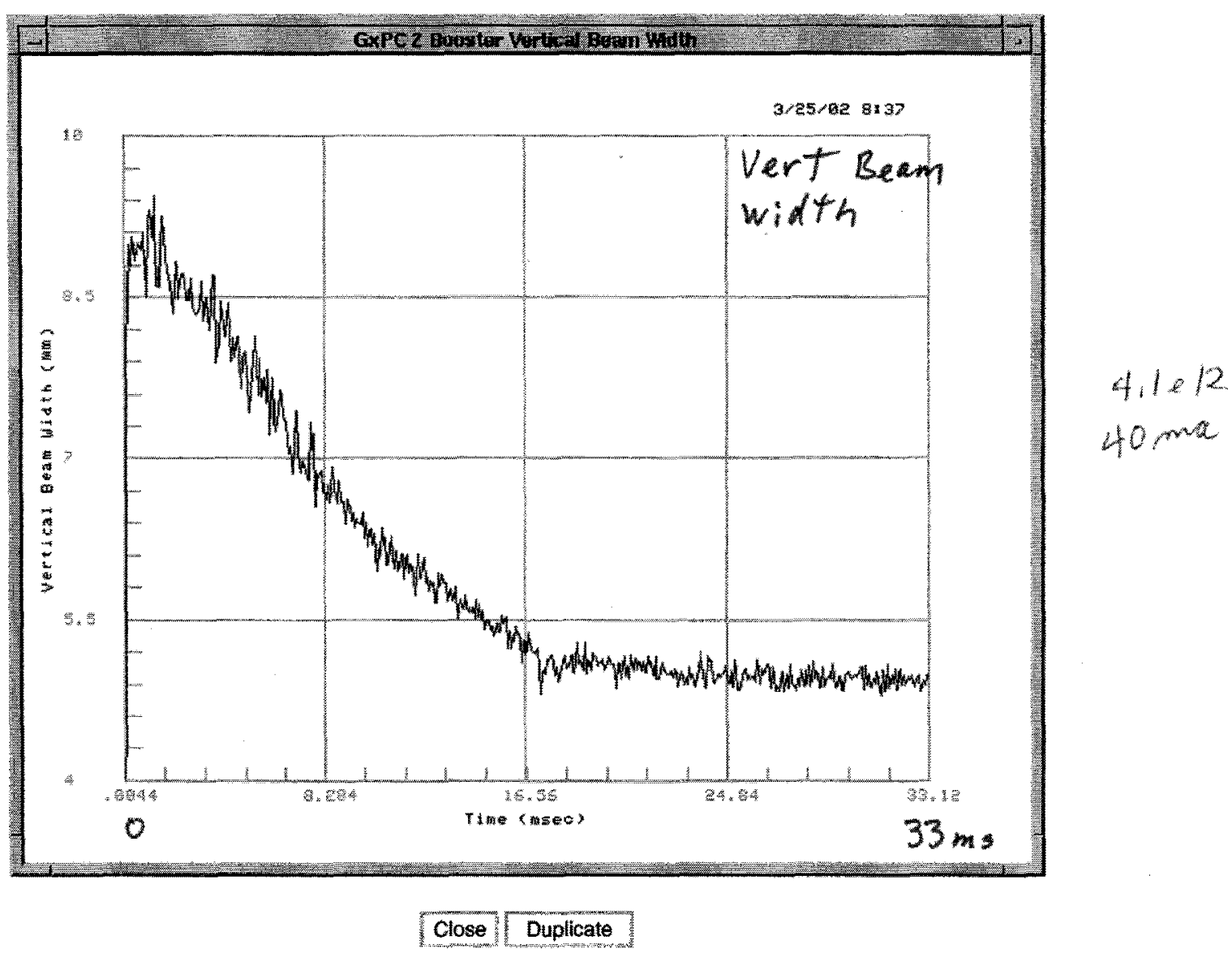




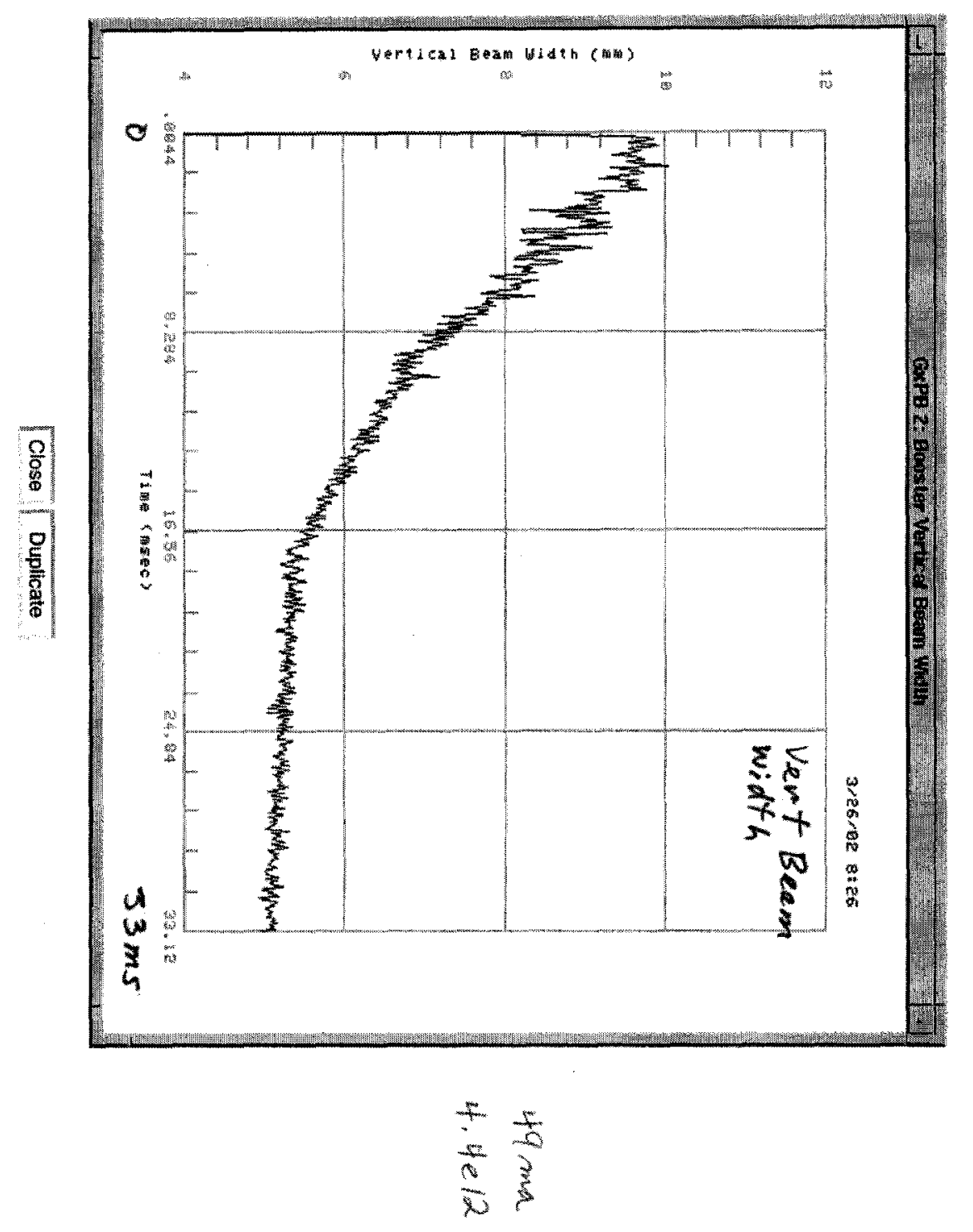




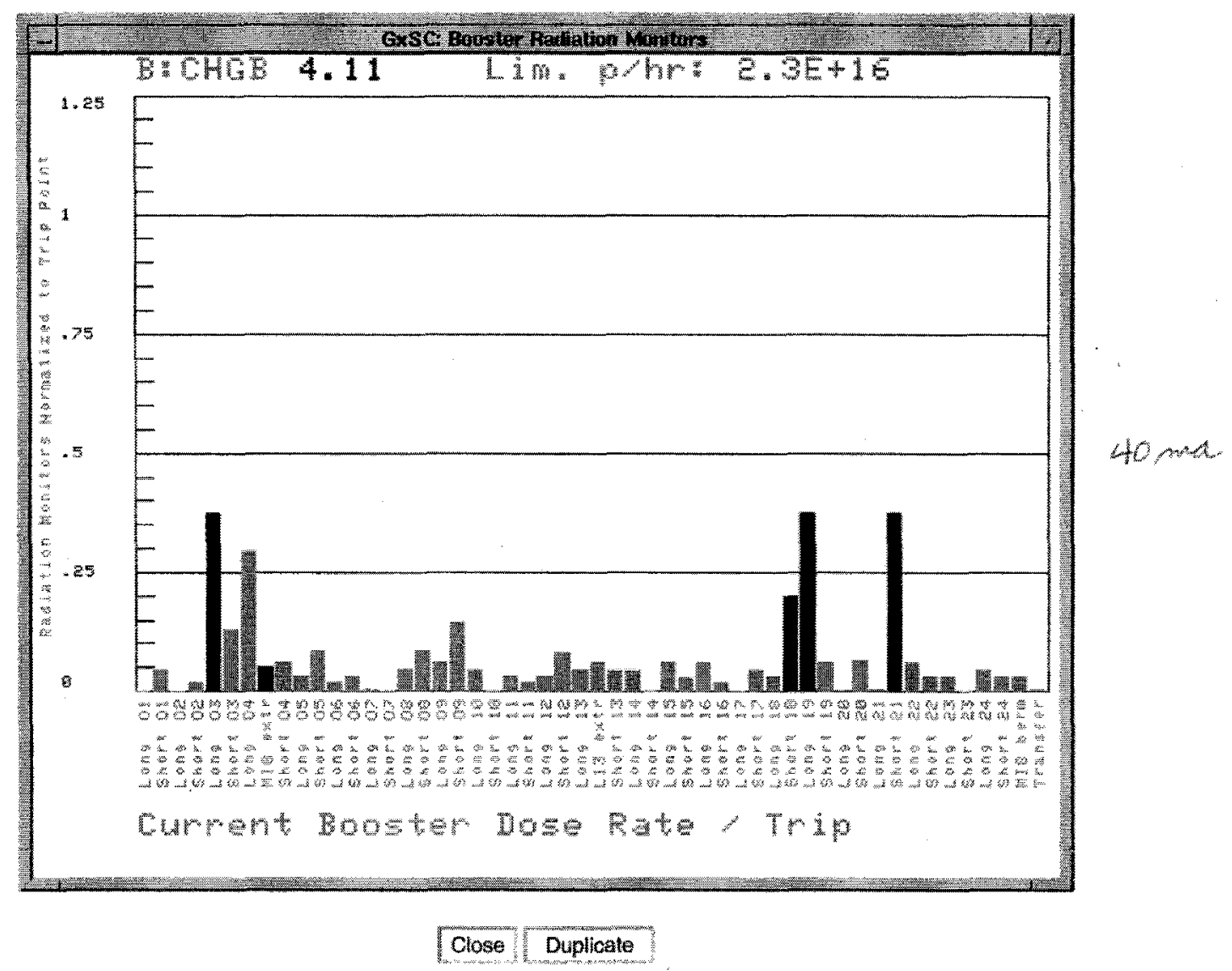




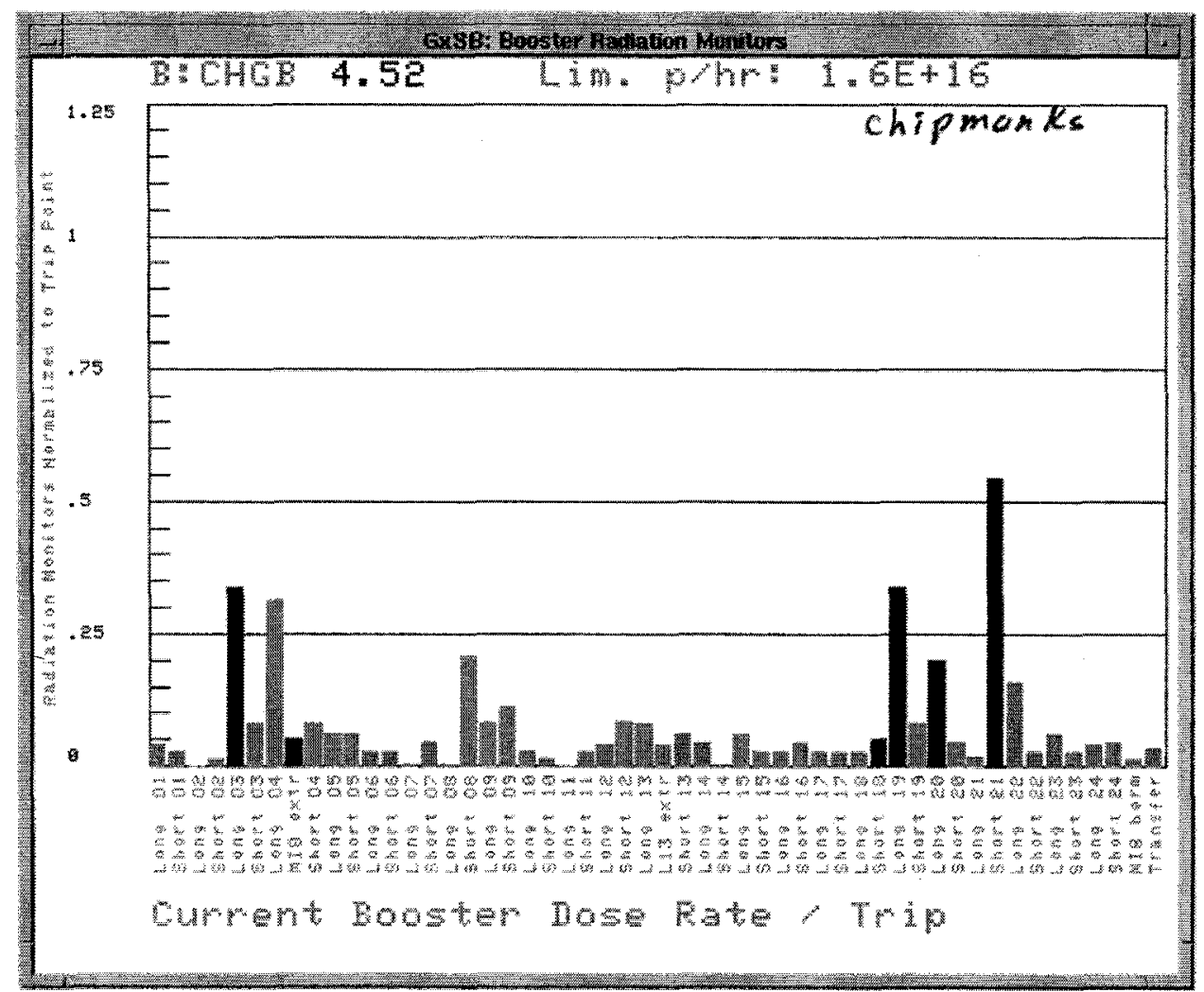

49 ma

Close $/$ Duplicate 


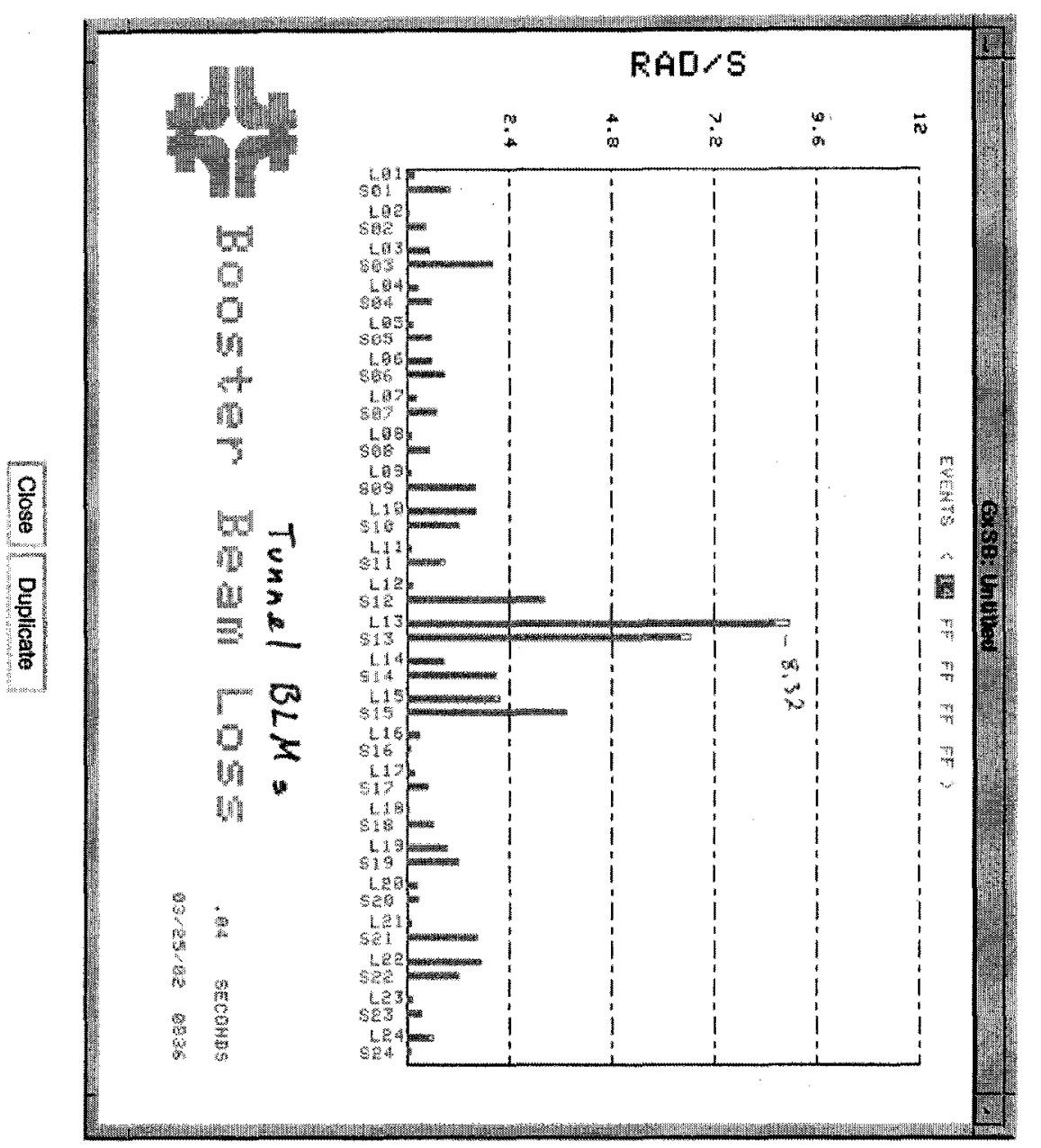

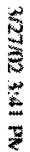

$\begin{array}{ll}5 & x \\ 0 & \frac{1}{n}\end{array}$ 


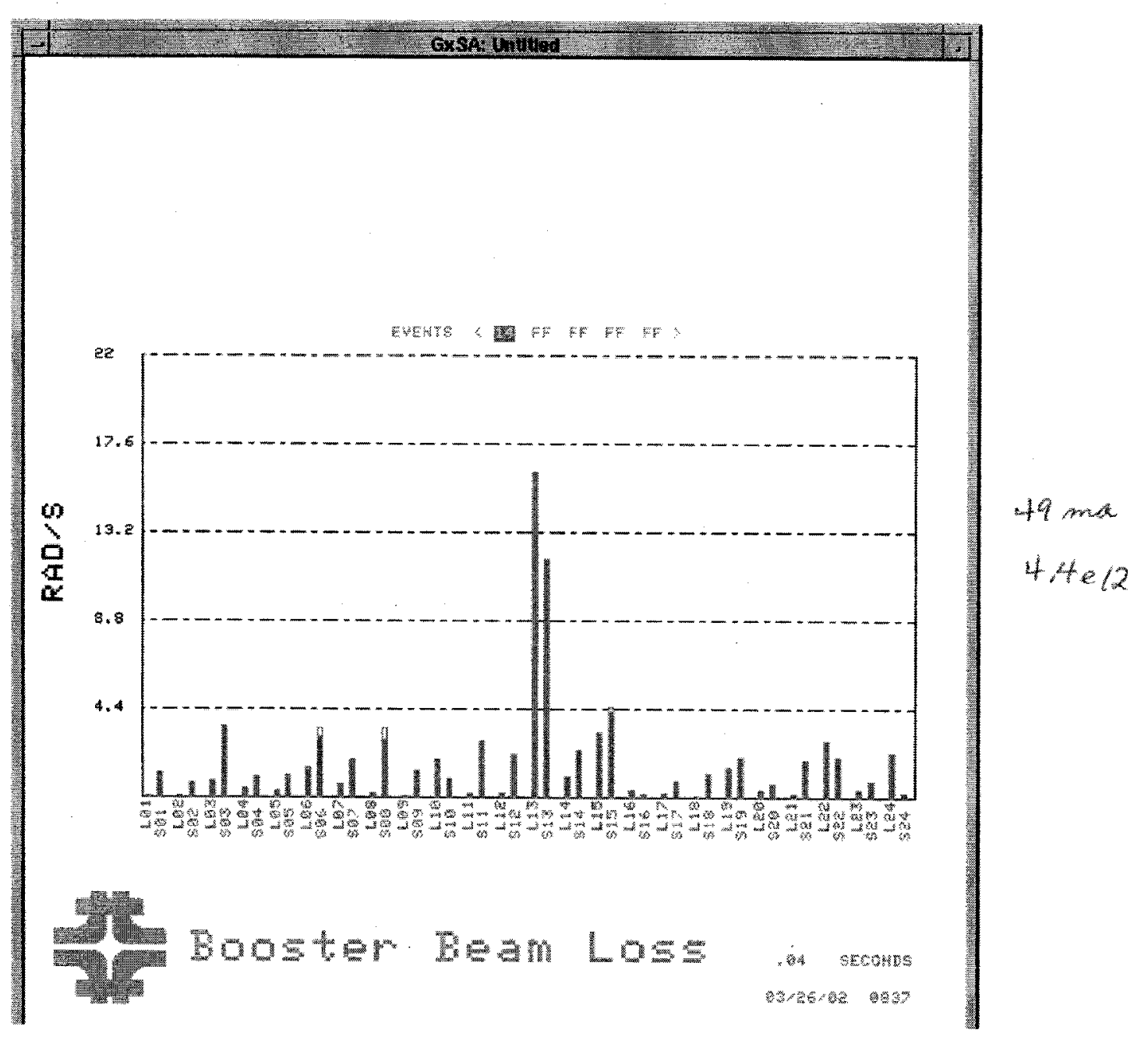




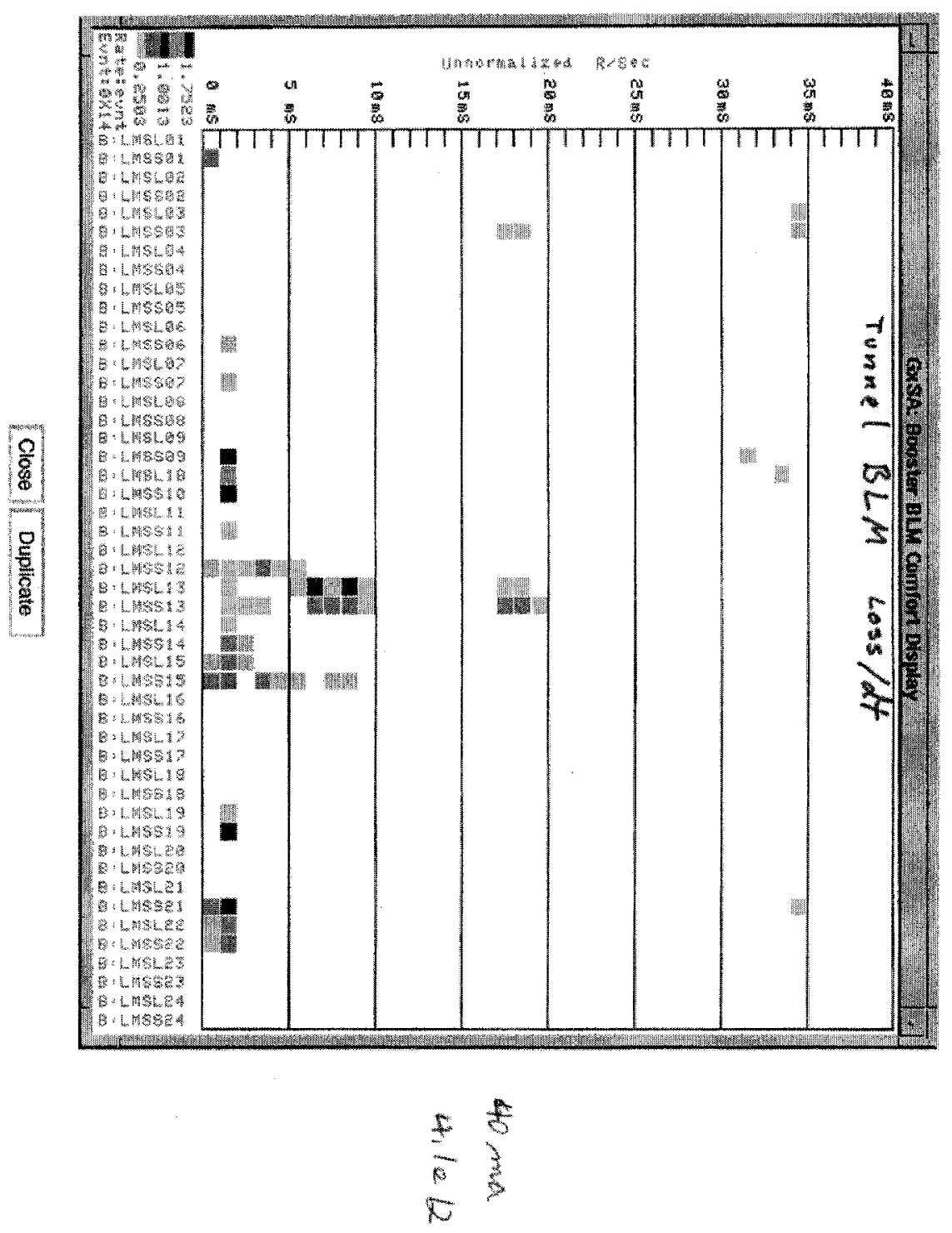

曹 


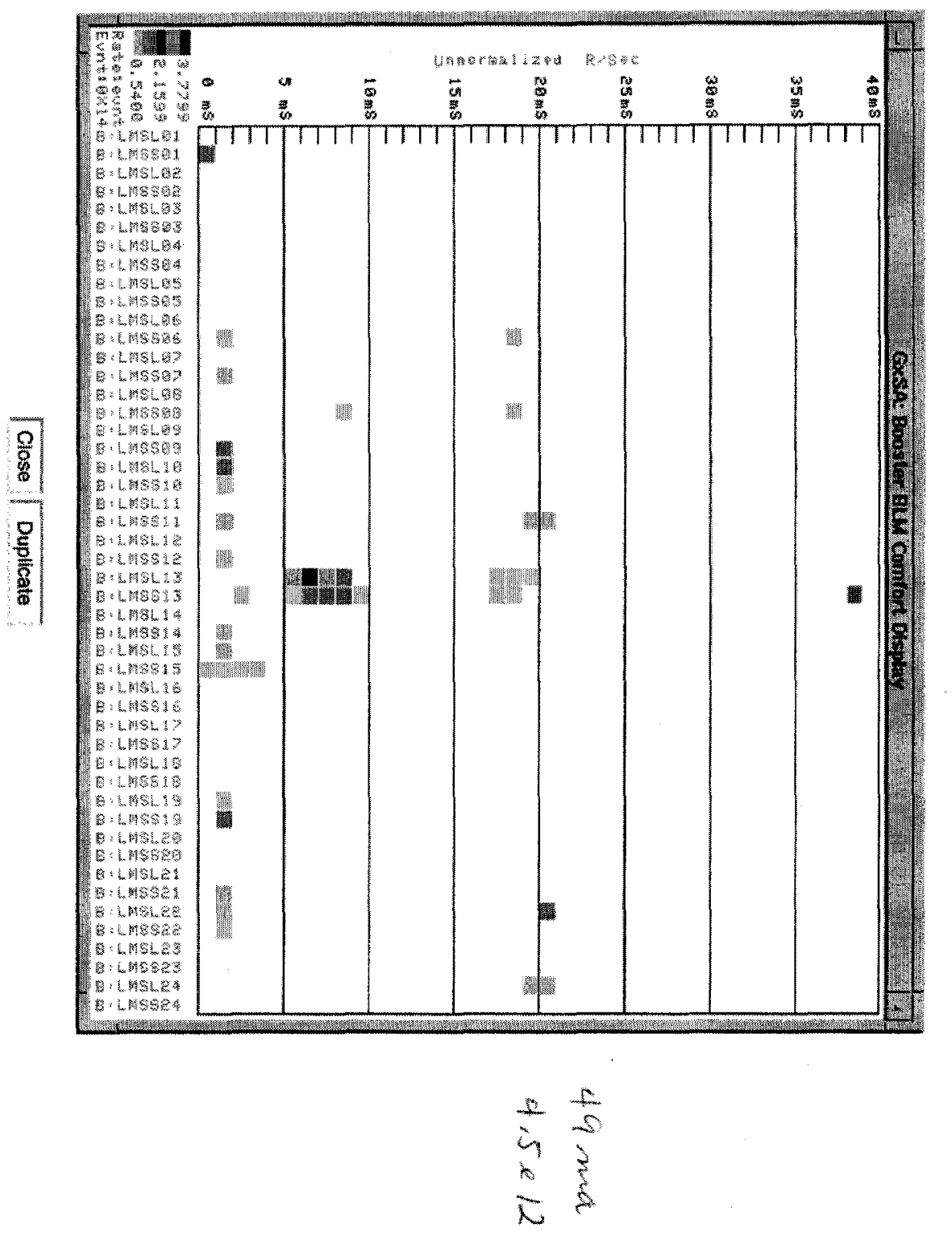




$$
\begin{aligned}
& \text { 25-Mar- }-22 \\
& 12: 43: 18 \\
& {\left[\begin{array}{r}
1+2 \\
2 \\
\text { ns } \\
88.9 \mathrm{mV} \\
80.9 \mathrm{mV}
\end{array}\right]}
\end{aligned}
$$

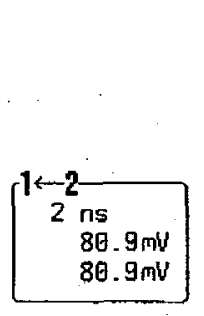

$2 \mathrm{~ns}$

1 disabled

$10 \mathrm{mv} 509 \mathrm{x}$

3 disabled

4 disabled

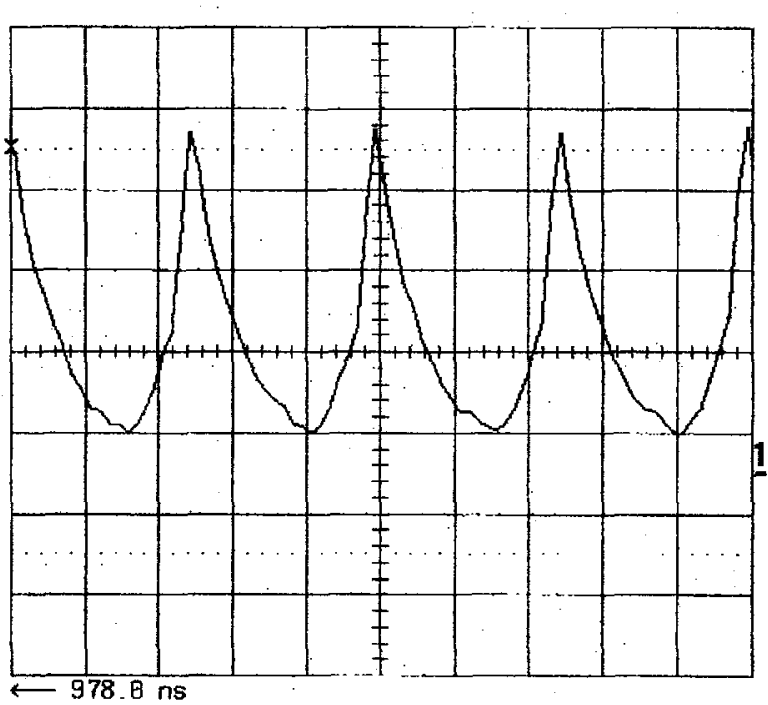

$\Delta \mathrm{t}$

Q.8. ns

$1 / 6 t$
$40 \mathrm{ma}$

$200 \mathrm{Mtz}$ bunches

First pass

by $<18$

$4 G S / 5$

NORMAL

Close $\longdiv { \text { Duplicate } }$

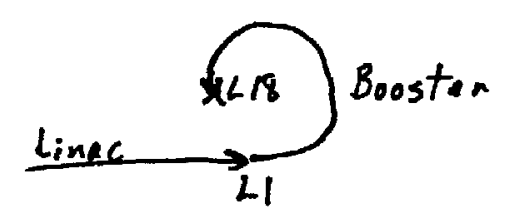




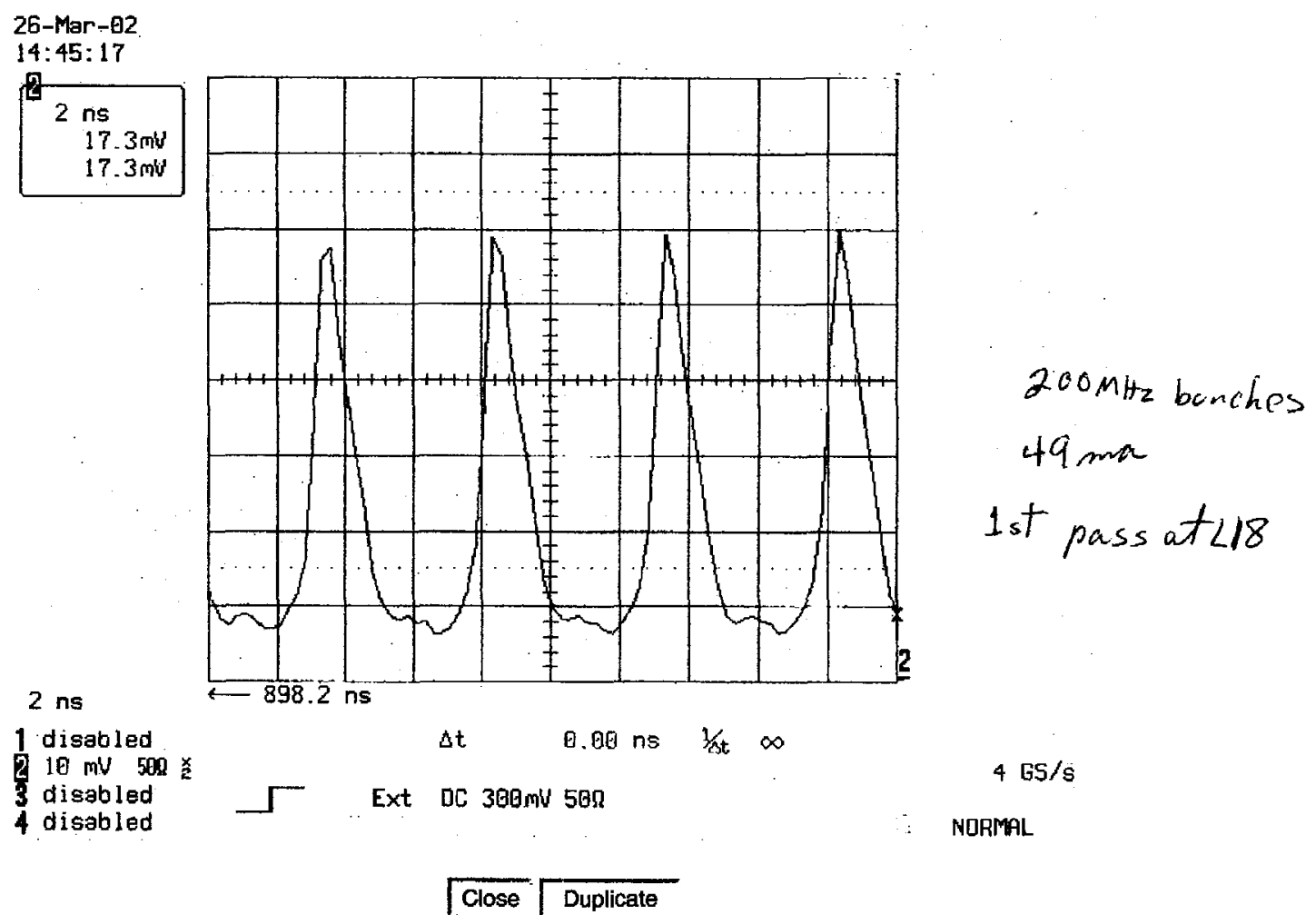




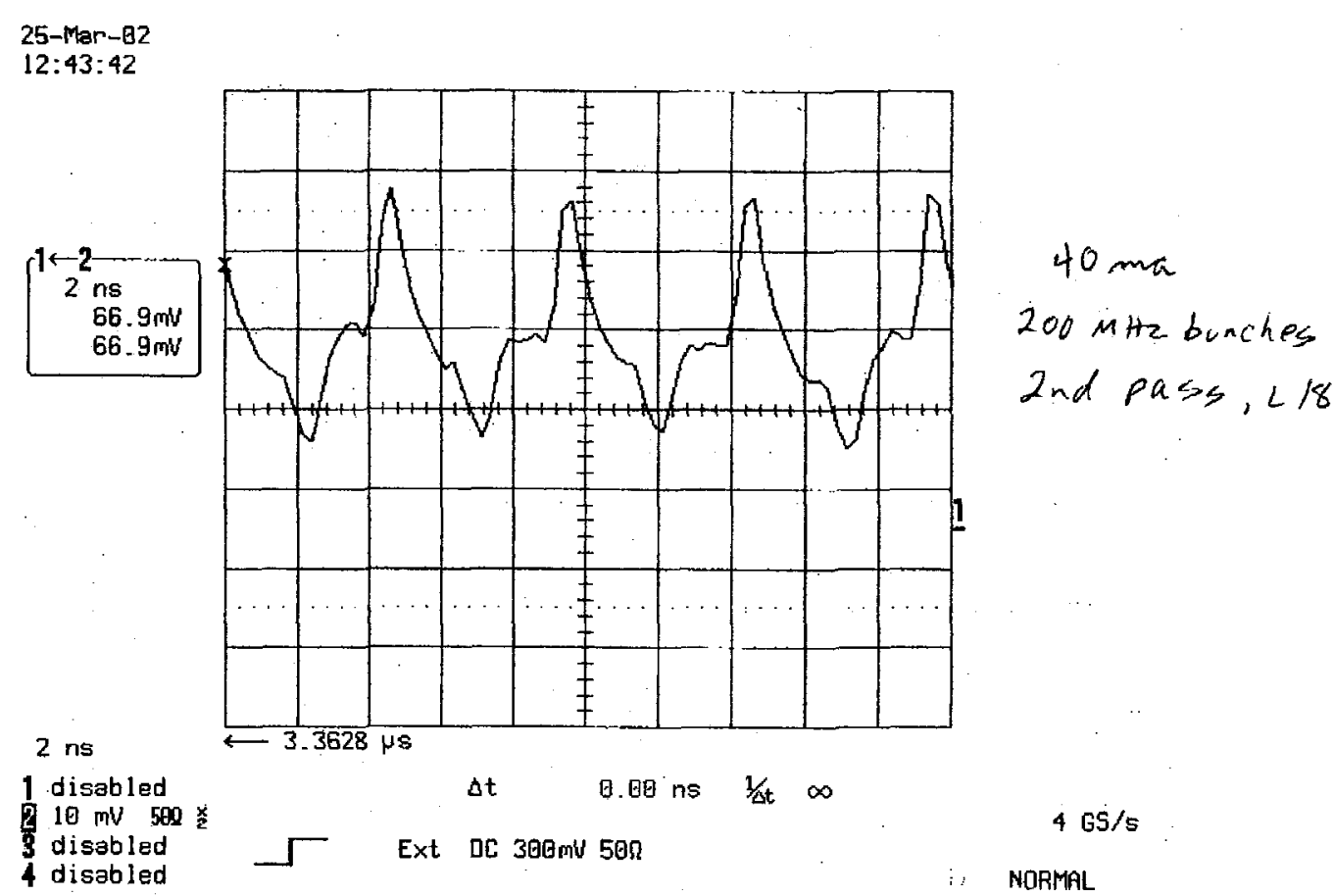

$\Gamma _ { \text { Close } } \longdiv { \text { Duplicate } }$ 


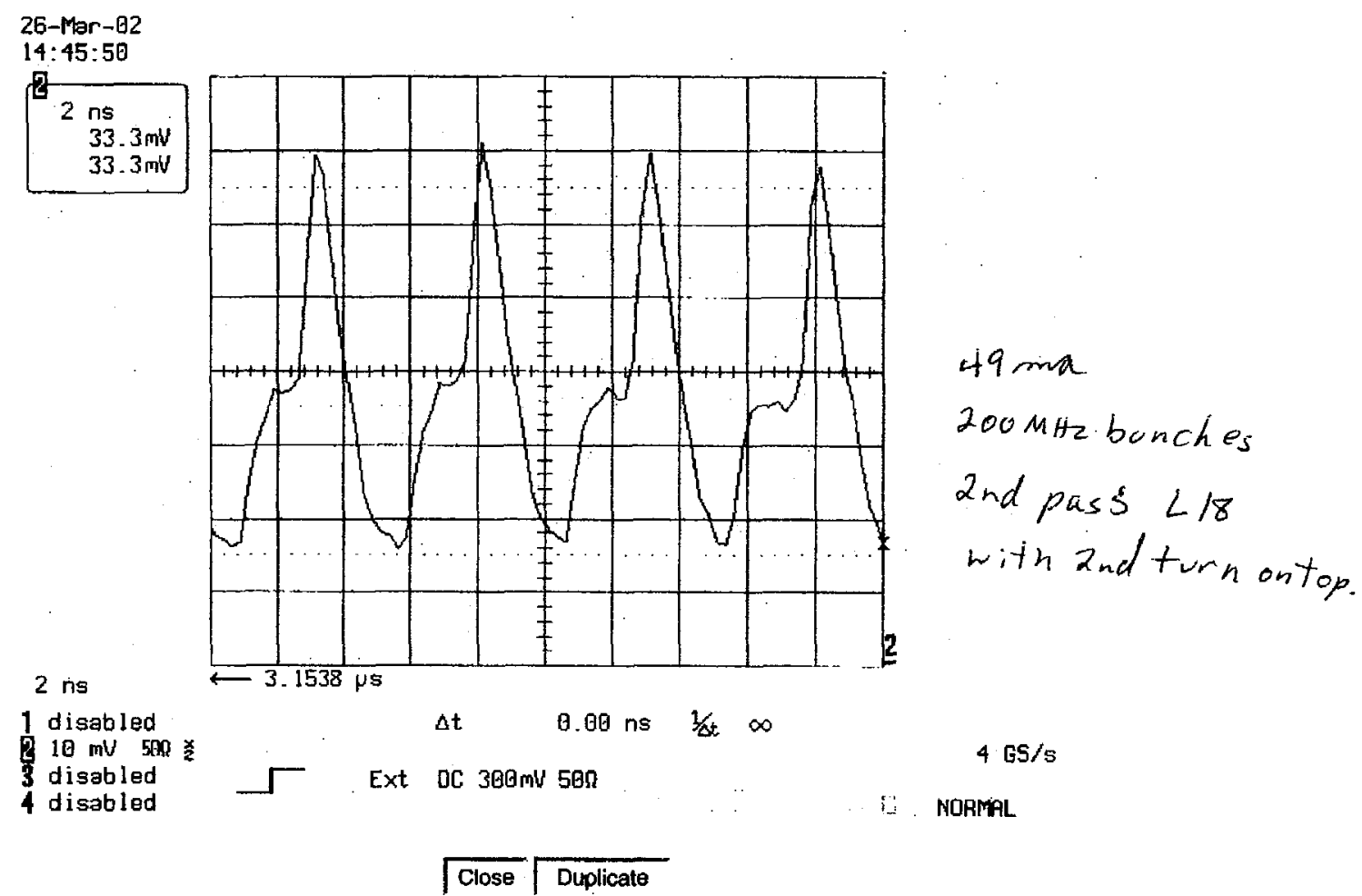



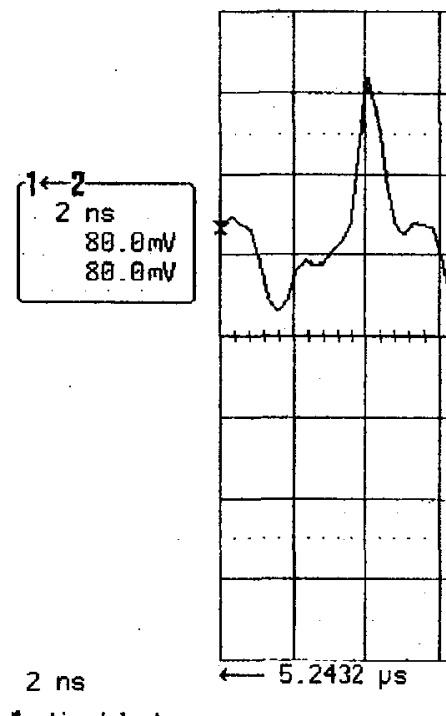

2 ns

1 disabled

$210 \mathrm{mV} .500$

4 disabled
disabled $-\sqrt{ }$

$\Delta t$

B. 0 o ns

40 ma $200 \mathrm{MHz}$ buaches

3 rd pass, 218

$\longdiv { \text { Close } } \longdiv { \text { Duplicate } }$ 
$26-$ Mar- -02

$14: 46: 30$

$2 \mathrm{~ns}$
$56.5 \mathrm{mv}$
$56.5 \mathrm{mv}$

nis

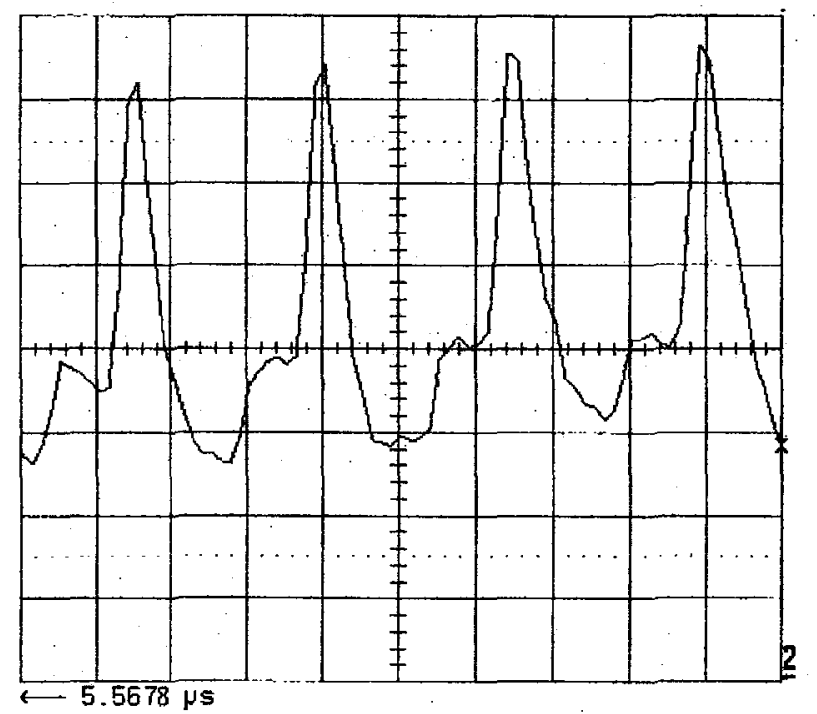

49 ma e L $L 18$

3rd pass istortion

2 mdpase of 2nd turn

Ist pase of 3rdturm

1 disabled

$\Delta t \quad 0.00$ ns $1 / 4 t \quad \infty$

$10 \mathrm{~mW} 500$

disabled

4 GS/s

4 disabled

Ext oc $380 \mathrm{~mW} 58 \pi$

$\longdiv { \text { Cilose } } \longdiv { \text { Duplicate } }$ 


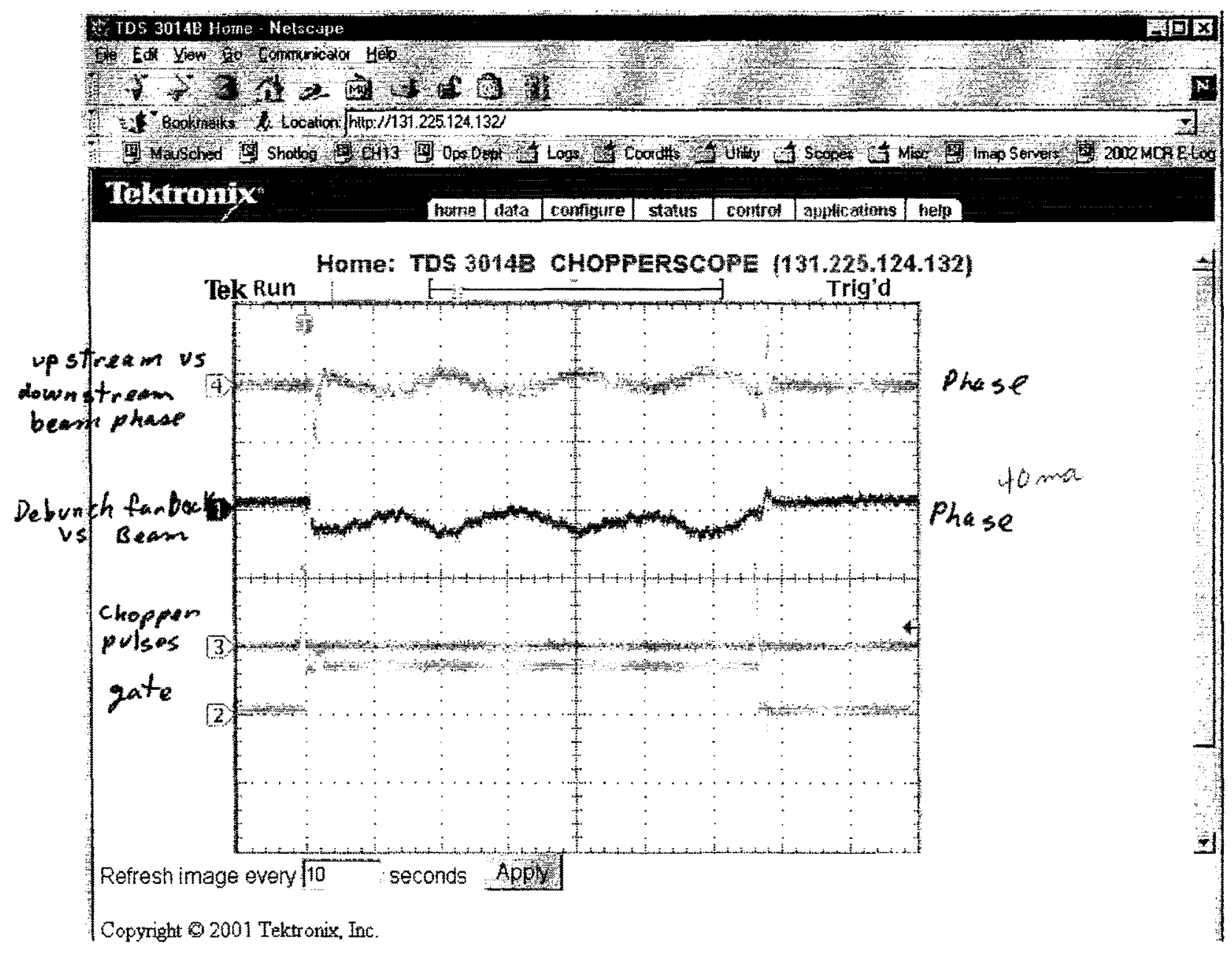




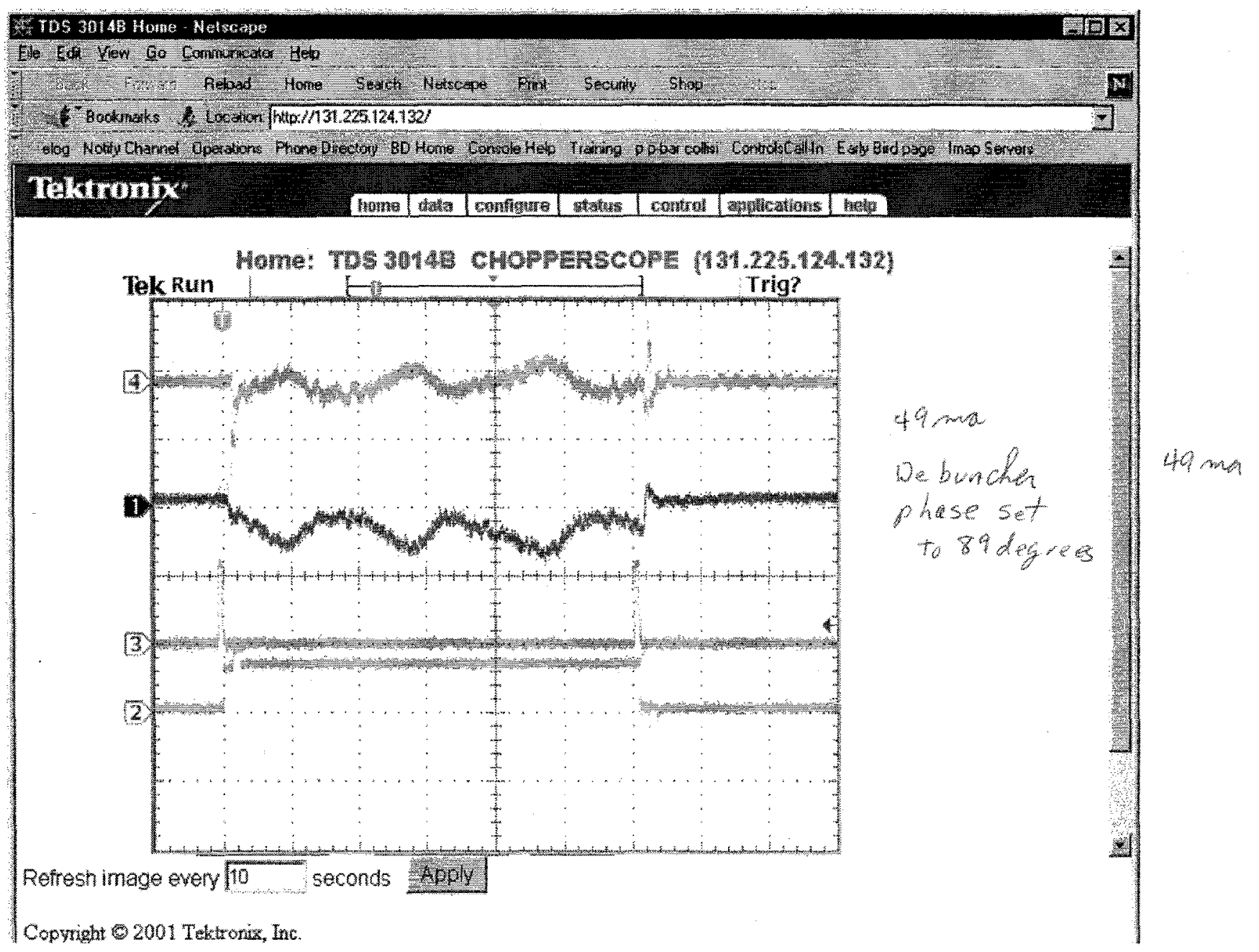




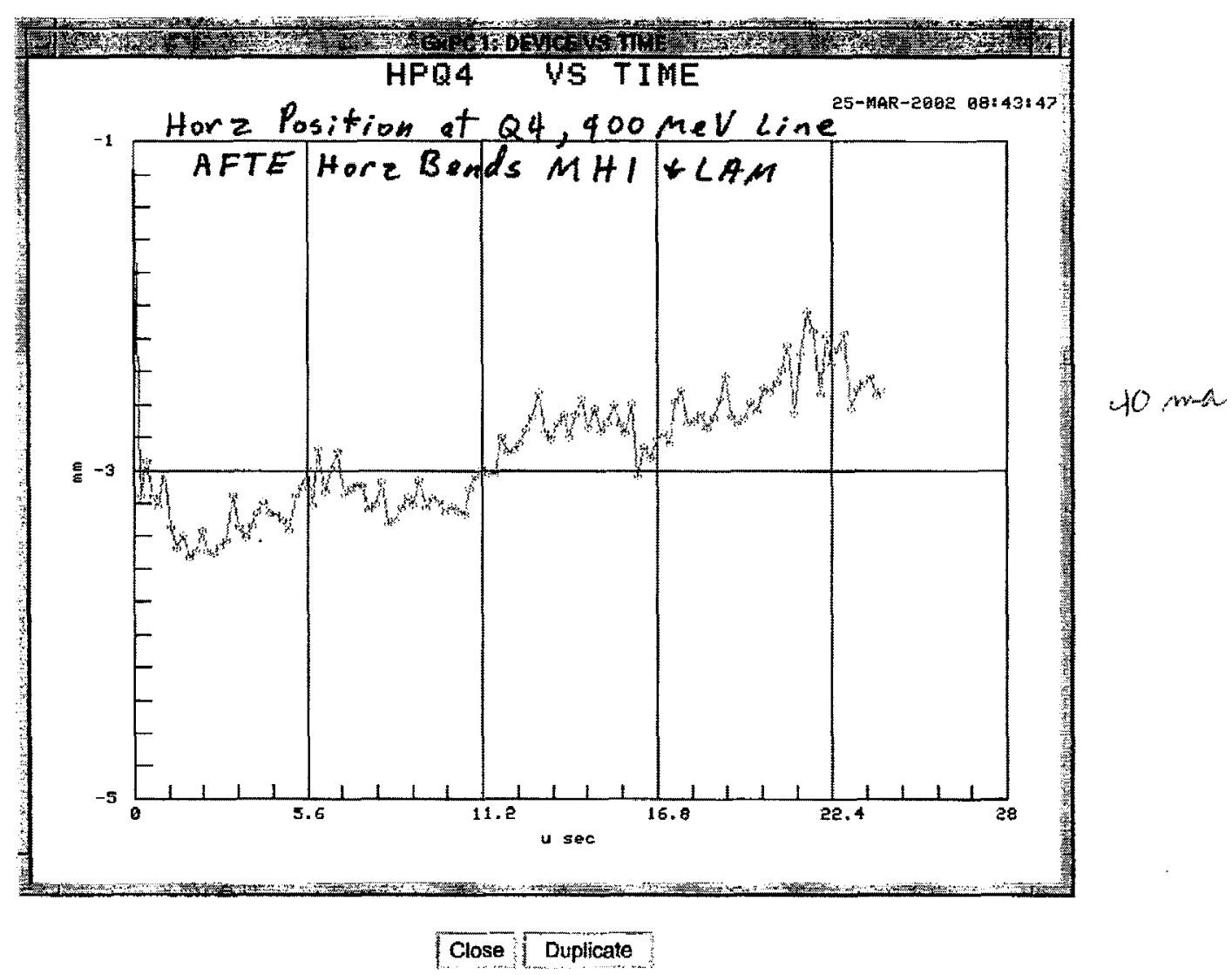




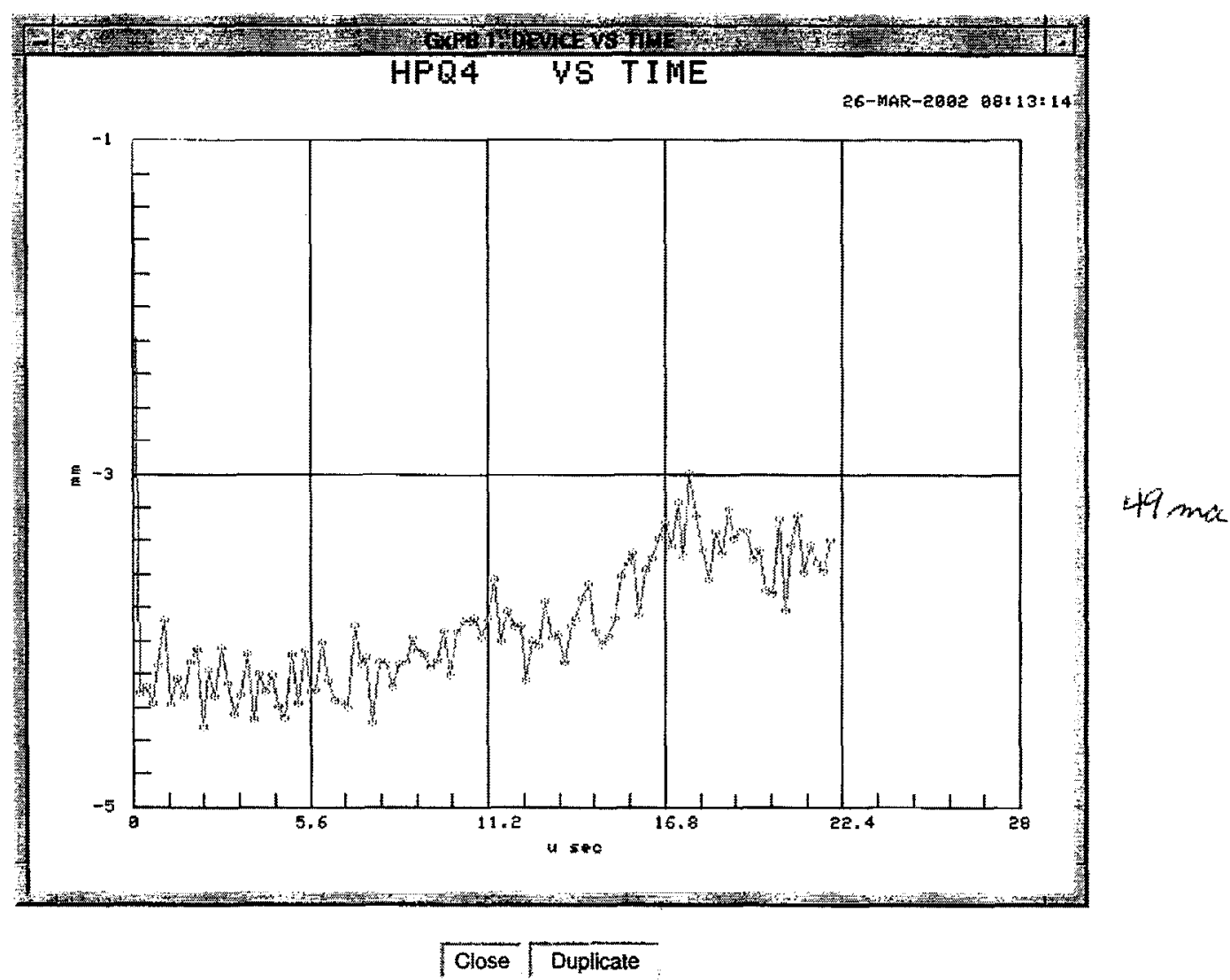




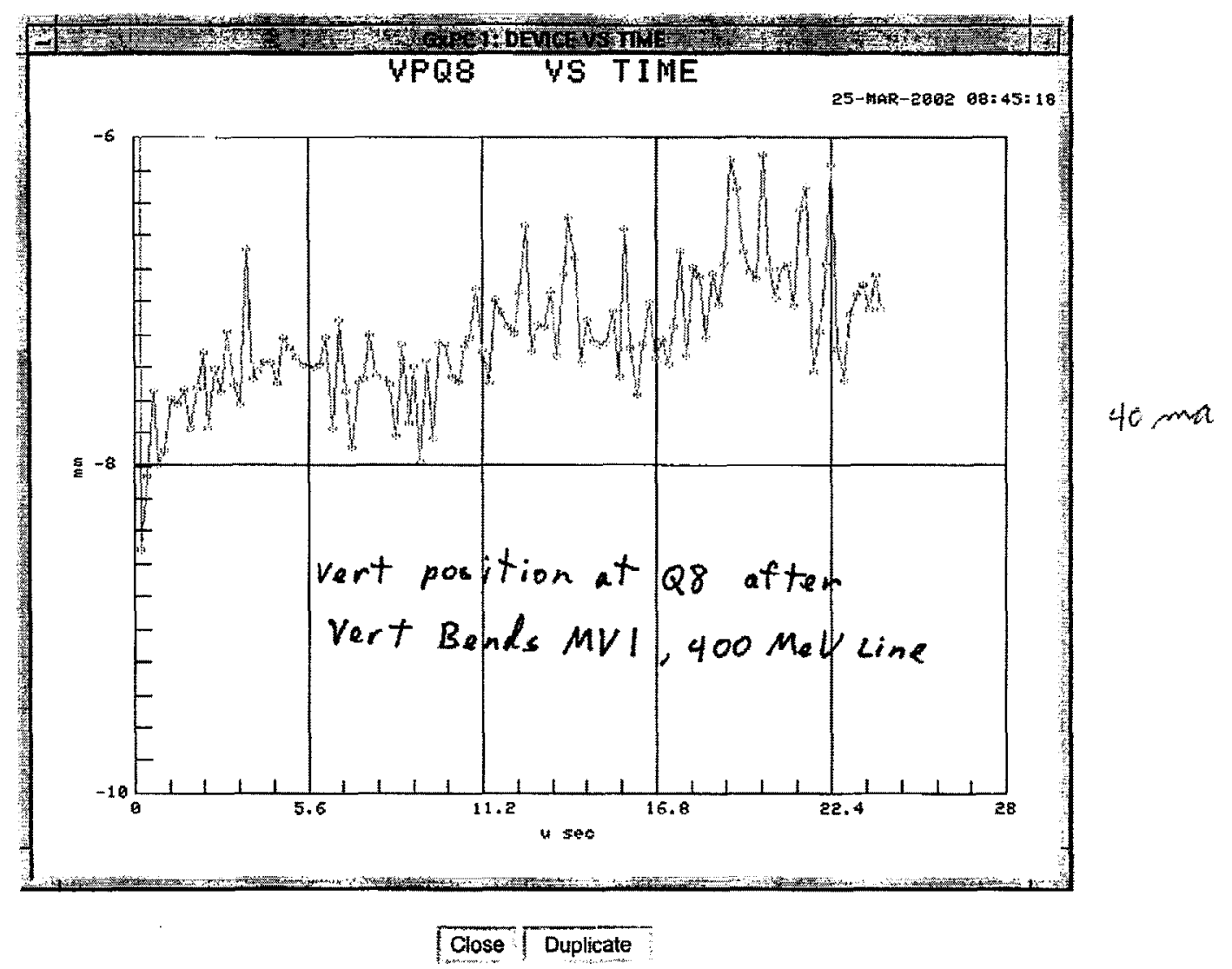




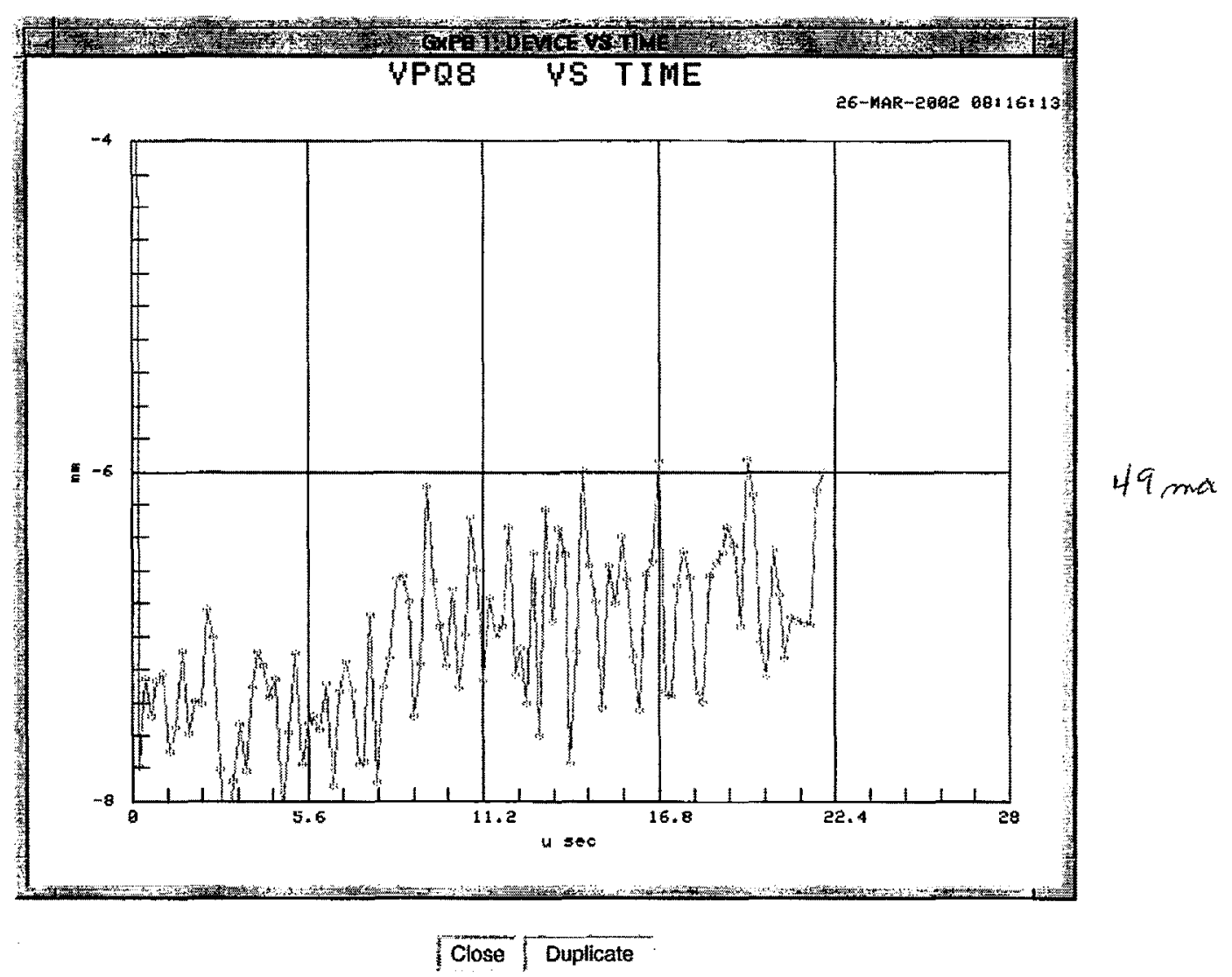




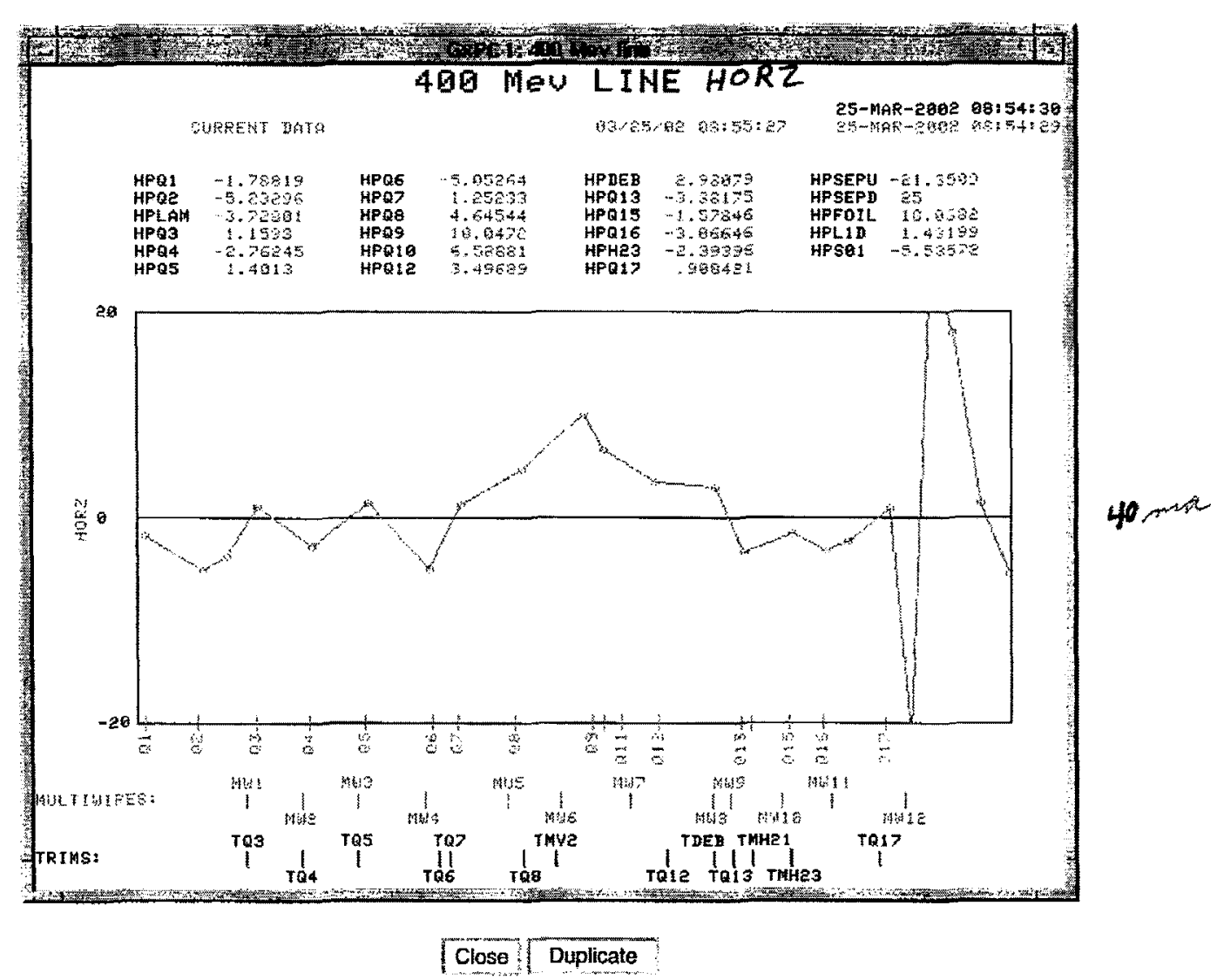




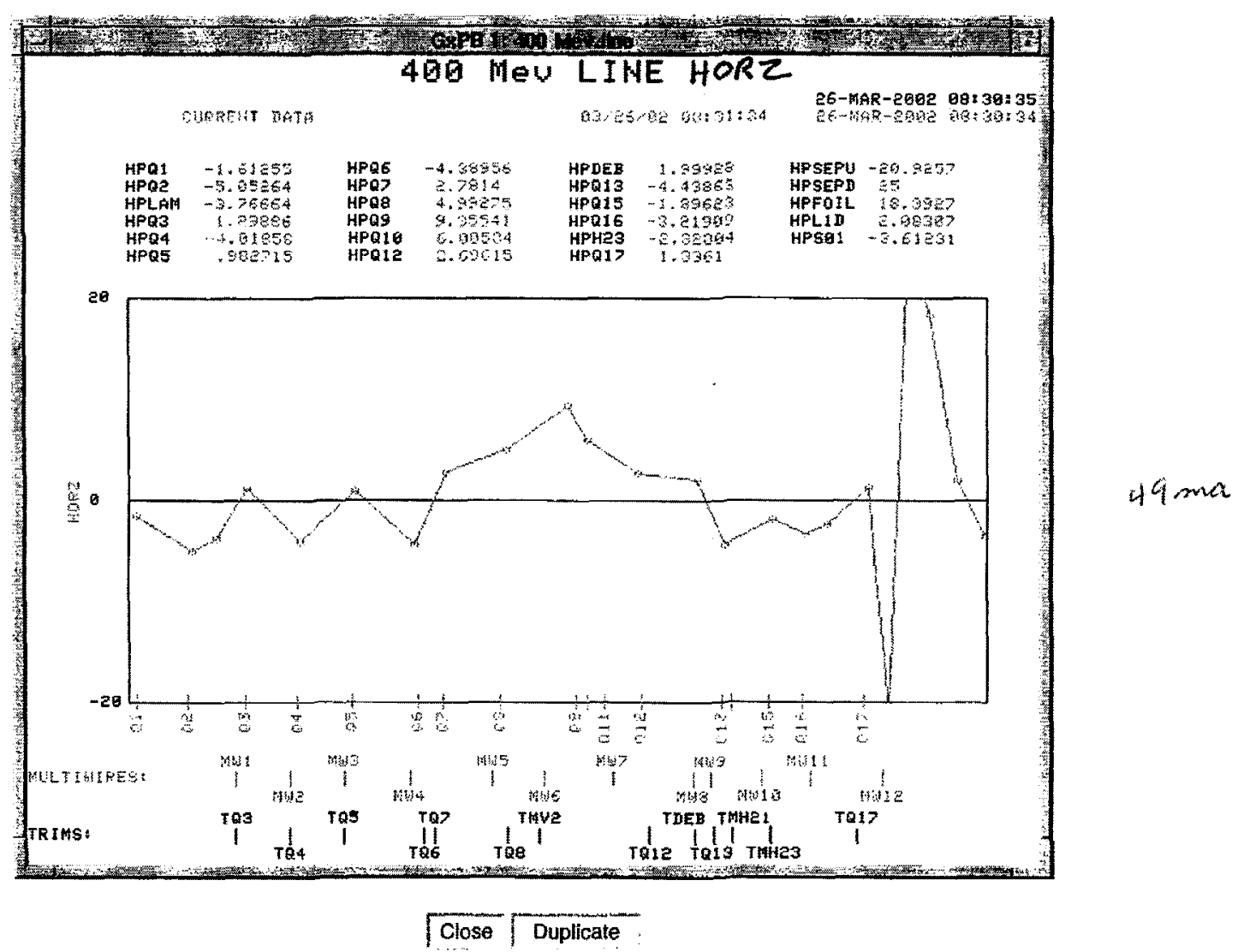




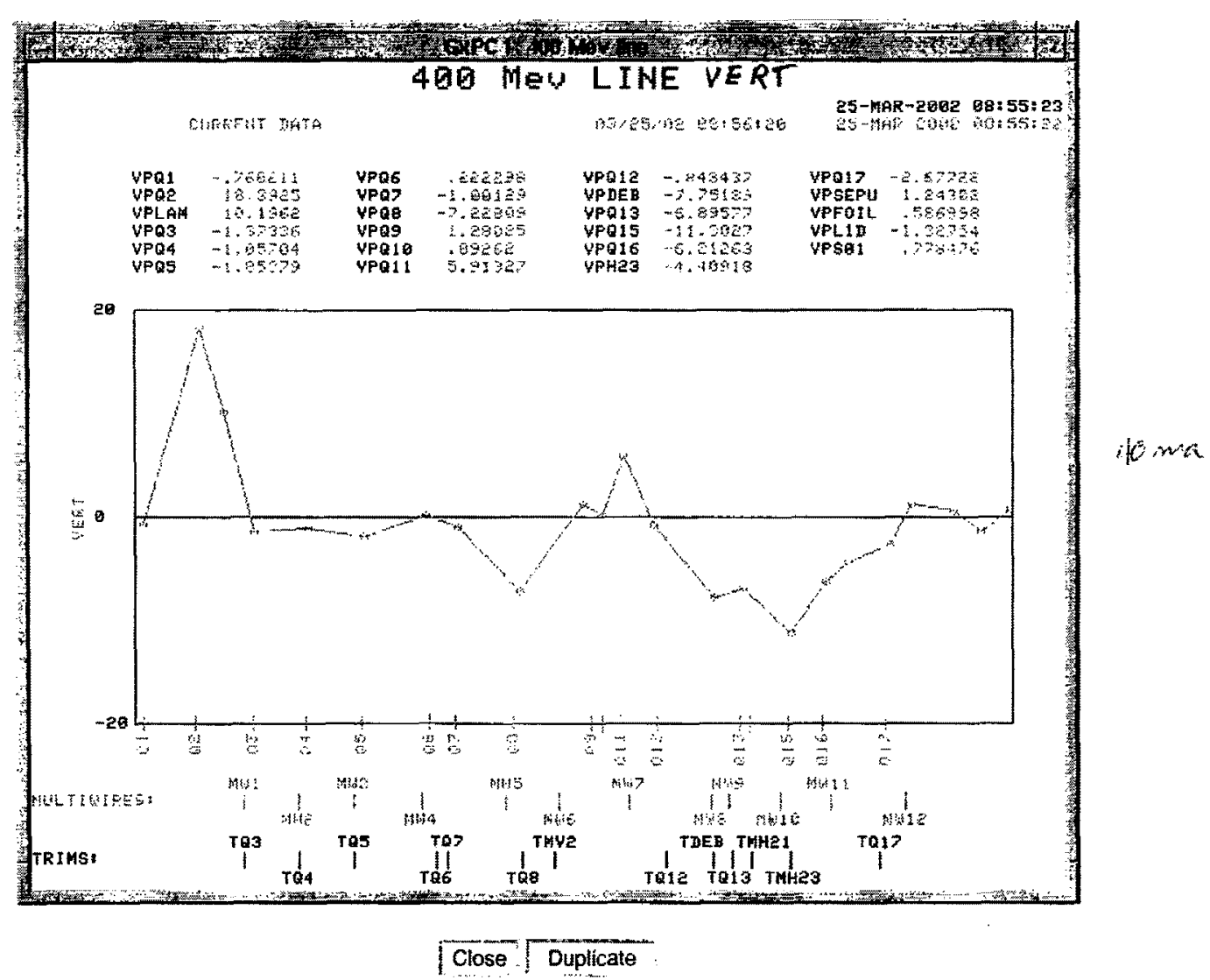




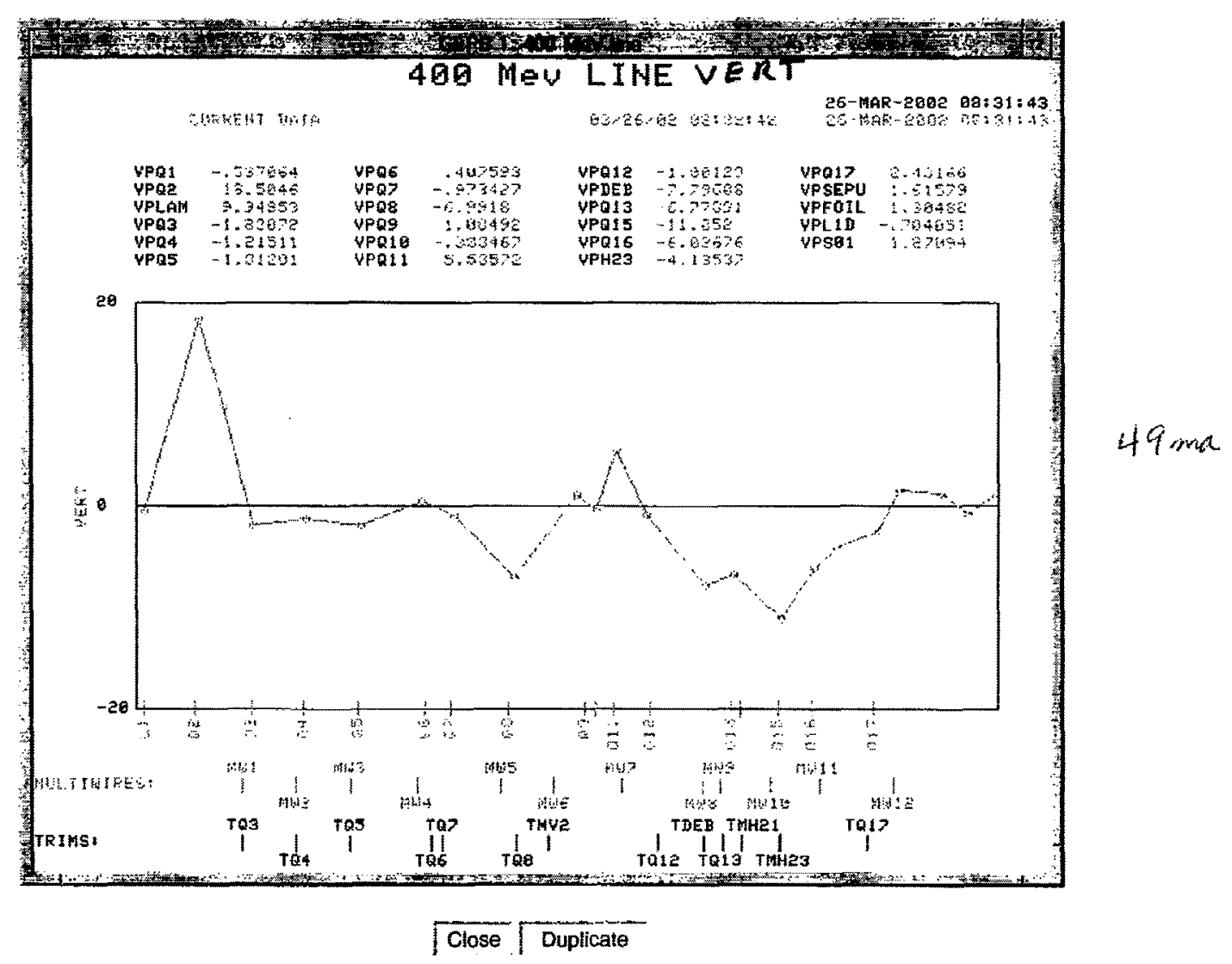




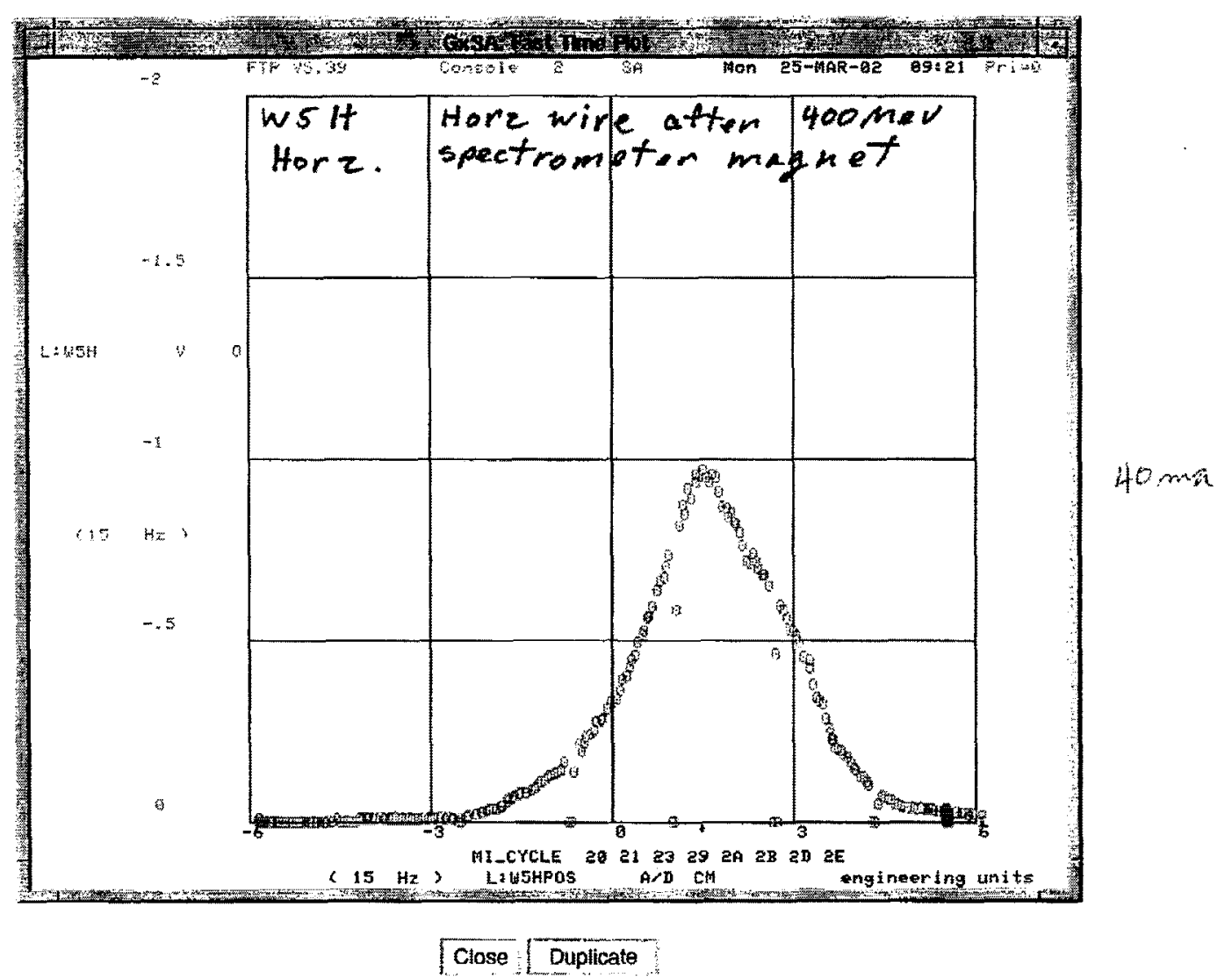




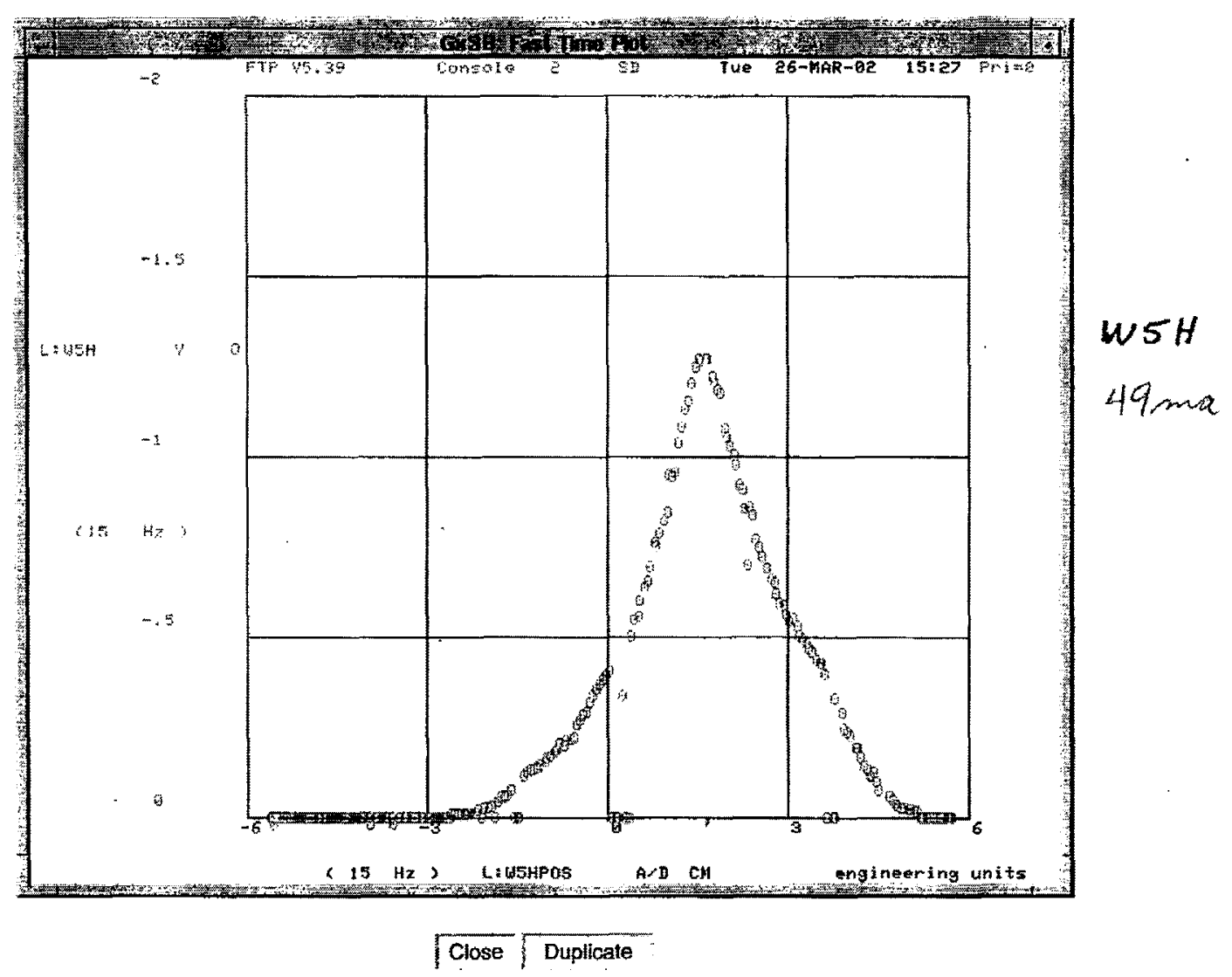




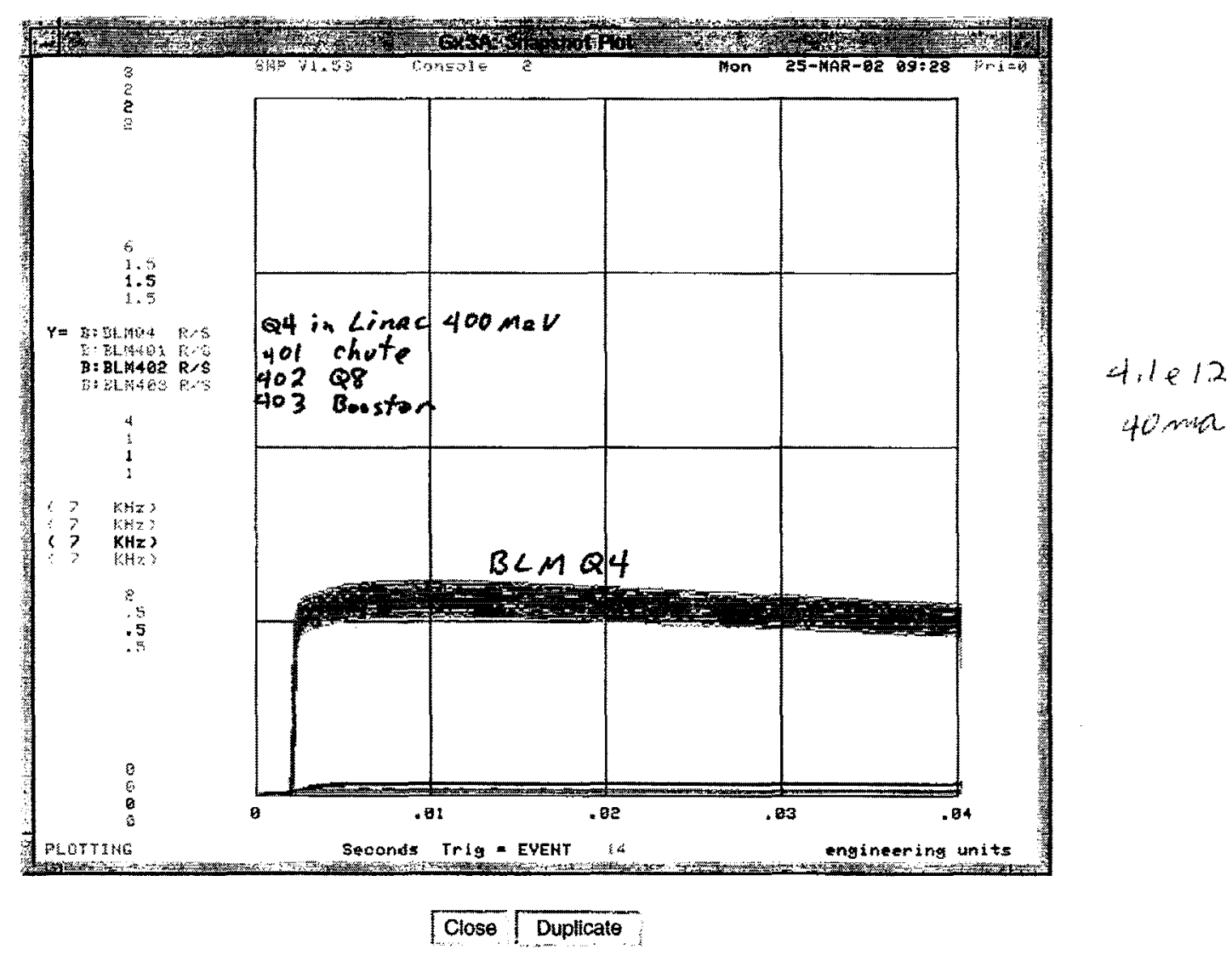




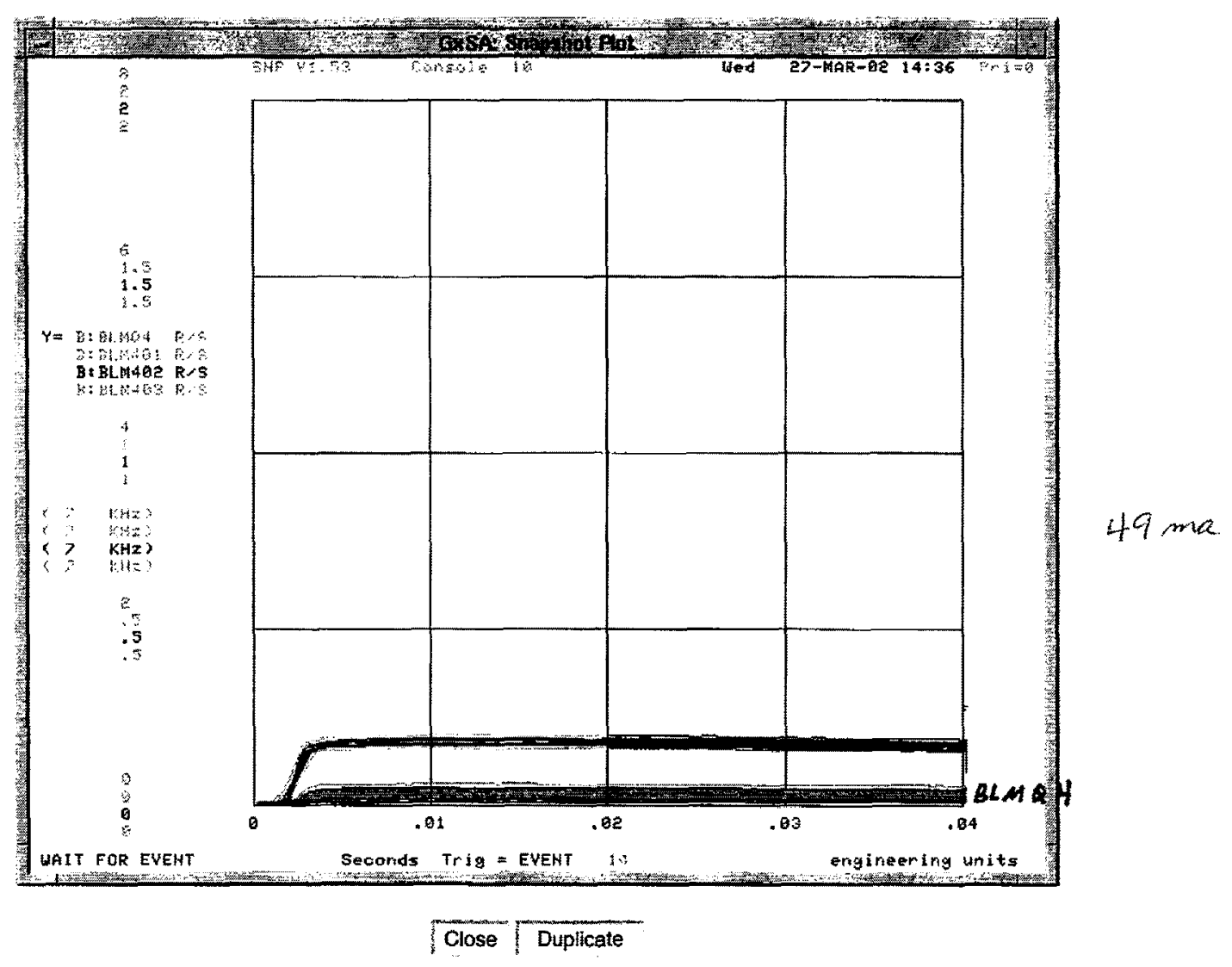




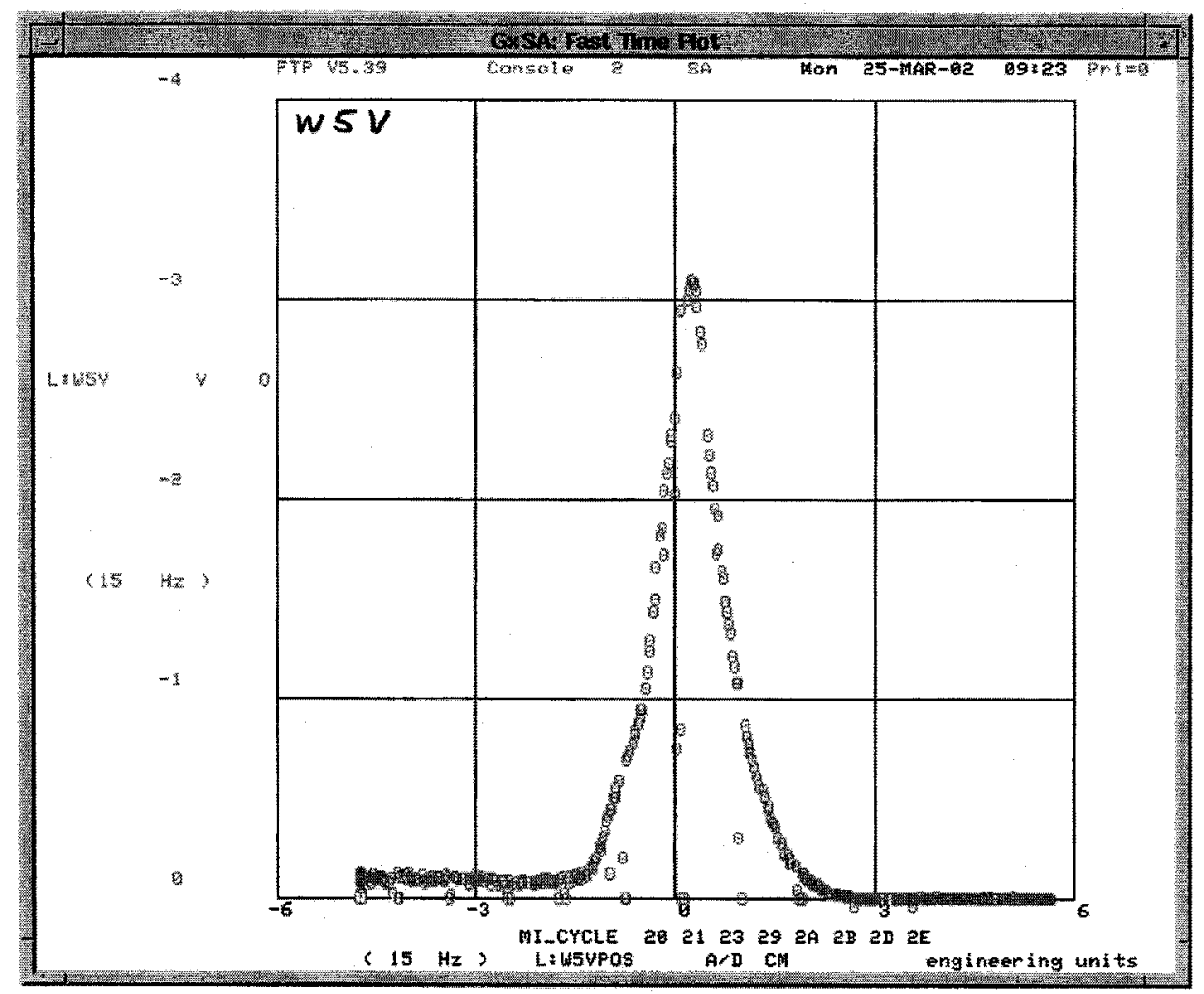

$40 \mathrm{ma}$

Close $\longdiv { \text { Duplicate } }$ 


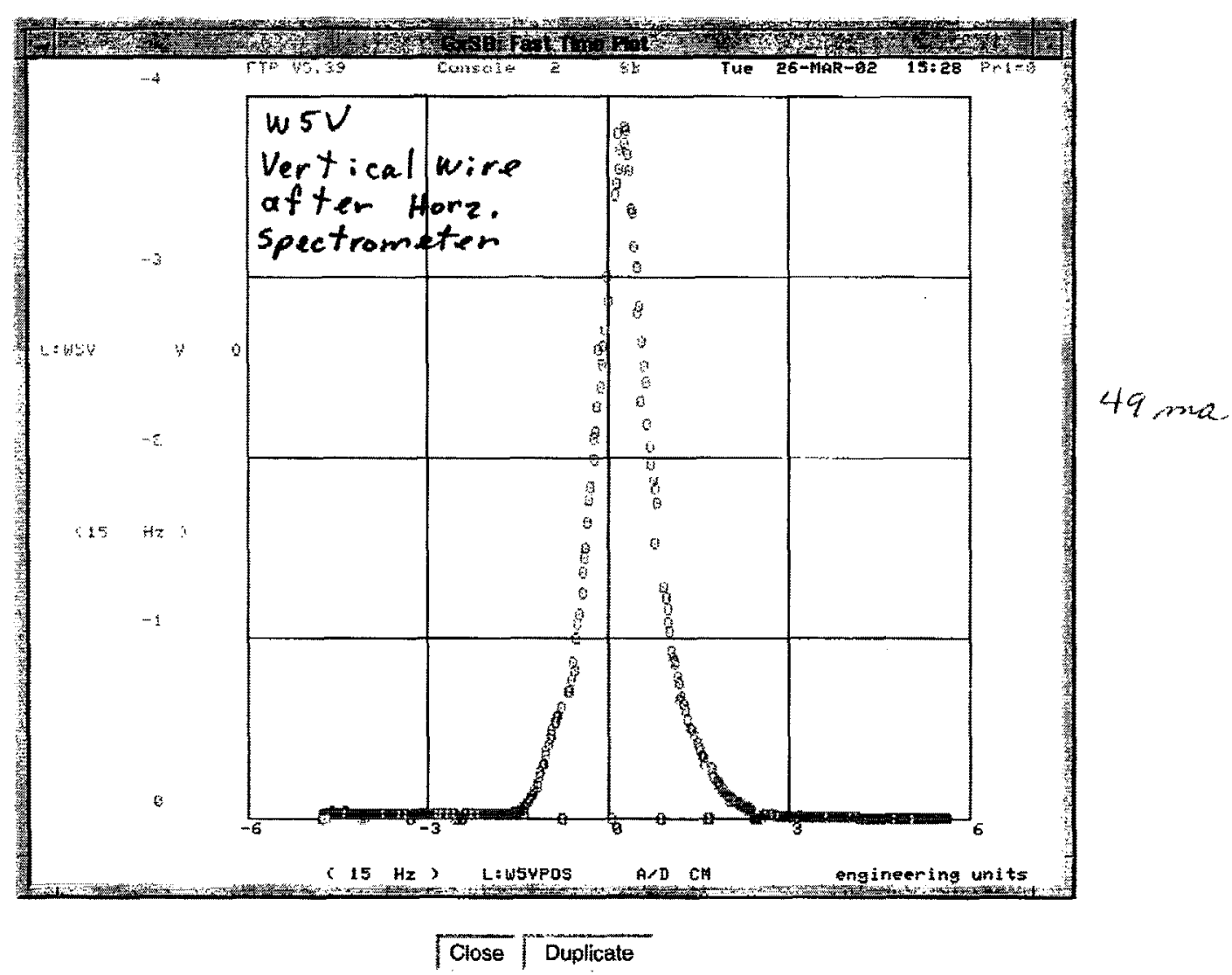




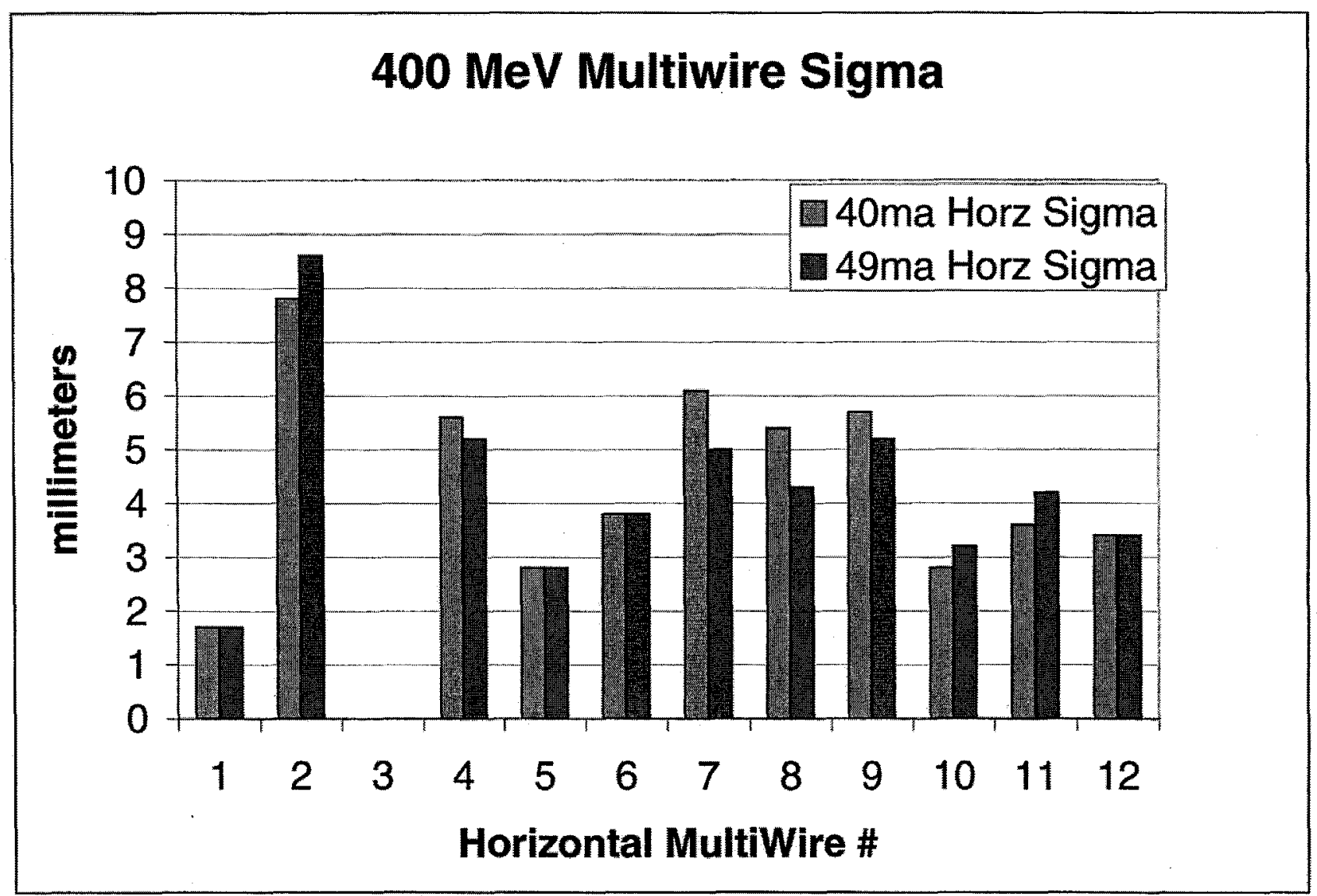




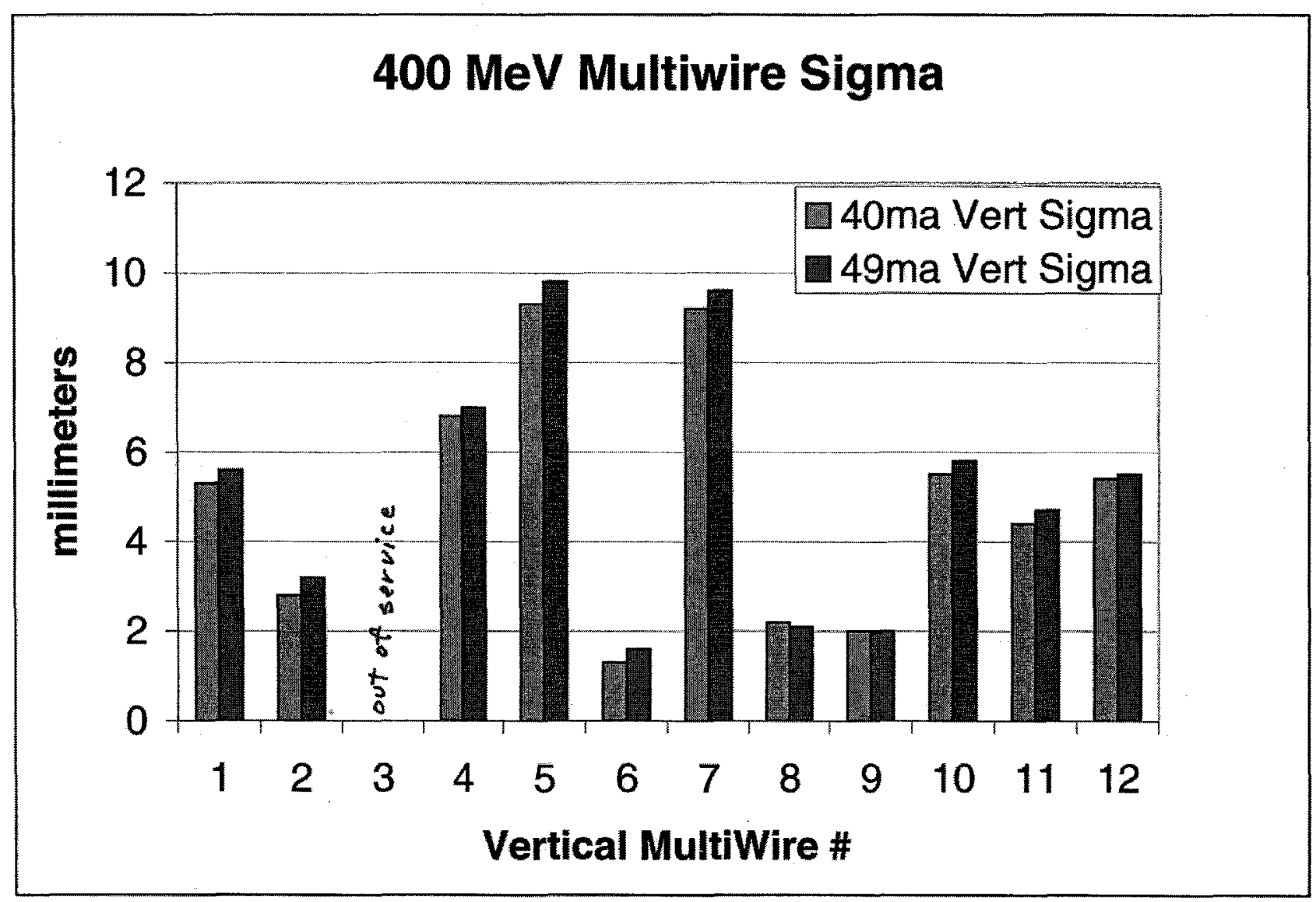




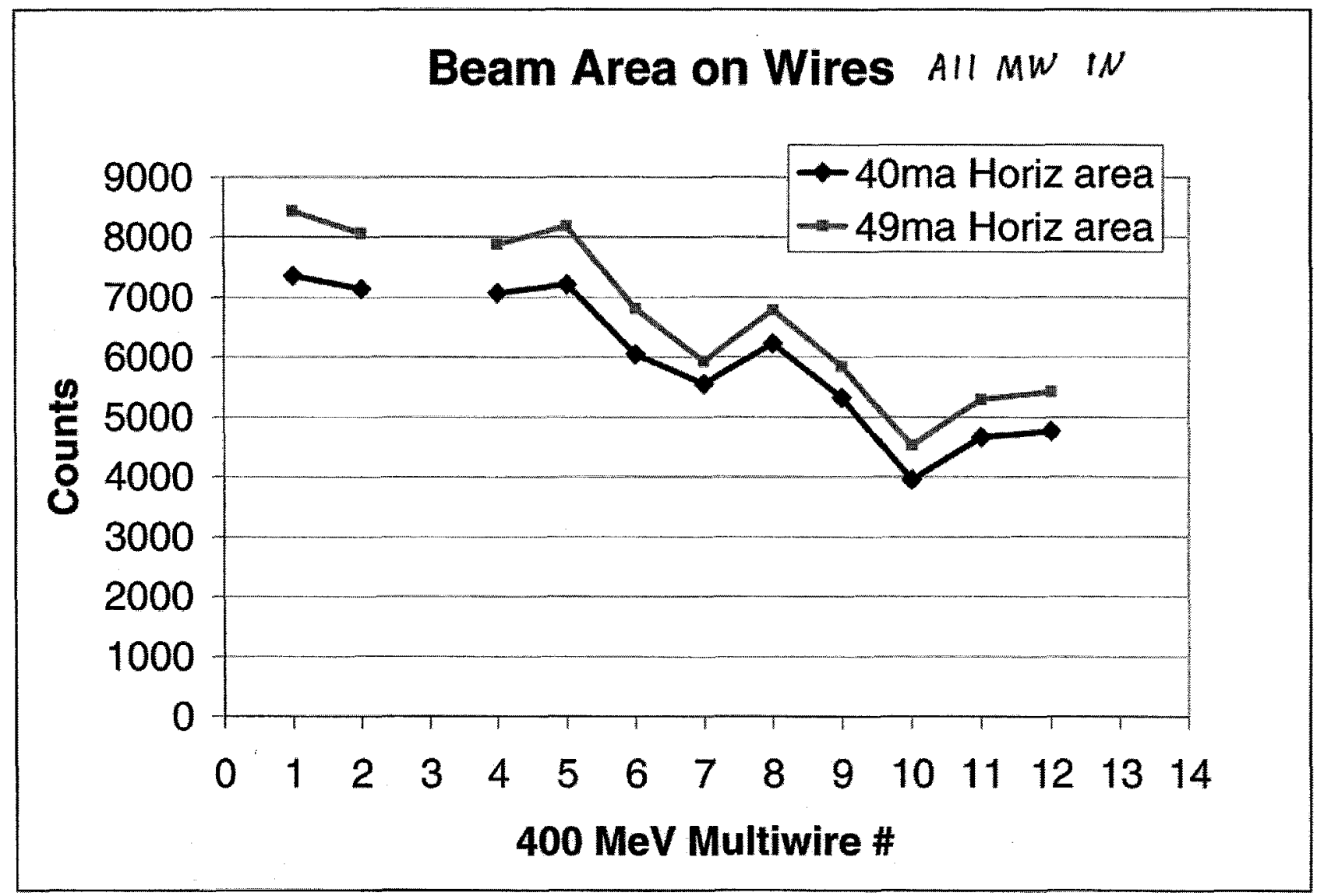




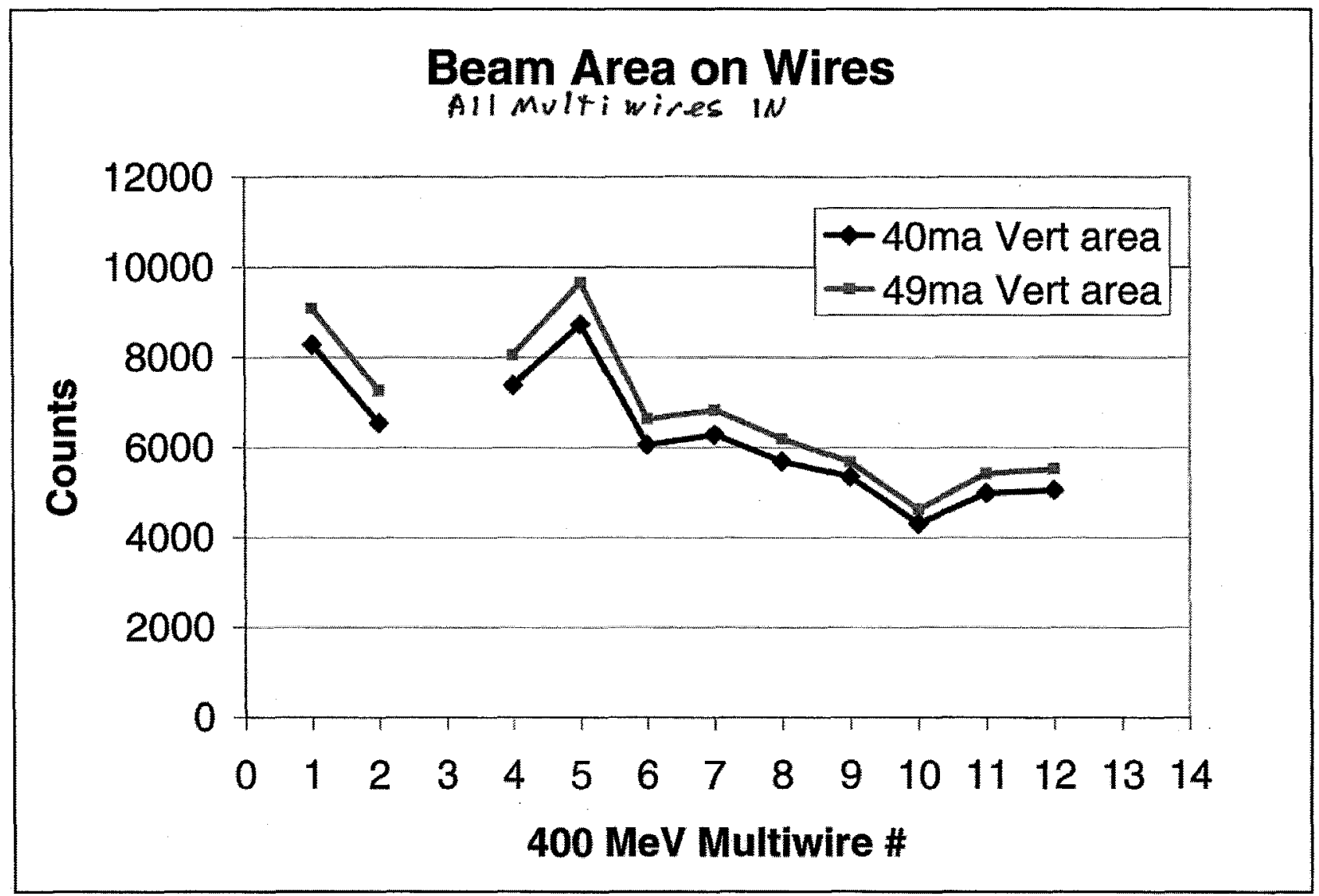



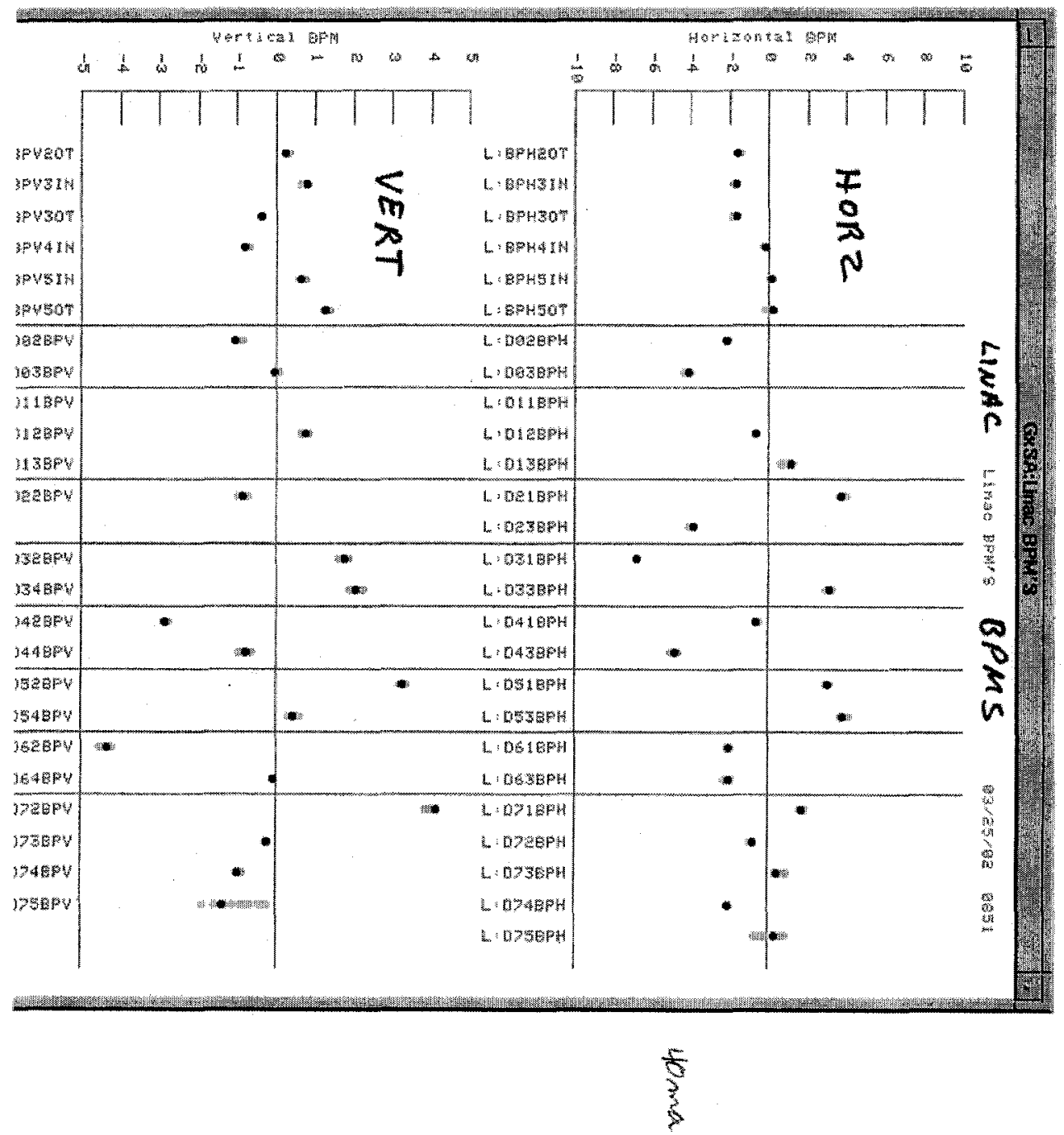

谞 


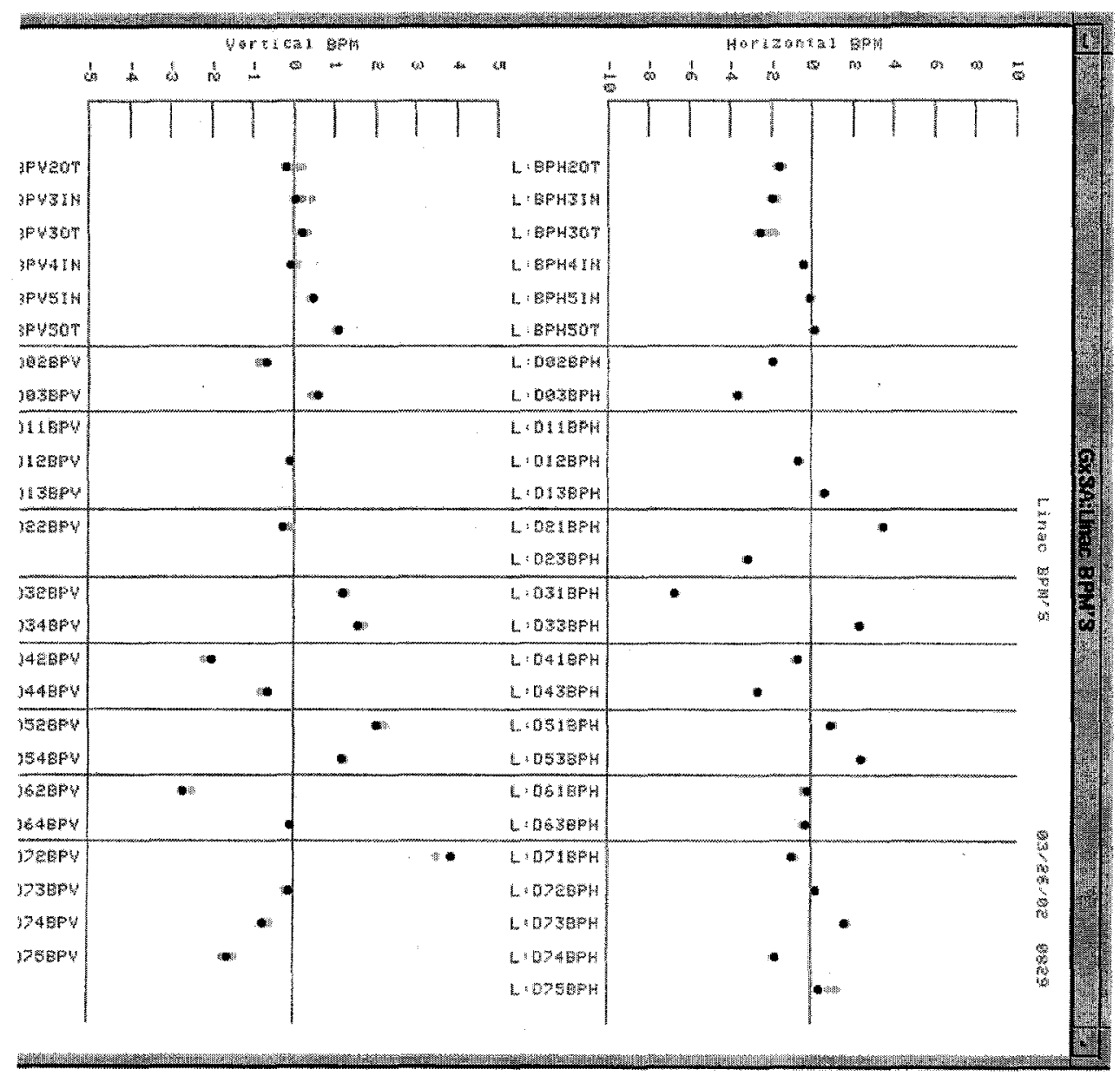

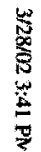

$$
\frac{5}{3}
$$




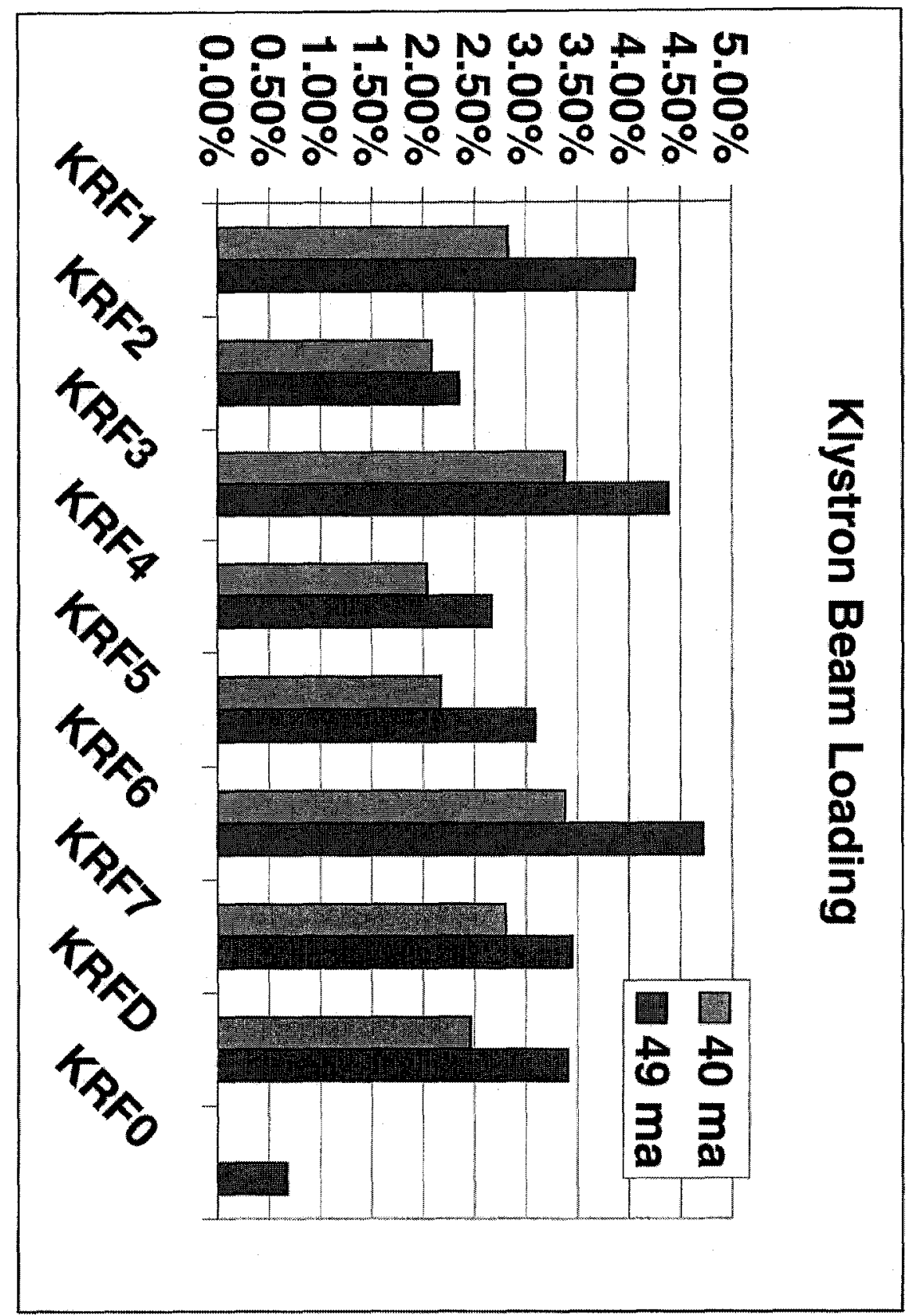




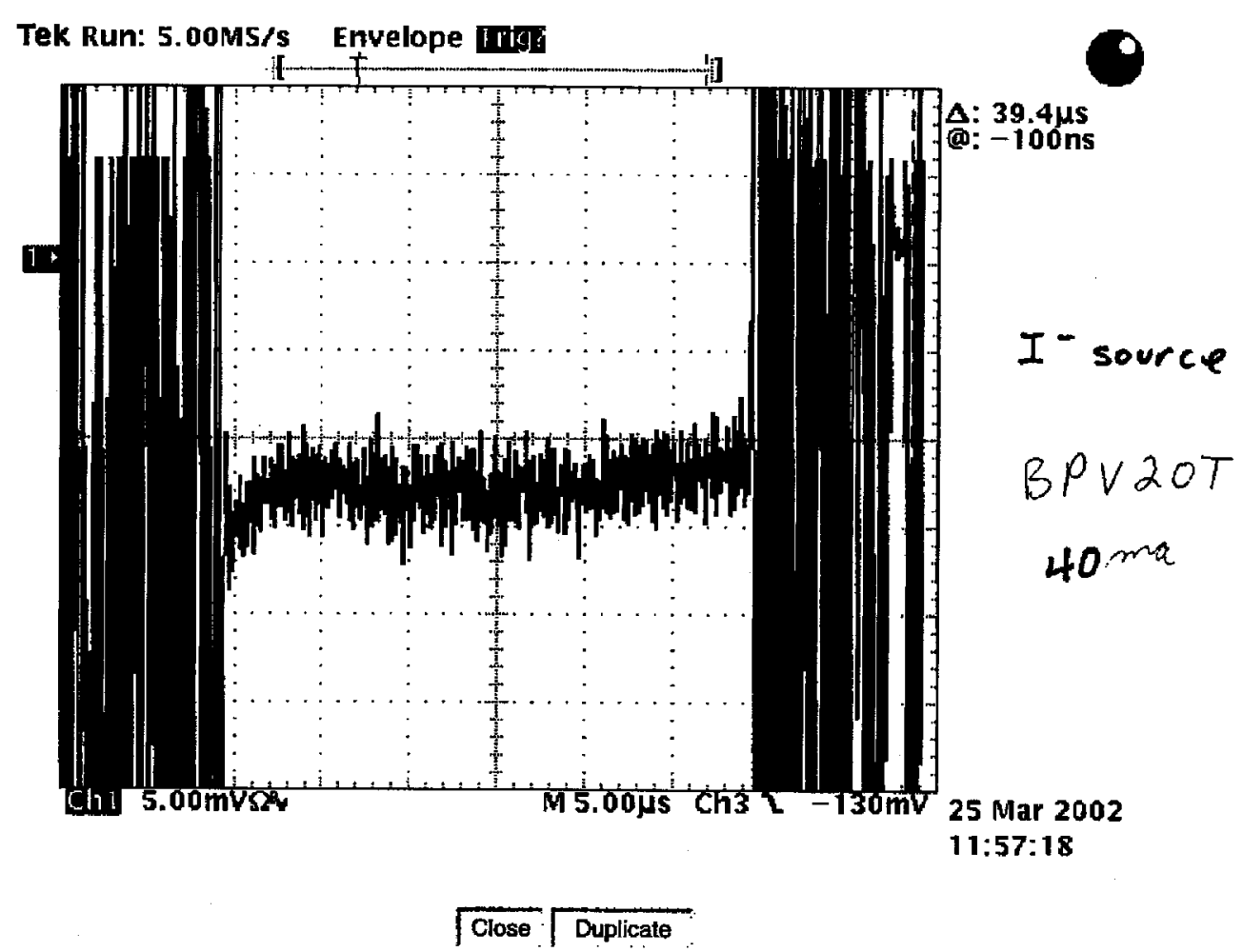




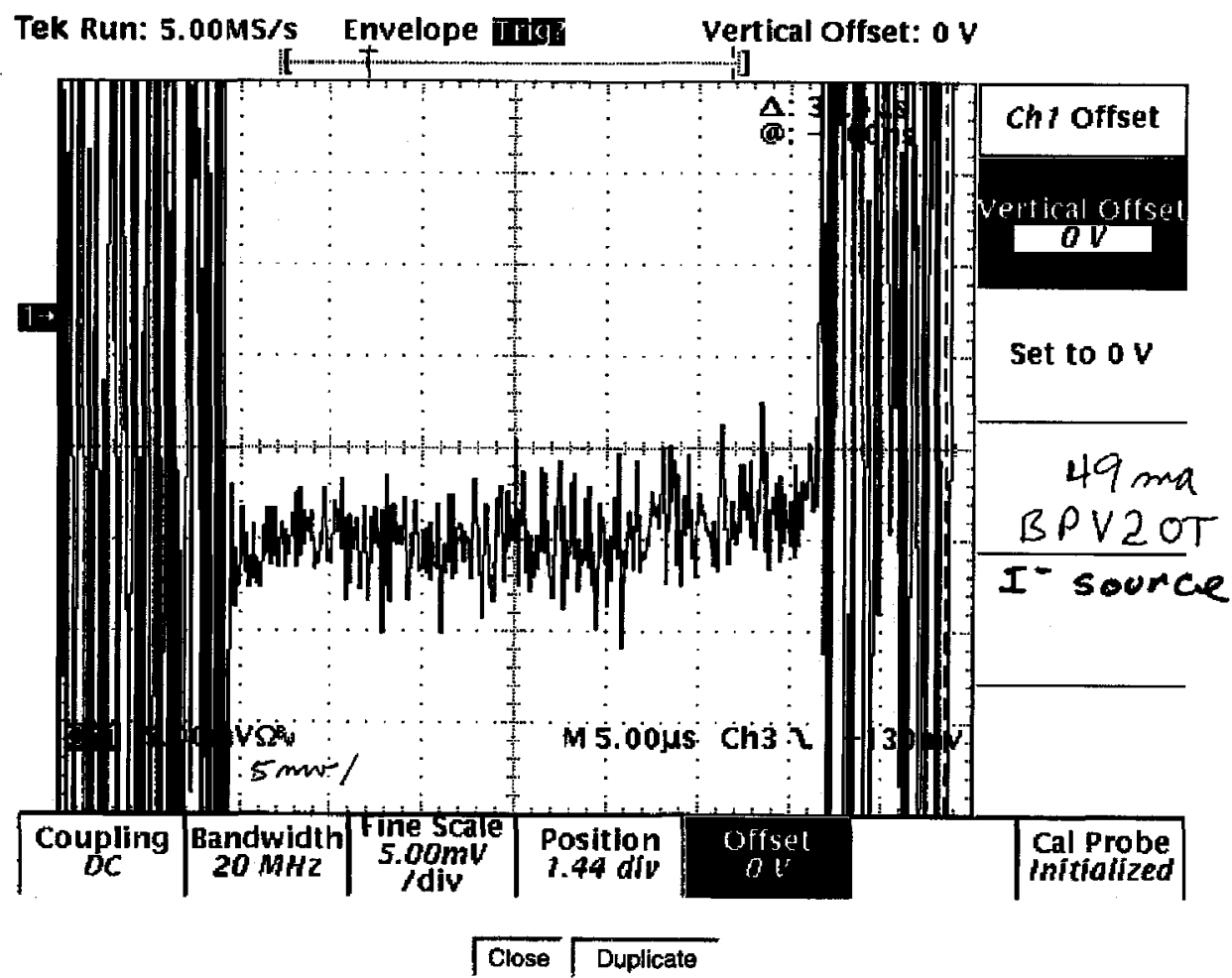


Tek Run: 5.00M5/s Envelope [ind? Vertical offset: $-70.000 \mathrm{mV}$

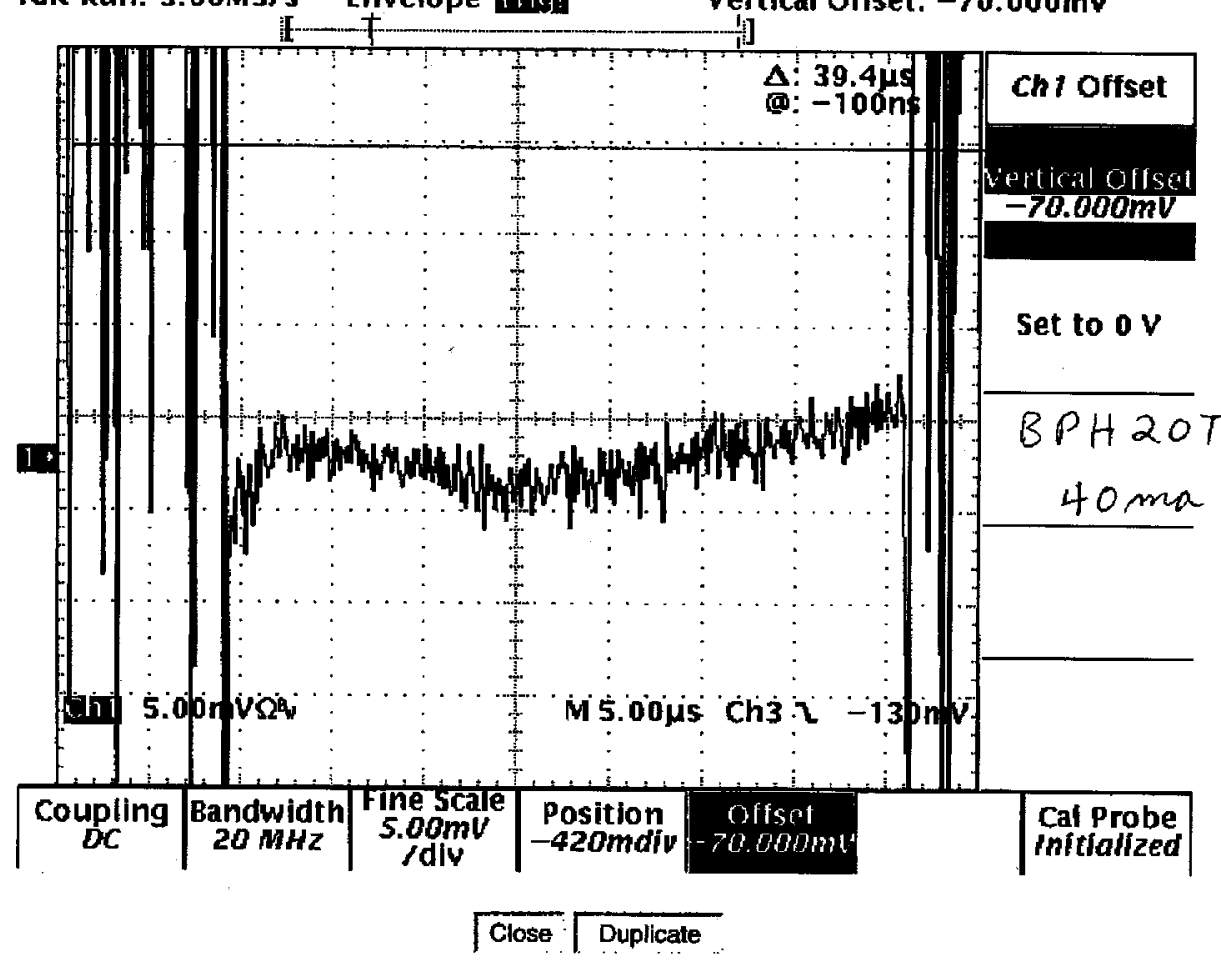




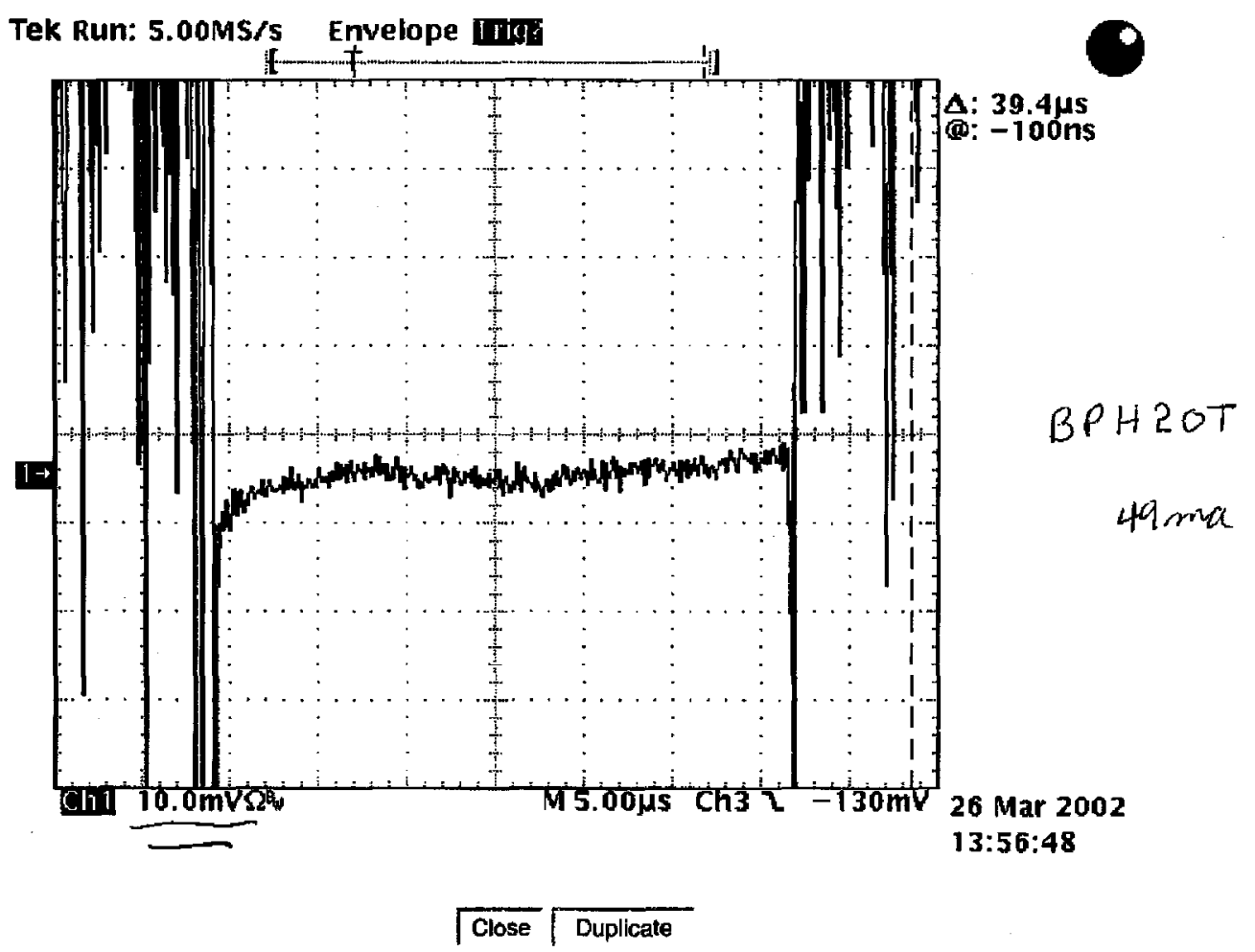




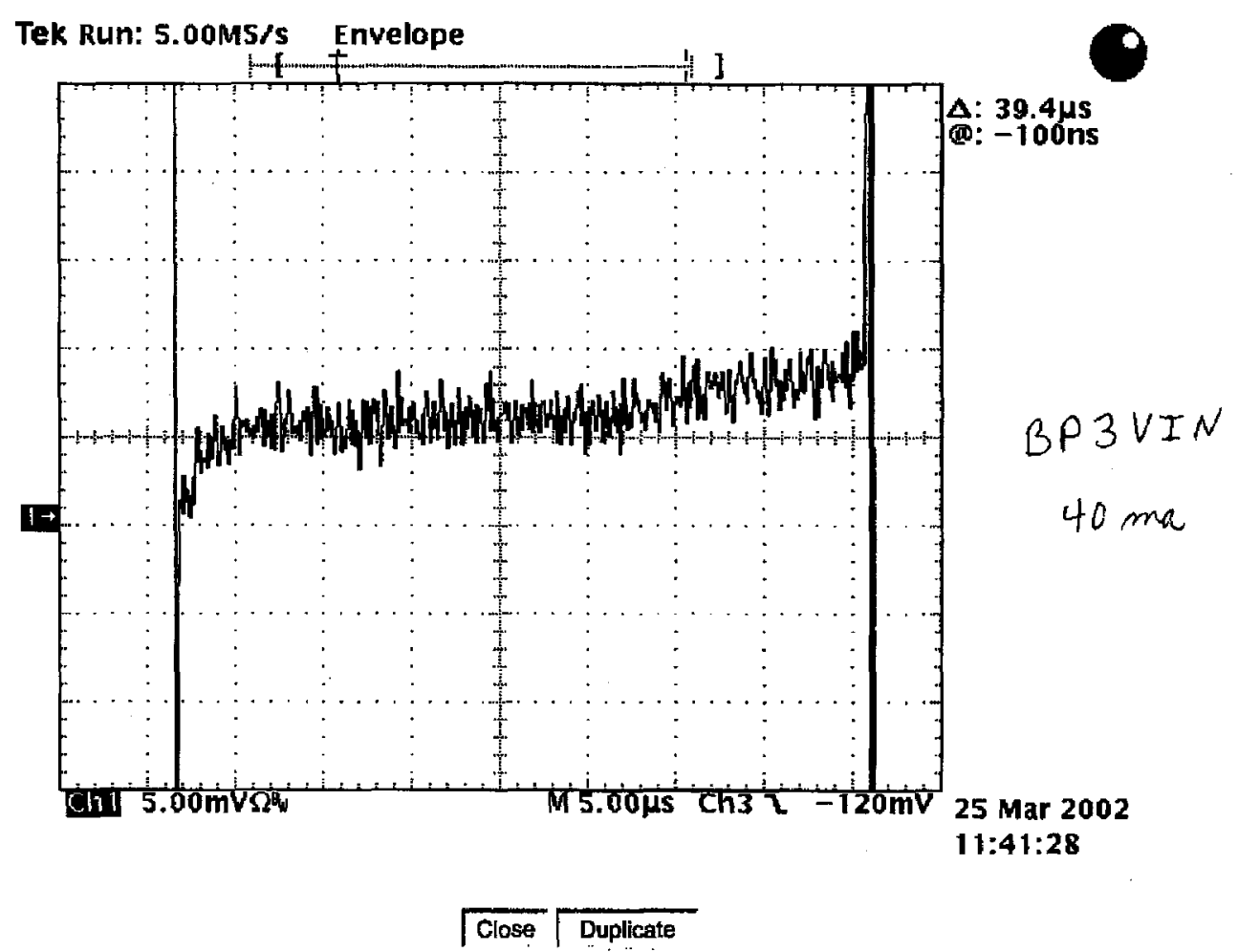


Graphic

htp://www-bd.fnal.gov/cgi-mach/machlog.pl?nb=booster\&action=view\&page=-3436\&butto

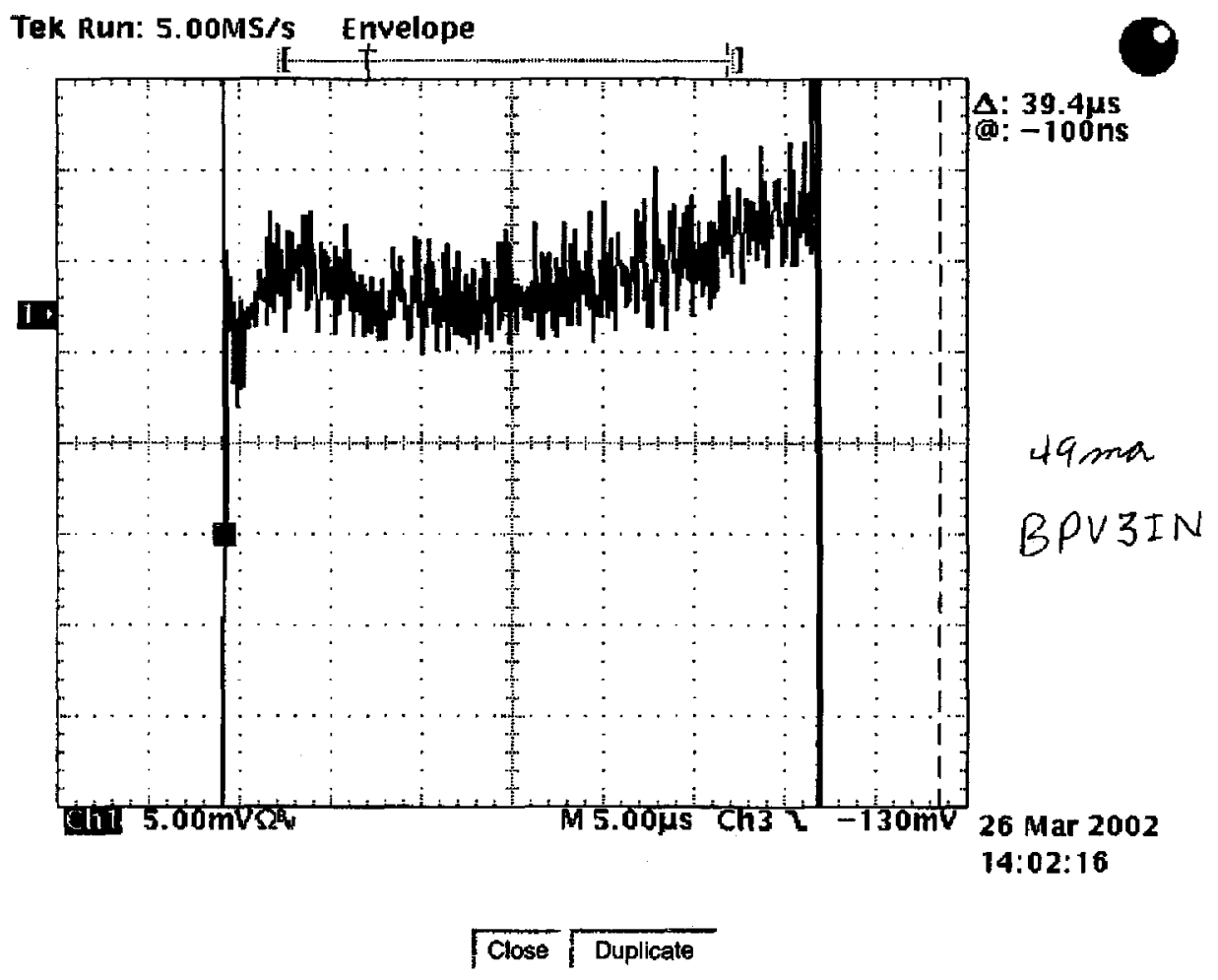

1 of 1

3/2802 3:44 PN 


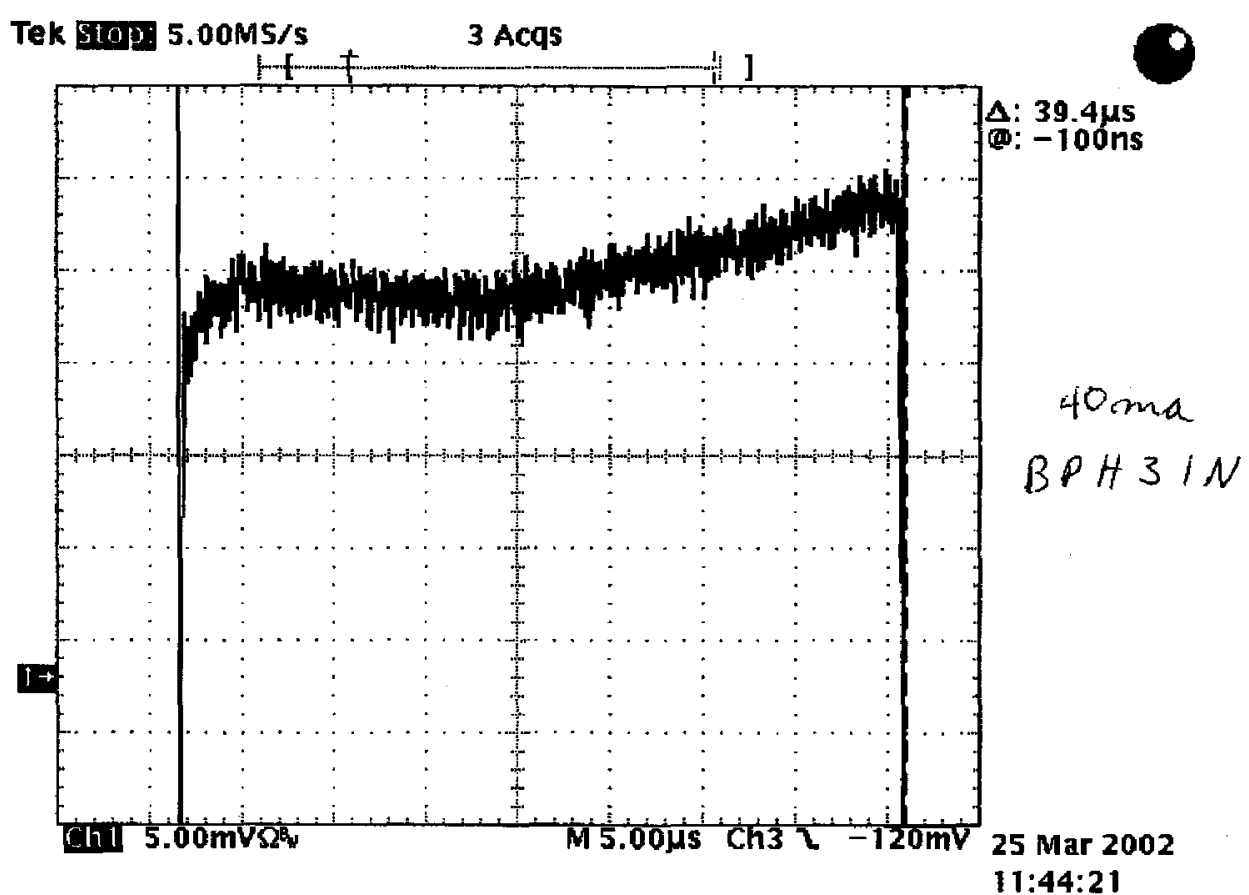

$\overline{\text { Close }}: \longdiv { \text { Duplicate } }$ 


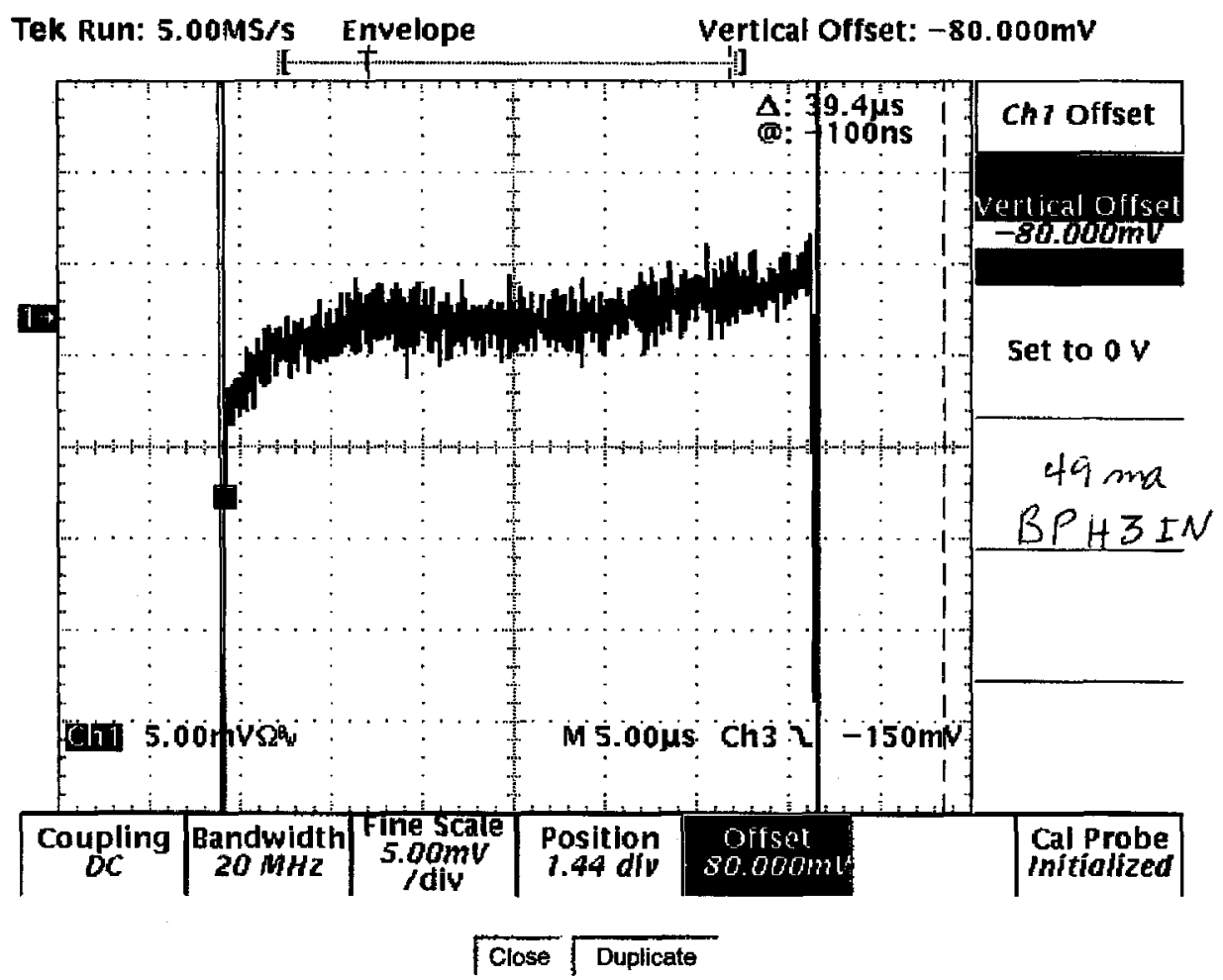




$$
F
$$




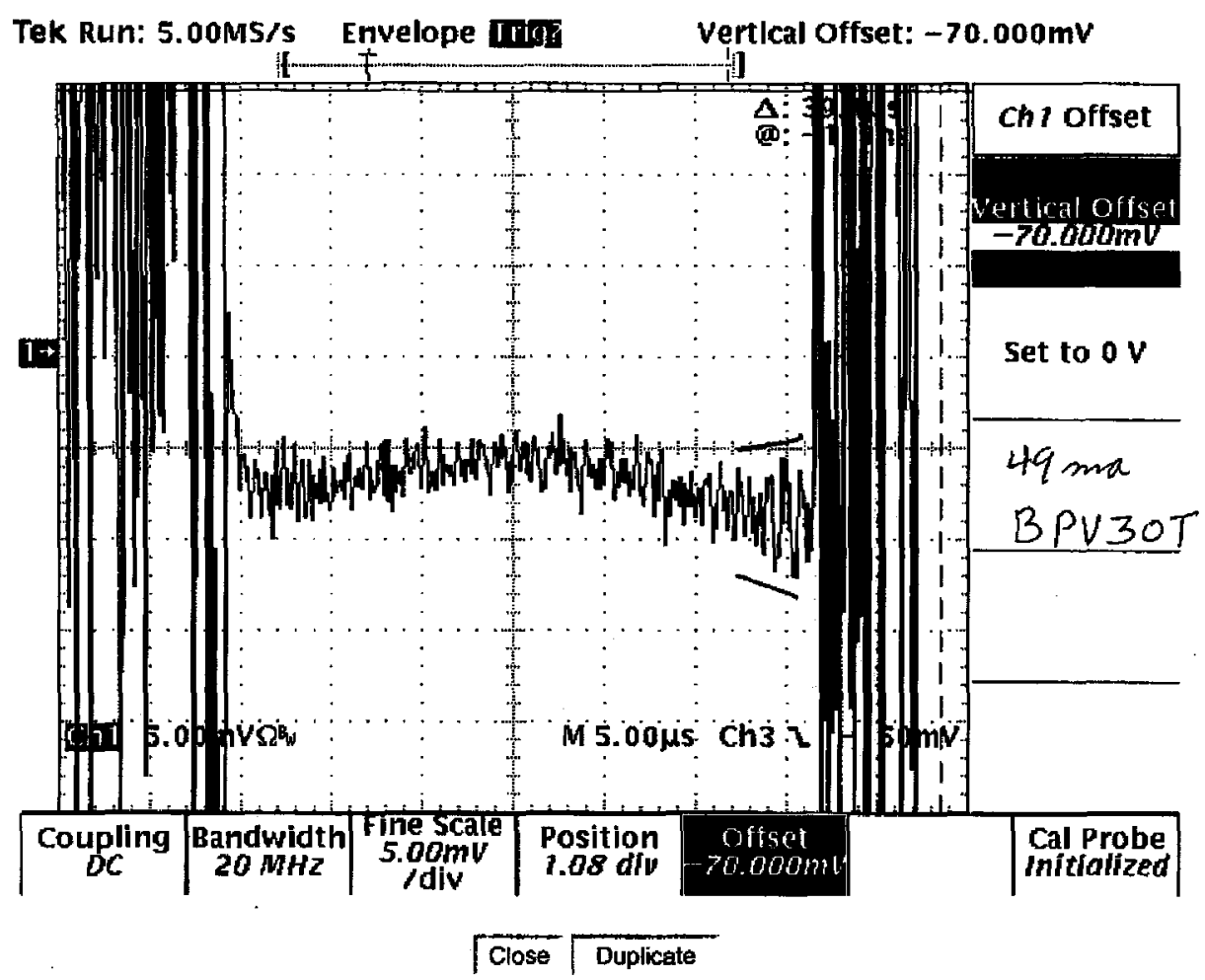




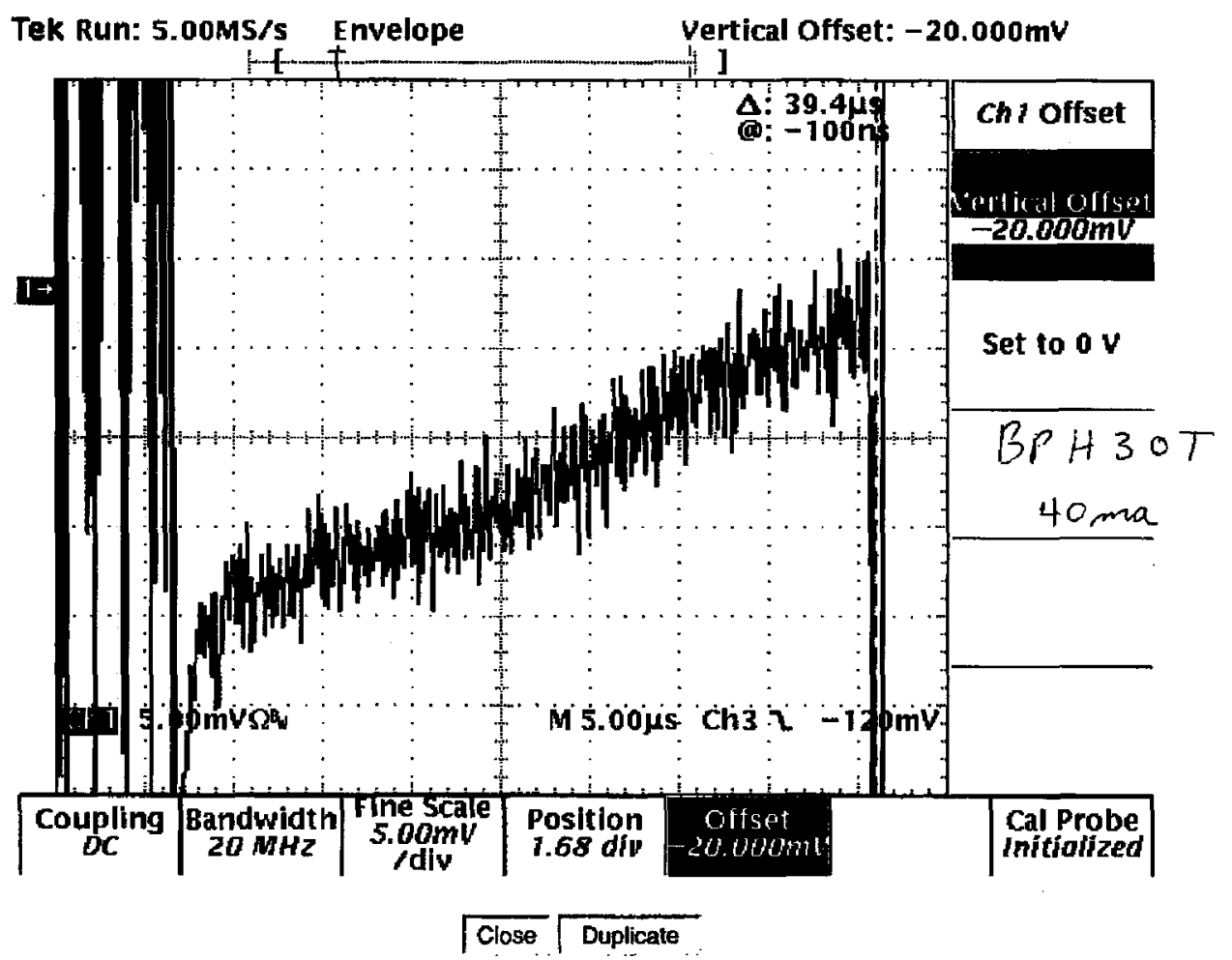




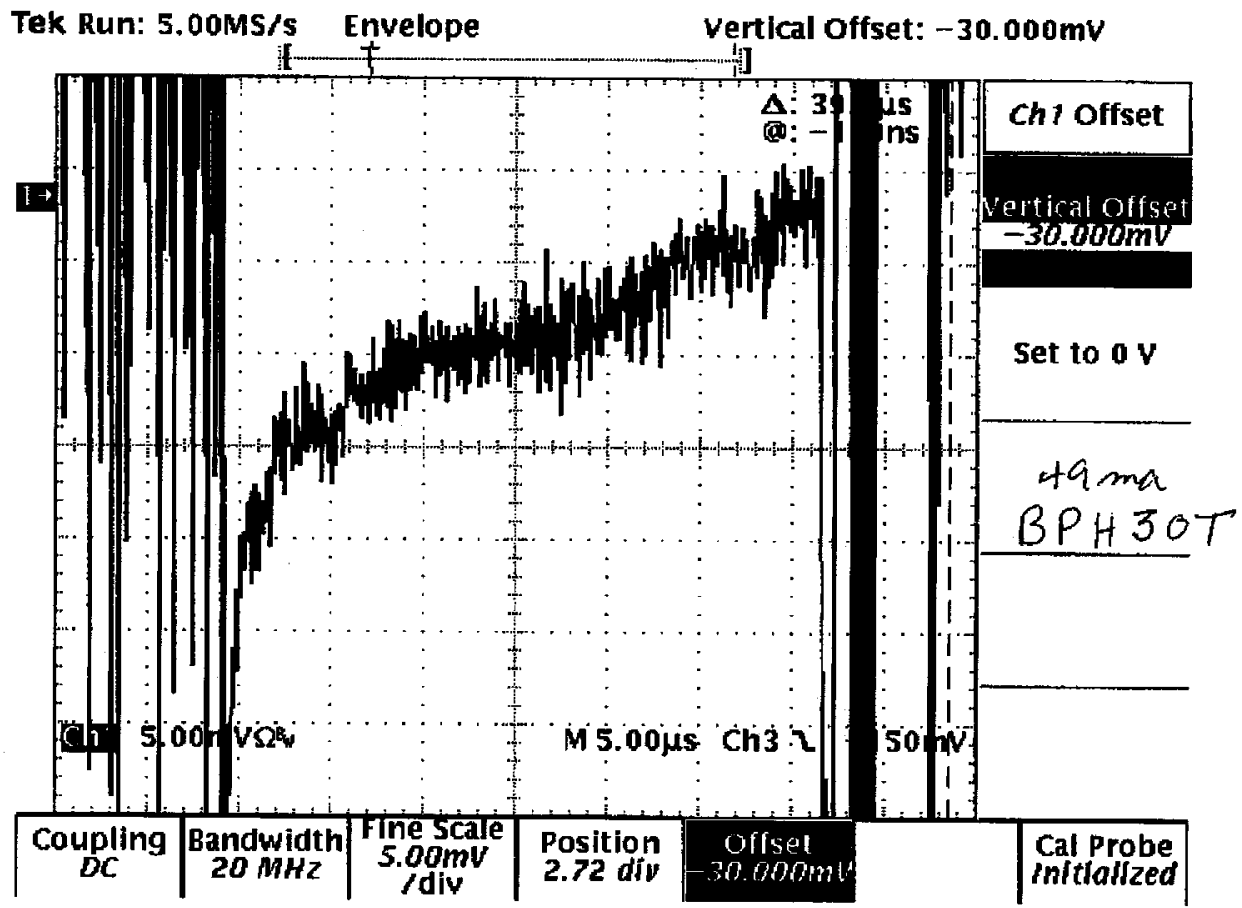

$\longdiv { \text { Close } } \longdiv { \text { Duplicale } }$ 


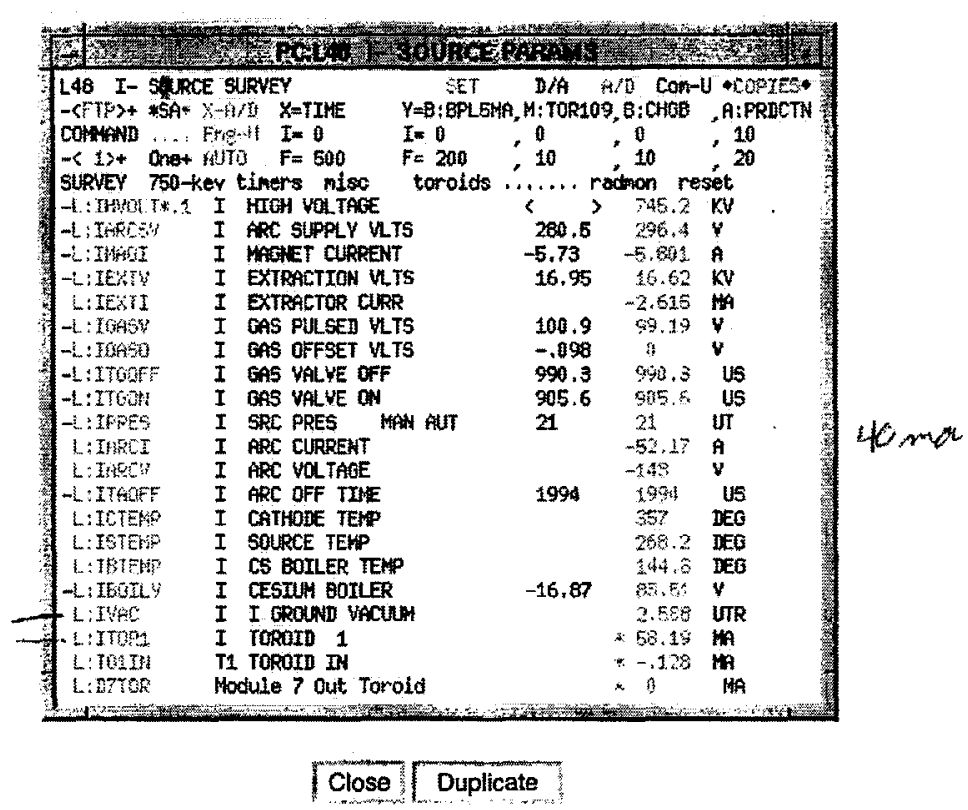




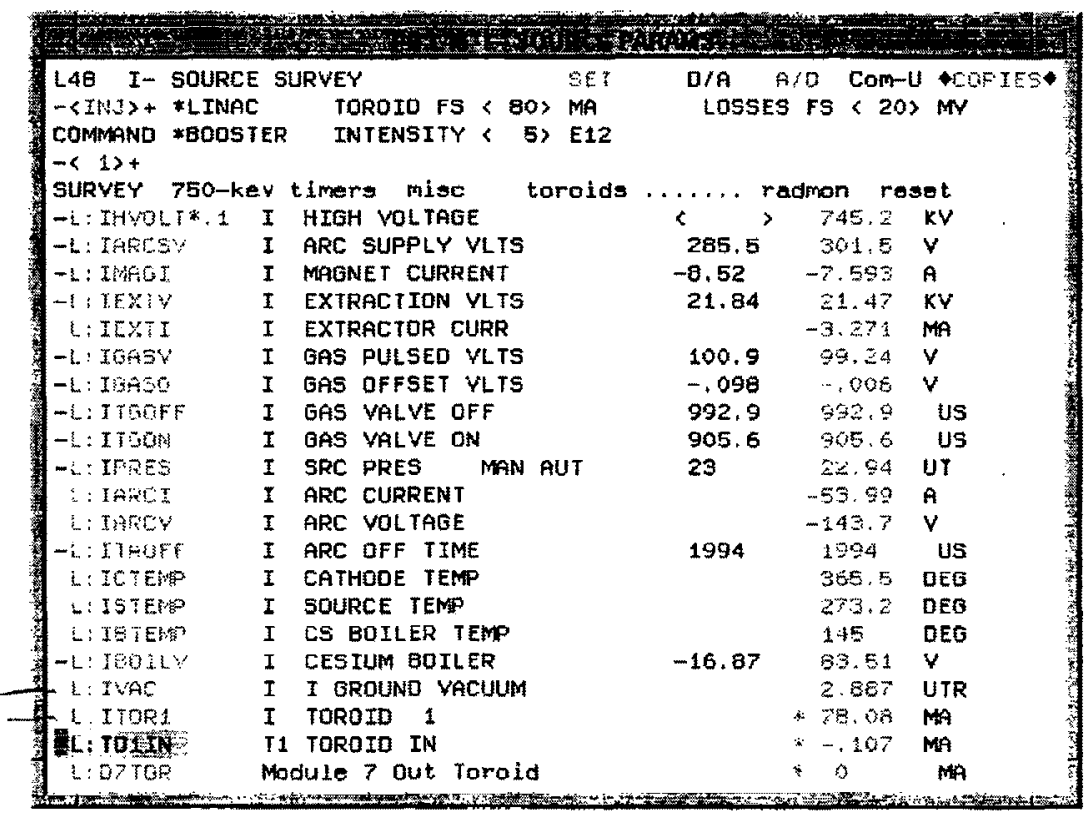

Close Duplicate 


\section{Appendix A}

Beam from the H- source is described here as seen on early LINAC BPMs. These pictures illustrate why a short linac pulse is shorter. This also illustrates why we need to get a better handle on source conditions. We have merely "tuned up", blind to the real character of the beam, for many years when switching sources. If the sources could deliver consistant and more monochromatic beam which held it's position during the spill the linac would be much more stable.

The H- source has often been better for the Booster despite delivering poorer beam. A good deal more work needs to be done to move these observations from the realm of "lore" to that of knowledge. Scope signals of the horizontal BPM at the output of tank 3, relayed to the control room, could be used to tune the sources.

Any study which does not consider beam from BOTH sources is incomplete. Policies or opinions about whether low or high beam current is advantageous must include data from both sources. 


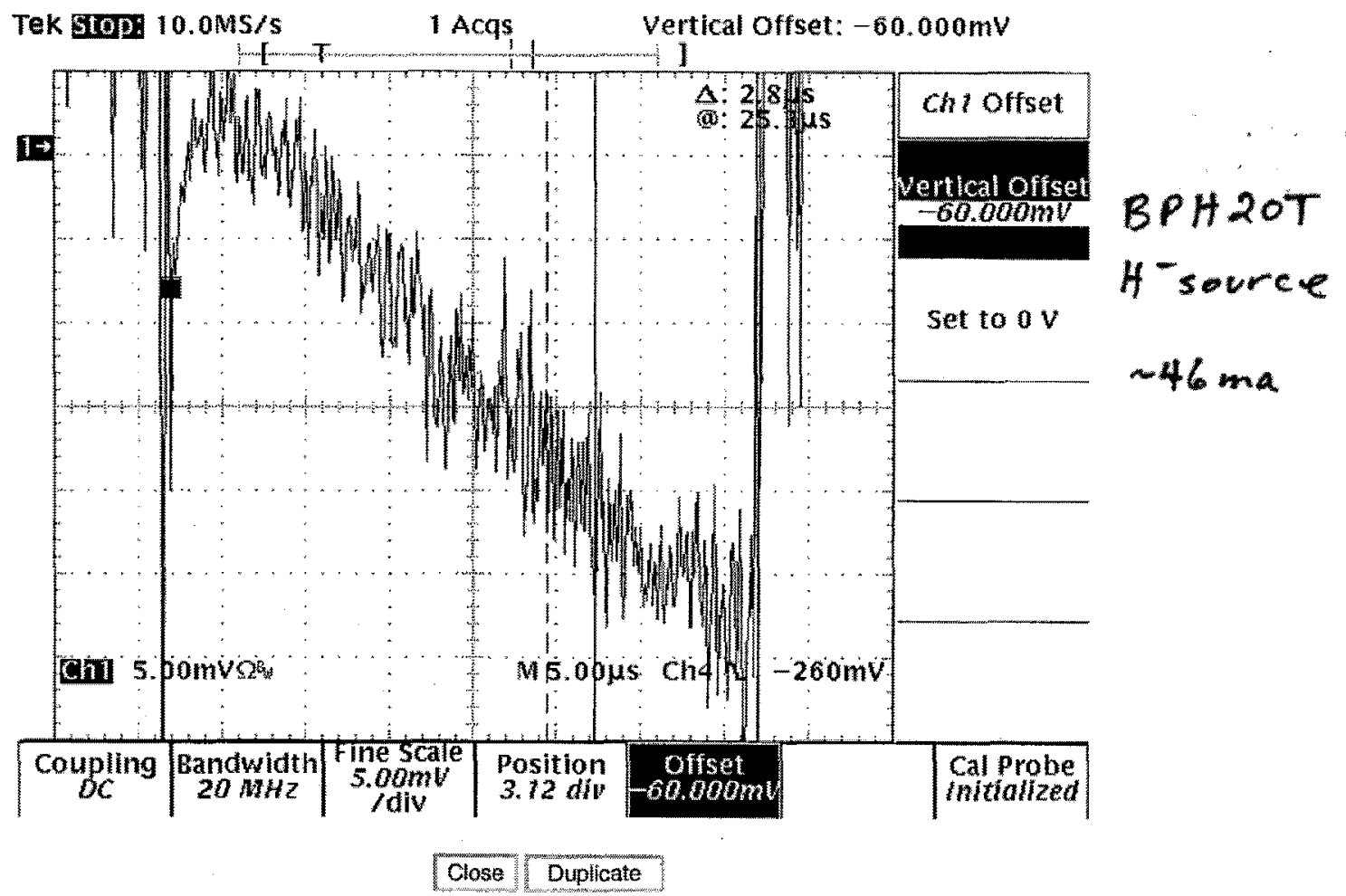




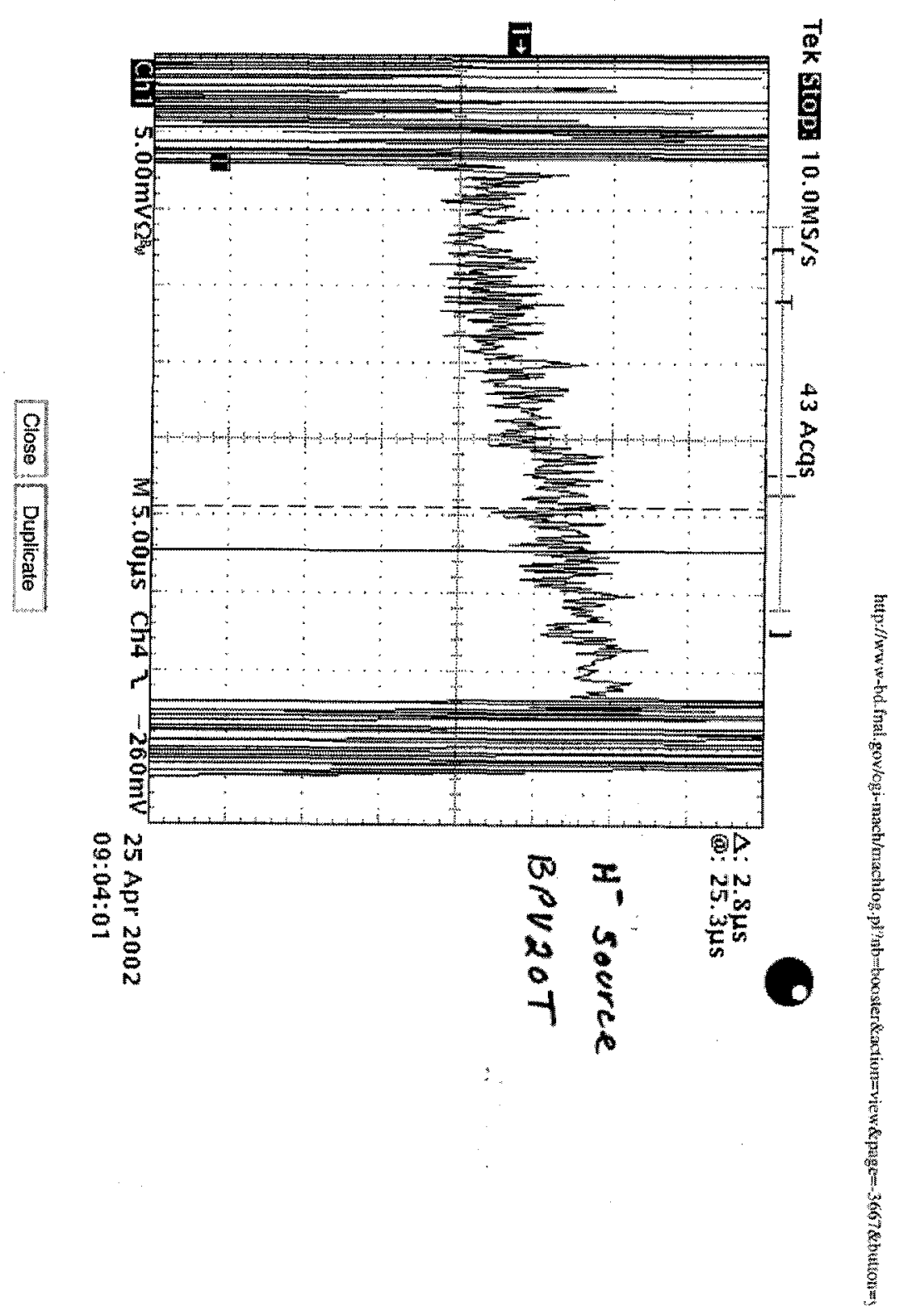


Grsphic

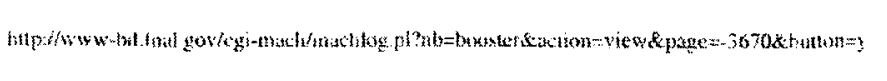

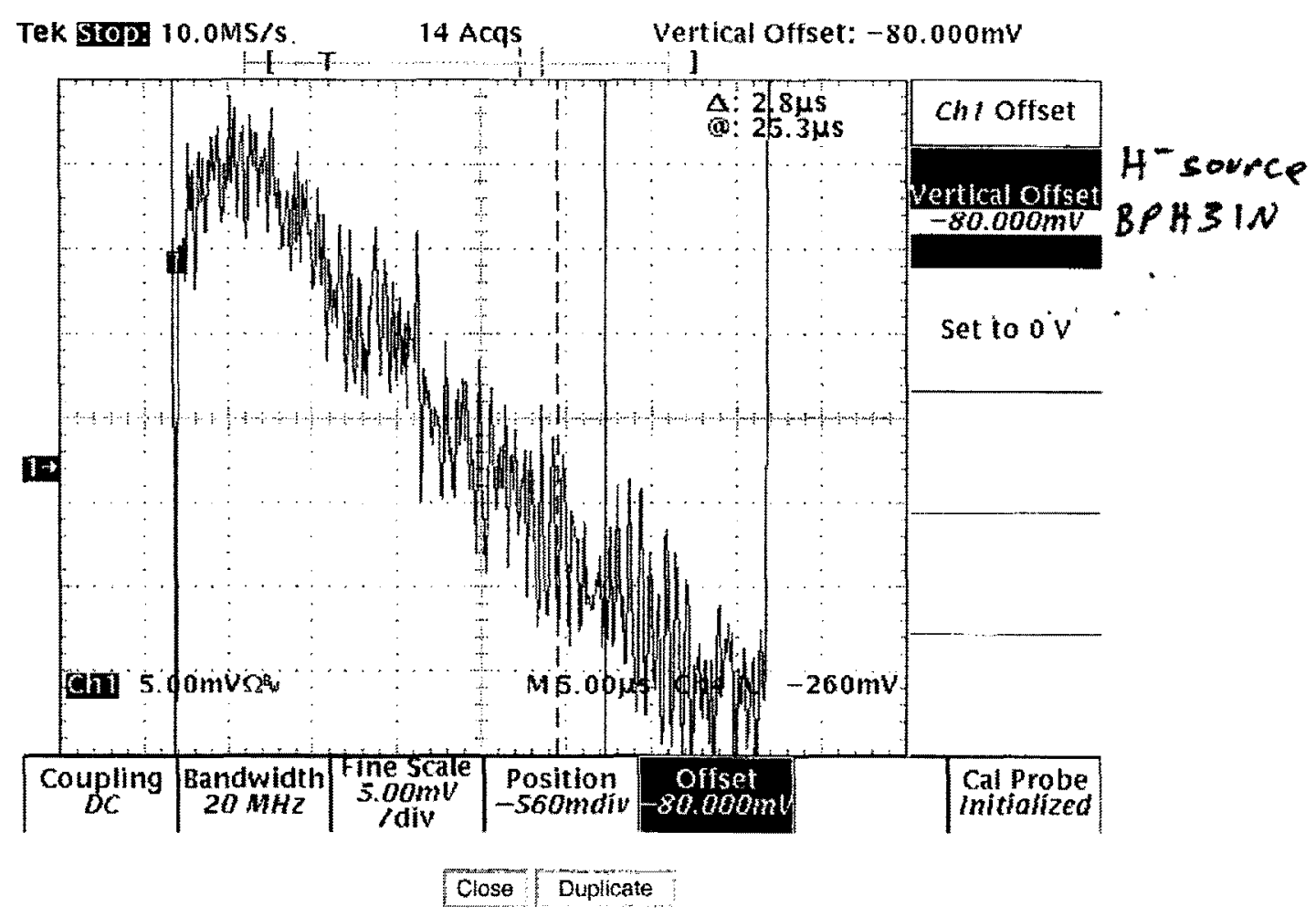




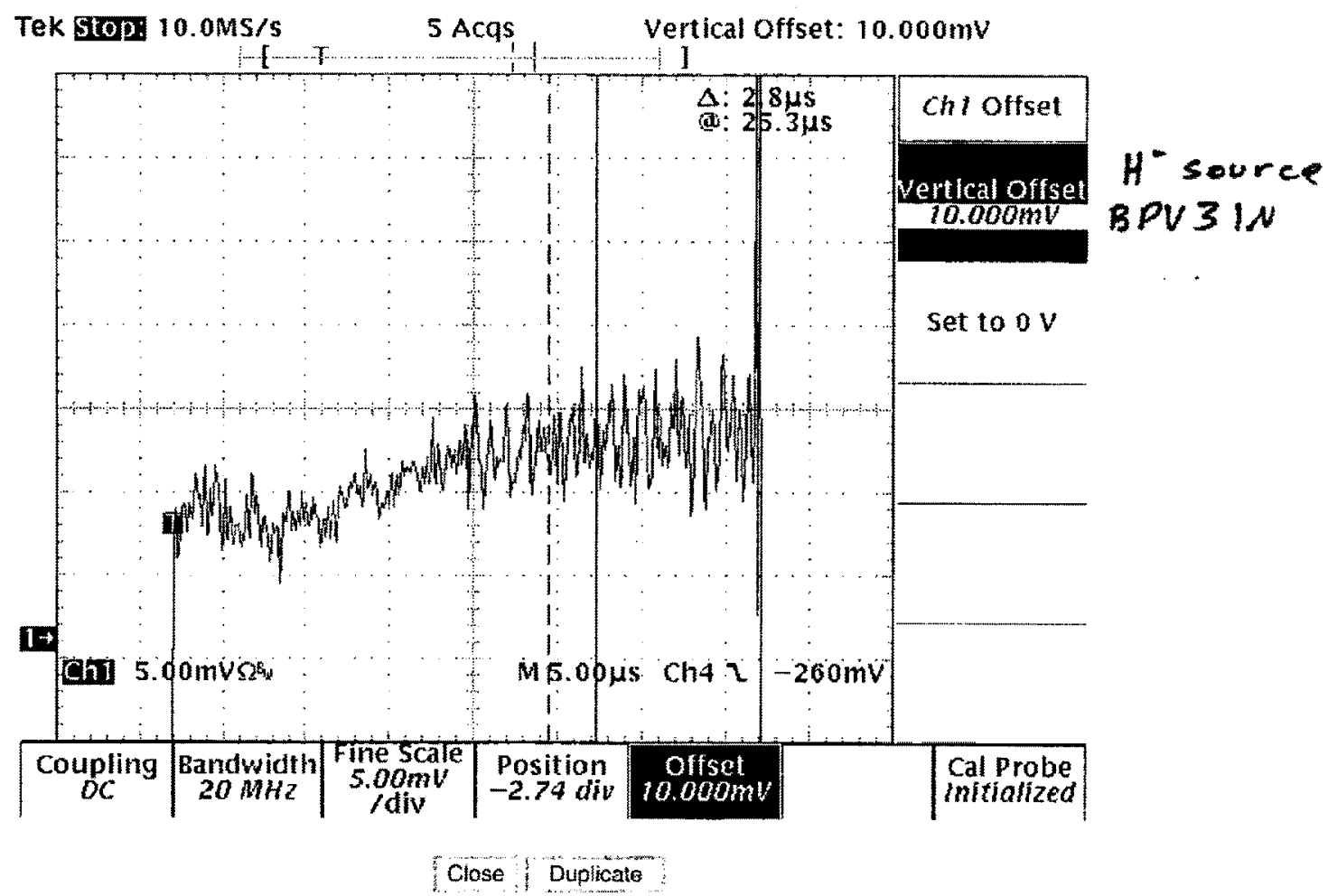




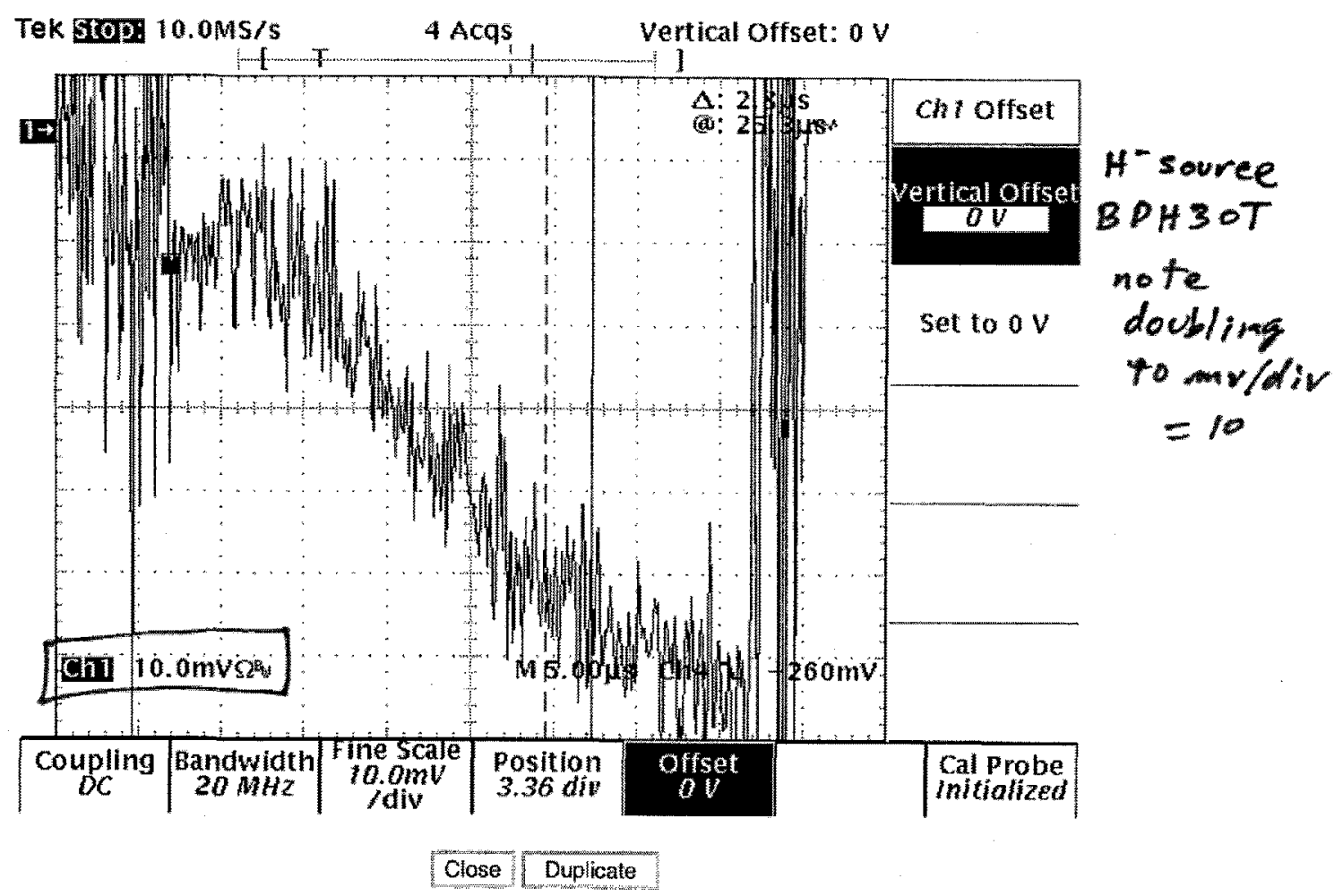


Graphic

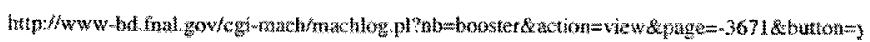

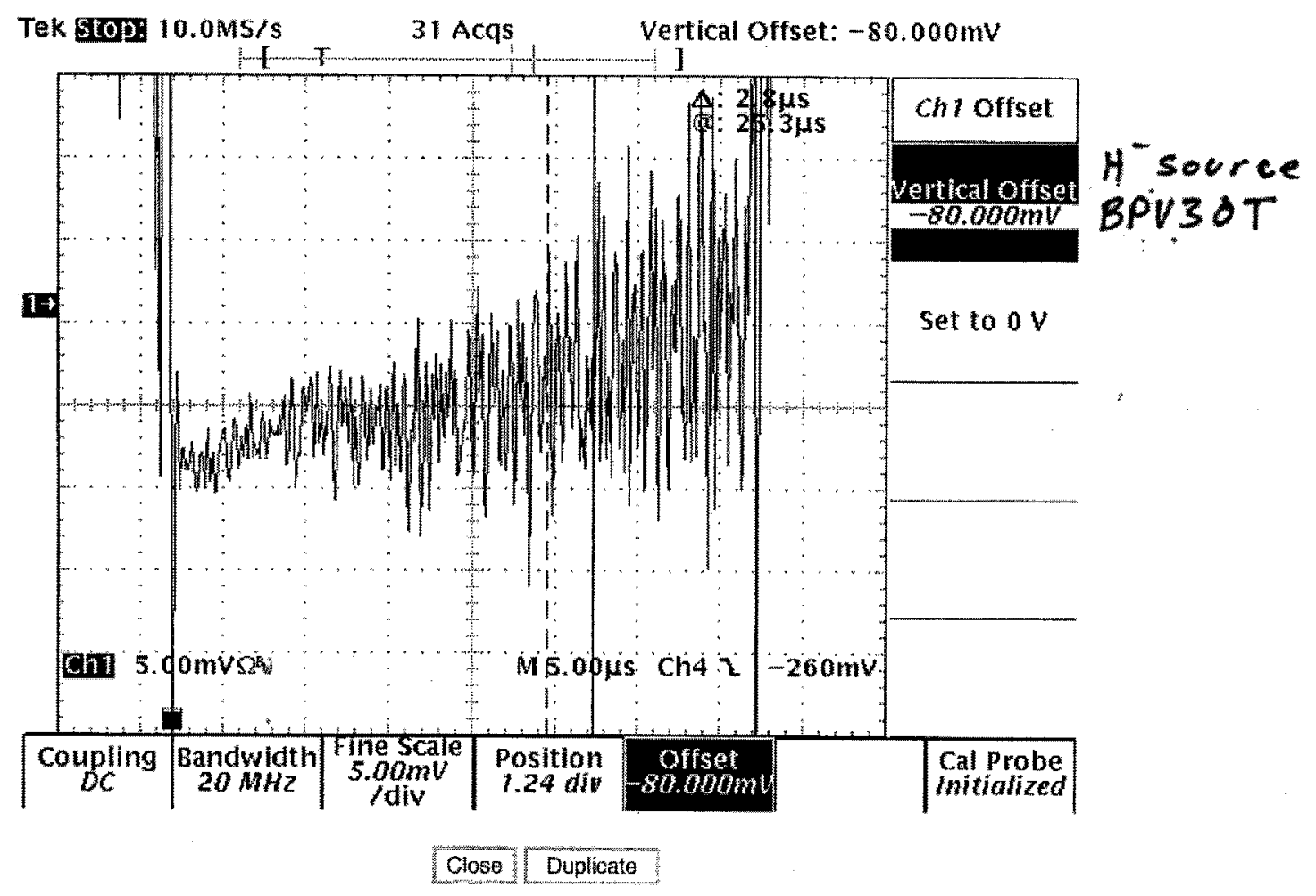




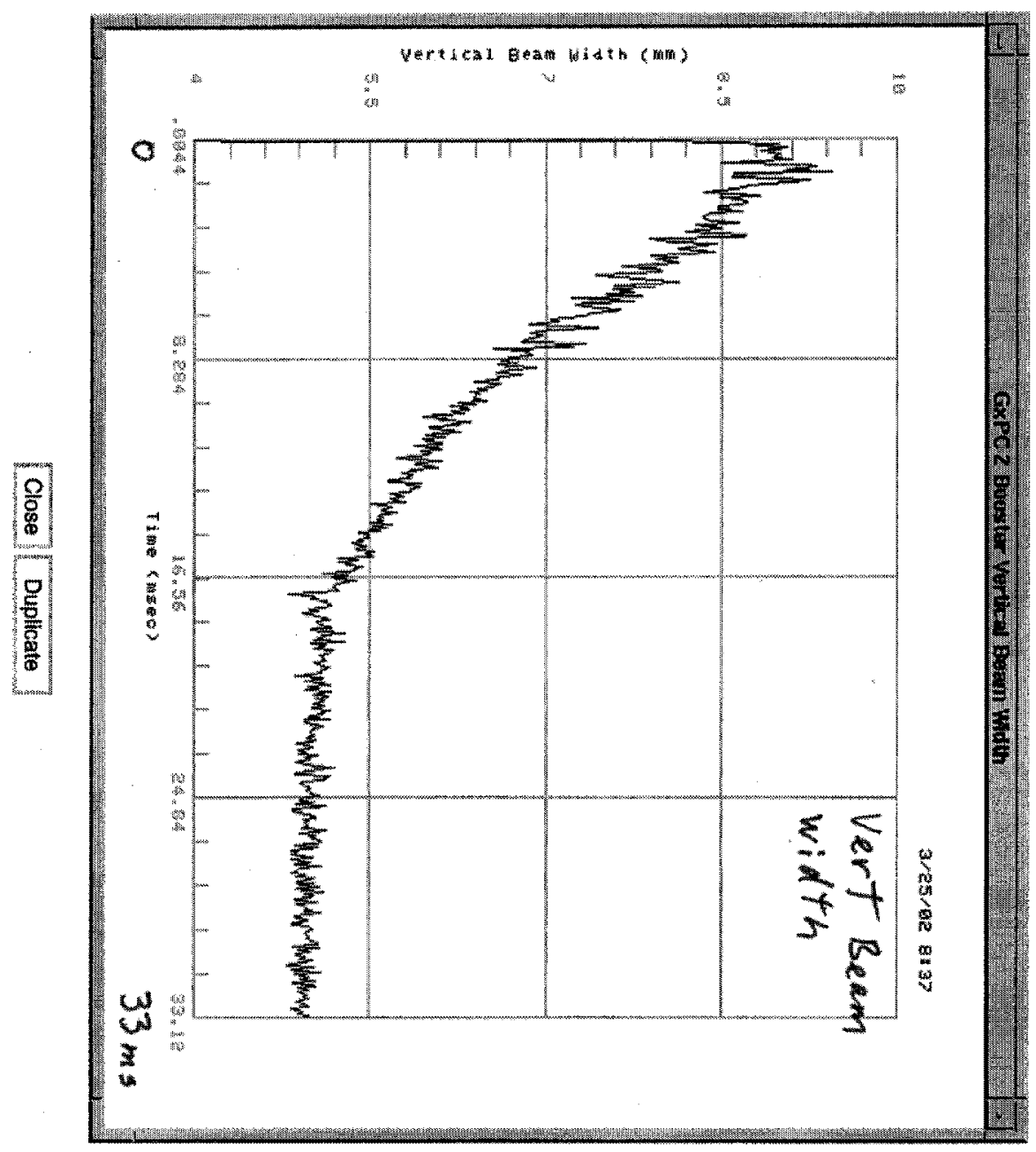

$$
5=
$$

